FISHERIES RESEARCH InSTITUTE

School of Fisheries

University of Washington

Seattle, WA 98195

\title{
MANAGEMENT OF BRISTOL BAY RED KING CRAB: A CRITICAL INTERSECTIONS APPROACH TO FISHERIES MANAGEMENT
}

T. LOHER, P.S. HILL, G. HARRINGTON, AND E. CASSANO

Approved

Submitted
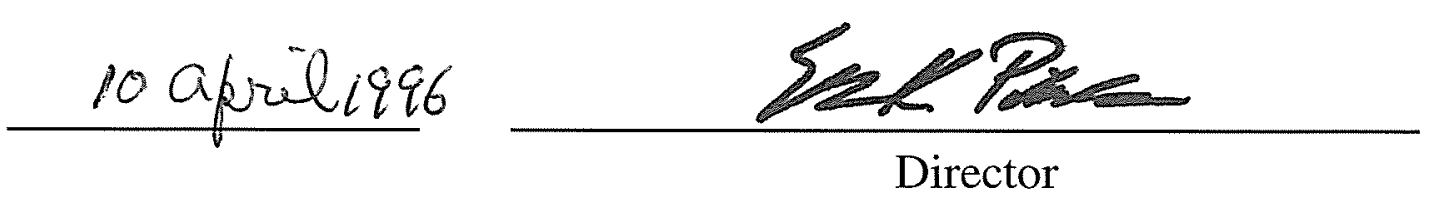



\section{CONTENTS}

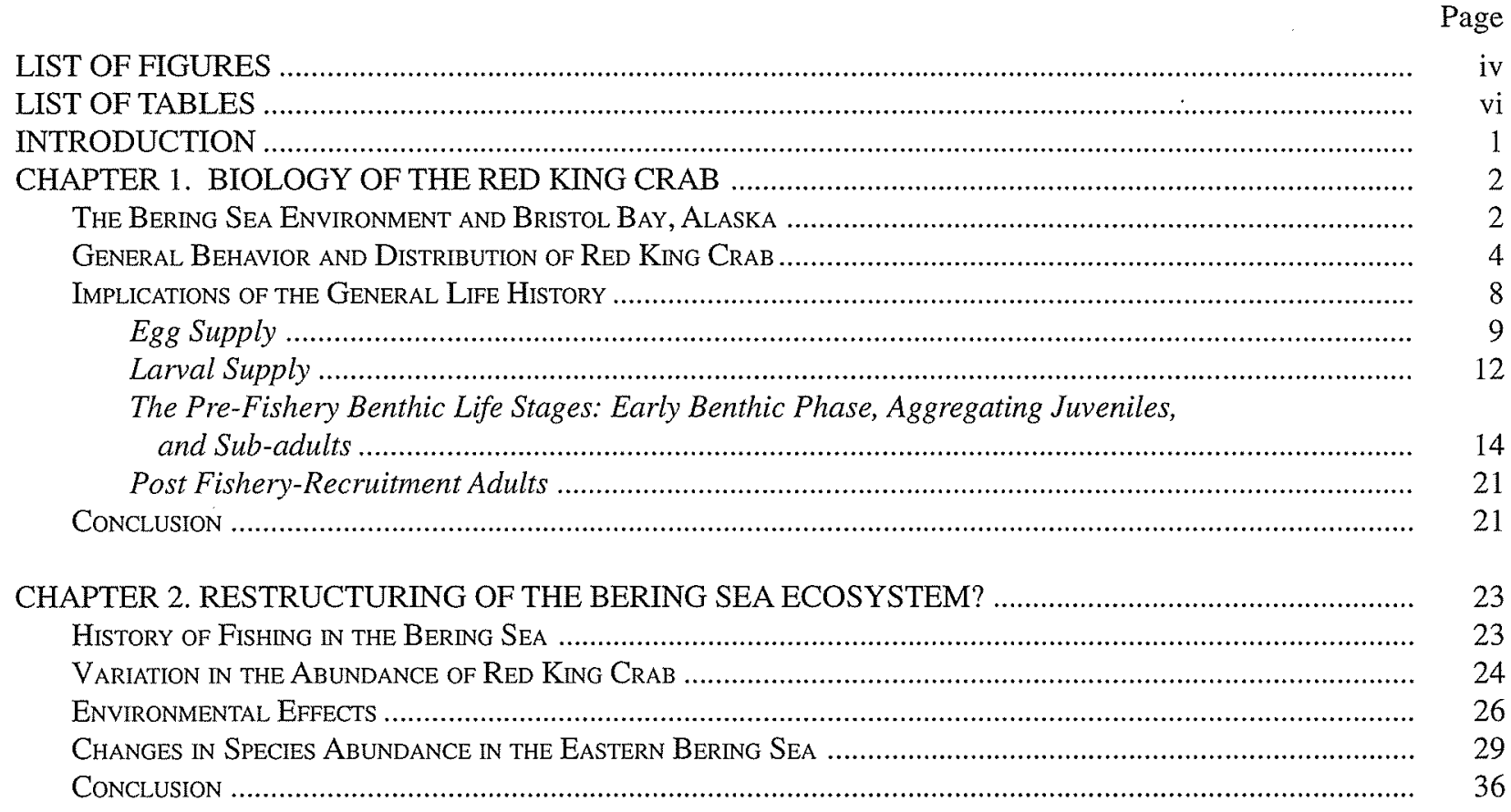

CHAPTER 3. RED KING CRAB MANAGEMENT IN BRISTOL BAY, BERING SEA, ALASKA ................ 39

ObJectives of MANAGing the Red King CRAB FISHERY ........................................................................... 40

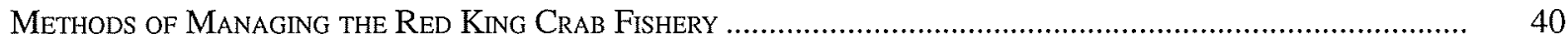

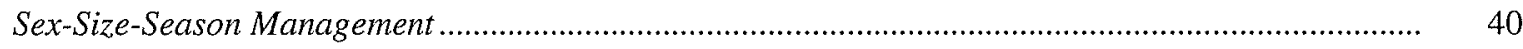

Exploitation Rate Management ......................................................................................................... 41

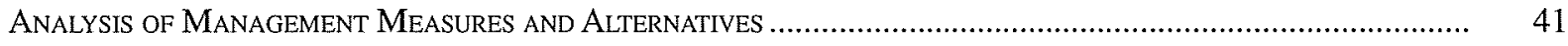

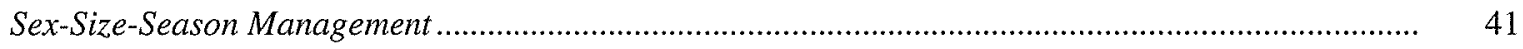

Exploitation Rate Management ..........................................................................................................

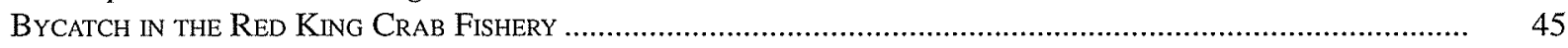

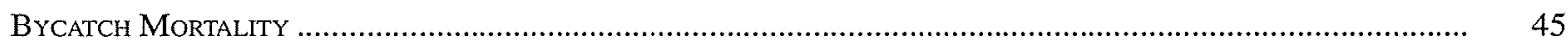

Red King Crab Bycatch in Other Crab Fisheries .................................................................................. 46

Groundfish TRaWl Fishing EfFects on Red King CRab ........................................................................

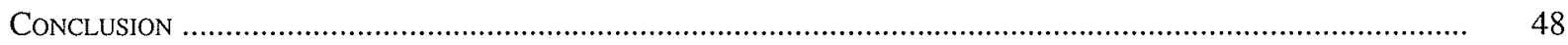

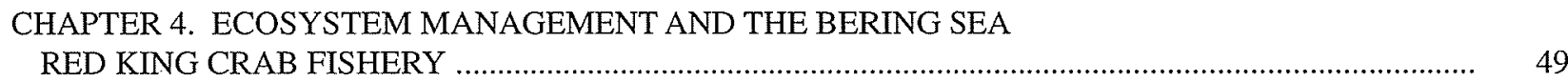

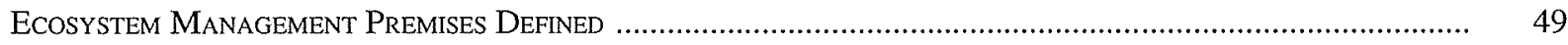

The Role of Ecological KNowledge IN ECoSystem Management ...........................................................

One Possible Ecosystem Management Tool: The Concept of R- And K-SPecies ……...............................

ThE ECONOMICS OF BYCATCH IN THE RED KING CRAB FISHERY ............................................................... 56

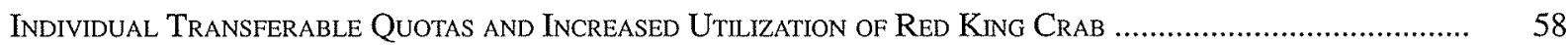

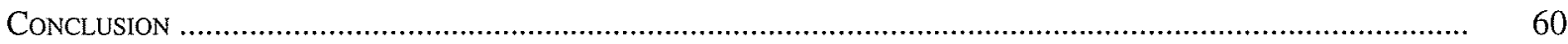

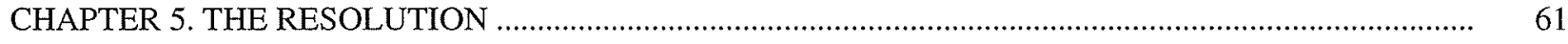

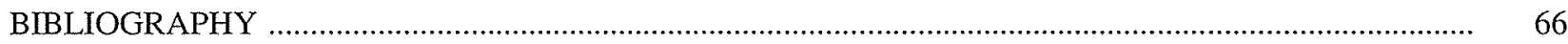




\section{LIST OF FIGURES}

Figure $\quad$ Page

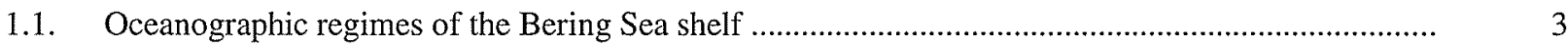

1.2. Long-term circulation patterns in Bristol Bay ….......................................................................

1.3. Distribution and abundance of red king crab larvae in Bristol Bay ...................................................

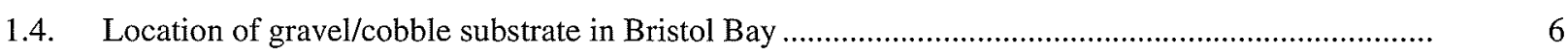

1.5. Distribution of juvenile red king crab in Bristol Bay ....................................................................

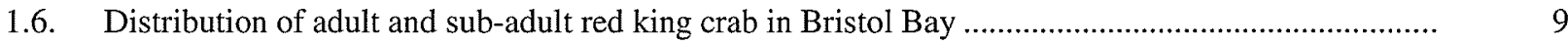

1.7. Sex-specific distribution of adult red king crab in Bristol Bay ...................................................... 10

1.8. Location of breeding concentrations of Bristol Bay red king crab …........................................... 16

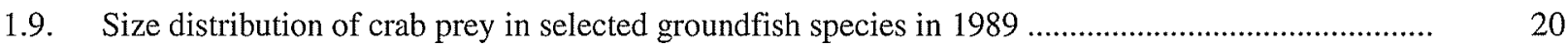

1.10. The life cycle of the red king crab and changes in important factors controlling abundance as the species passes from one stage to another ................................................................ 22

2.1. Commercial landings from the eastern Bering Sea, 1954-92 …..................................................... 23

2.2. Abundance of legal sized male red king crab from annual NMFS trawl surveys in the eastern Bering Sea, 1969-94 ........................................................................................... 25

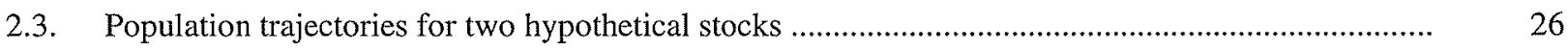

2.4. Salmon production and intervention model fits from 1925 to 1992 displayed

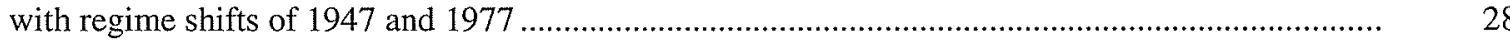

2.5. Biomass of the offshore pelagic fish consumer guild in the eastern Bering Sea, 1979-93.

2.6. Biomass of Greenland turbot and arrowtooth flounder in the eastern Bering Sea, 1979-93

2.7. Exploitation rate of arrowtooth flounder in the eastern Bering Sea, 1979-93 .................................... 31

2.8. Biomass of the crab and fish consumer guild in the eastern Bering Sea, 1979-93.

2.9. Skate biomass in the eastern Bering Sea, 1965-86

2.10. Biomass of the inshore benthic infauna consumer guild in the eastern Bering

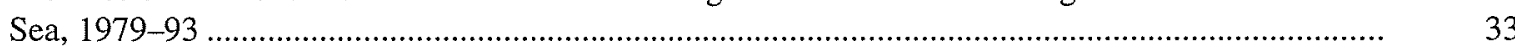

2.11. Exploitation rate of yellowfin sole and other flatfish in the eastern Bering Sea ................................ 34

2.12. Yellowfin sole exploitation rate and biomass versus red king crab recruitment in the eastern Bering Sea, 1970-93 
2.13. Relationship between red king crab abundance and shallow water flatfish abundance in the eastern Bering Sea....

2.14. Length-at-age for rock sole and yellowfin sole in the eastern Bering Sea, $1979-93$

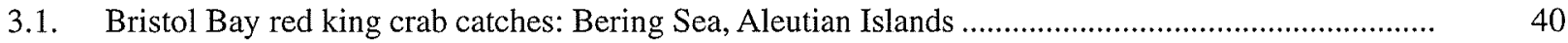

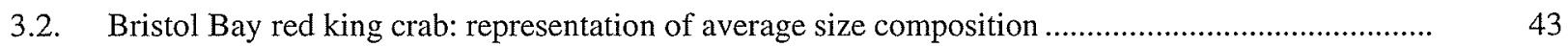

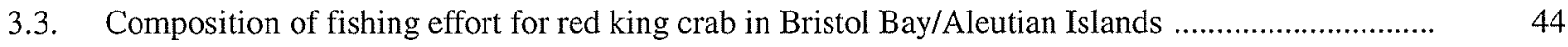

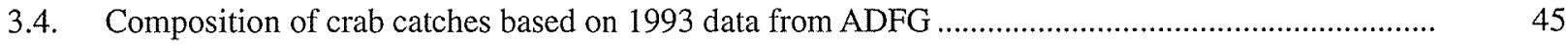

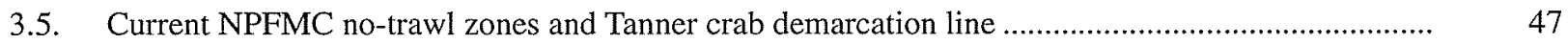

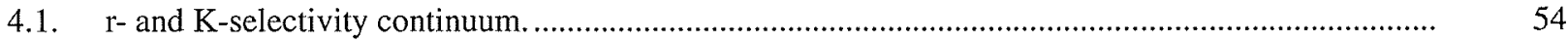

4.2. Generalized responses of K-selected and $\mathbf{r}$-selected species to a single

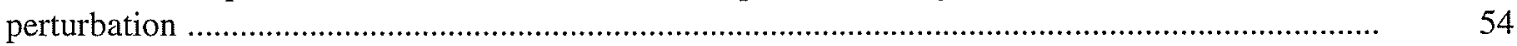

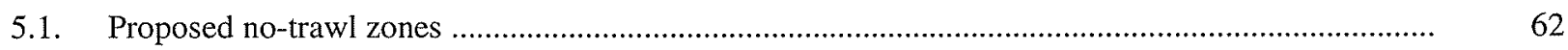




\section{LIST OF TABLES}

Table Page

1.1. Consumption of crab by non-commercial fish in the southeastern Bering Sea ................................ 18

2.1. The eight most abundant species in 1979 and 1991 trawl surveys ................................................... 34

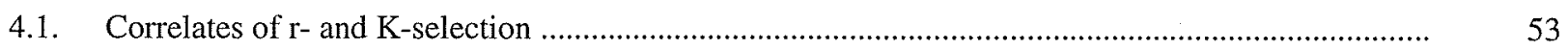

4.2. Increased costs and decreased product value produced by the open-access

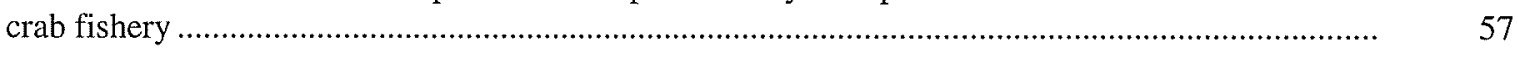

4.3. Advantages and disadvantages of individual transferable quotas to reduce

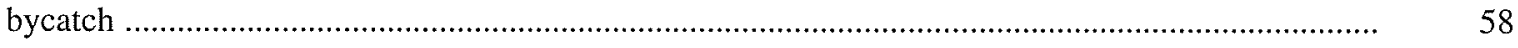

4.4. Increased utilization of red king crab stocks under the critical intersections

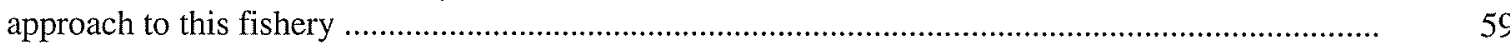




\section{ACKNOWLEDGMENTS}

This document was prepared for the joint School of Marine Affairs/School of Fisheries course, Contemporary Issues in Fisheries Management, Winter of 1995, for professors Drs. Dan Huppert and Robert Francis. We thank Drs. Huppert and Francis for providing us with the background and the skills to analyze this issue. Also, we thank Dr. Dave Fluharty for alerting us to this timely issue and for providing the preliminary research information. A special thanks to Dr. Jerry Reeves, who took the time to contribute information, answer questions throughout the writing of the document, and provide vital graphics for Chapter 3. We also thank Dr. Pat Livingston for providing insight and graphics vital to Chapter 2. Thanks to Dr. David Armstrong, who provided insight for Chapter 1 . Thanks to Mary Newton for compiling and formatting this document, and to Marcus Duke for the final editing, formatting, and layout. And to our expert reviewers, Drs. Robert Otto, Warren Wooster, Jerry Reeves, Dan Huppert, and Robert Francis, we are extremely grateful. Our document was tremendously improved by their thoughtful and thorough comments and suggestions. The opinions presented in the document are those of the authors. While this document represents a cooperative effort, primary authorship for each chapter is as follows: Chapter 1, Timothy Loher; Chapter 2, P. Scott Hill; Chapter 3, Gretchen Harrington; Chapter 4, Edward Cassano; Chapter 5, joint authorship.

\section{KEY WORDS}

Bristol Bay, ecosystem management, fishery, red king crab 



\section{INTRODUCTION}

Red king crab (Paralithodes camtschaticus) formerly represented one of the most lucrative fisheries in the Bering Sea and Gulf of Alaska. Following rapid capitalization, the fishery exploded in the late 1970s with peak catches nearing 70,000 $\mathrm{t}$ in the eastern Bering Sea alone. Then, in the early 1980s, the productivity of this fishery collapsed by over an order of magnitude and has remained at low levels over the past 1012 years. The cause of the decline has been attributed to an assortment of factors, including overharvest, yet a variety of restrictions and regulations since the collapse have failed to result in an increased stock. Much speculation surrounds the dynamics of this species, and there has been much debate on how to proceed in the future. Can we do anything to return a booming red king crab industry to this region, or will this fishery become little more than a footnote in history? Were the historical catches reflective of the true potential abundance of this species or were they an anomaly?

We approach this problem from the basis of "ecosystem management," which acknowledges the interdependence between the managed stock and the physical and biotic environment. This approach purports that we cannot truly expect to manage a complex fishery based solely on the intrinsic population parameters of a few selected commercial species. However, this does not require consideration of every possible interaction between every species and every physical factor of the ecosystem. This simply would not be possible, and would result in the consideration of many factors that would be insignificant. Instead, we must consider "critical intersections" between the managed population and external forces: points where the stock is highly impacted and its abundance constrained.

We begin this process for the red king crab by analyzing its life history to determine where its abundance is most likely restricted. Next, we look at the changing nature of the environment in which the stock exists in order to gain an understanding of how trends in crab abundance may reflect variability in the ecosystem. Finally, we critically assess how well the past and present management actions have addressed the factors that appear to control king crab abundance, potentially allowing for, or failing to allow for, a recovery of the stock. Within this framework, we present recommendations for a plan to manage red king crab in Bristol Bay that (1) addresses factors over which we can expect to exert reasonable control, (2) allows for the stock to recover to levels greater than at the present time, (3) increases the potential economic and social value of the combined Bristol Bay fishery resources, and (4) aids in expanding our understanding of this and similar systems.

We note that, while this report focuses on a single fishery, the concepts we present can potentially be expanded and applied to complex fisheries worldwide. While we consider the recommendations we make regarding Bristol Bay red king crab to be sound, the emphasis of this report is on the process by which we came to our conclusions: a "Critical Intersections Approach" (CIA) to fishery management. 


\section{CHAPTER 1. BIOLOGY OF THE RED KING CRAB}

\section{The Bering SEA ENVIRONMENT AND Bristol Bay, Alaska}

The focus of our discussion is an analysis of southeastern Bering Sea red king crab in Bristol Bay. Therefore, it follows that we must first discuss the physical and oceanographic characteristics of this region. The Bering Sea lies in the North Pacific region and includes the waters bounded by Kamchatka to the west, Alaska to the east, the Aleutian Islands to the south, and extends northward to the Seward and Chukchi peninsulas. Bristol Bay is located in the southeastern Bering Sea, on the southwestern coast of Alaska between the Alaska peninsula and Cape Newenham. It extends from $\sim 55^{\circ}$ to $58^{\circ}$ north latitude, and $159^{\circ}$ to $164^{\circ}$ west longitude.

The bathymetry, oceanography, and climatology of the region help explain its high productivity. The eastern Bering Sea consists of a relatively flat and featureless shelf that gently slopes from the mainland to a steep drop at the shelf break into the deep Aleutian Basin. The waters of Bristol Bay are relatively shallow, generally $<100 \mathrm{~m}$ in depth. The region of shelf $<50 \mathrm{~m}$ in depth is considerably broader along the northern shores of the bay where the shallow shelf extends $\sim 100 \mathrm{~km}$ offshore, as opposed to the southern shore in which this contour is rarely located $>30 \mathrm{~km}$ off the Alaska Peninsula (Hood and Calder 1981). This $50 \mathrm{~m}$ break proves to be a significant feature in describing current regimes and the distribution of red king crab in relation to age.

The Aleutian Islands present only a minor restriction to the flow of waters from the North Pacific into Bering Sea and Bristol Bay. Thus, the Bering Sea can be thought of as a physical extension of the North Pacific, both biologically and oceanographically (Hood 1983). Biologically, this may appear to be an oversimplification, as the eastern Bering Sea has been described as a transition zone between the arctic and Aleutian zoogeographic provinces (R. Otto, National Marine Fisheries Service [NMFS], Kodiak, Alaska, pers. comm.). The dominant water movement from the North Pacific is through the Aleutian passes in a northeastward direction over the expansive, gentle sloping eastern Bering Sea shelf (Schumacher and Reed 1983). The circulation of the eastern Bering Sea is dominated by tidal currents (Kinder and Schumacher 1981). The interactions between tidal fluctuations and the relatively steeper bottom gradients at the $50 \mathrm{~m}, 100 \mathrm{~m}$, and $170 \mathrm{~m}$ isobaths create oceanographic fronts that separate the eastern Bering Sea shelf into three distinct hydrographic domains (Coachman 1986). The domains differ with regard to their depth, circulation, and vertical mixing (Schumacher and Reed 1983). Figure 1.1 displays a schematic representation of the structure and fluxes in the three eastern Bering Sea shelf domains.

Waters of the inner domain $(\sim 550 \mathrm{~m})$ tend to be homogenous because of the shallow depths, tidal mixing, and strong, wind-driven mixing. These waters are the least saline owing to the high amount of freshwater runoff and exhibit the greatest temperature fluctuations of the three domains. The moderate current flows northward through the Aleutian passes (Coachman 1986), and then turns northeastward, generally following the shape of the coast (Fig. 1.2). The larval and juvenile stages of the red king crab primarily inhabit waters of the inner domain (Hayes 1983). 


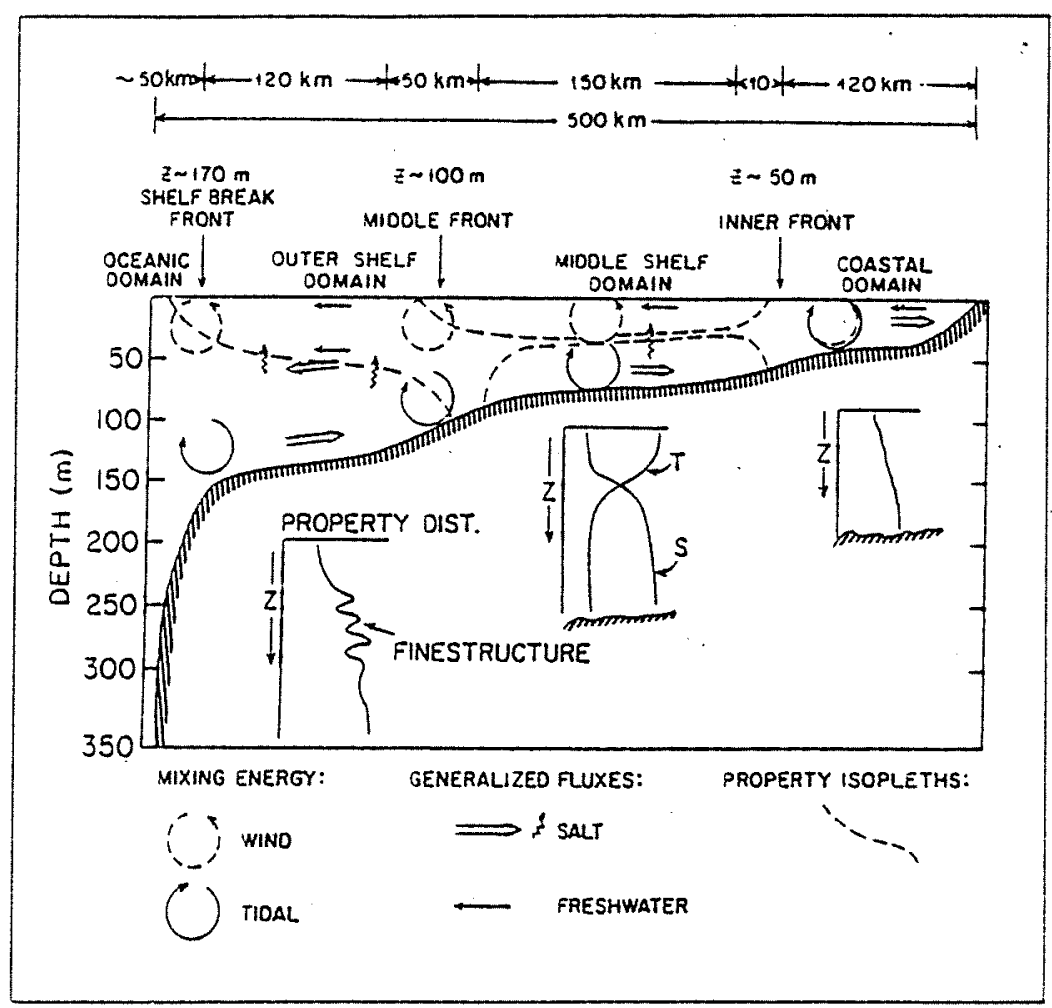

Figure 1.1. Oceanographic regimes of the Bering Sea shelf. Shown are primary water masses, vertical mixing patterns, and fronts between masses. Note the inner frontal zone occurring at the $50-\mathrm{m}$ isobath, separating a well-mixed coastal domain from a more stratified middle shelf domain. Source: Schumacher and Reed (1983).

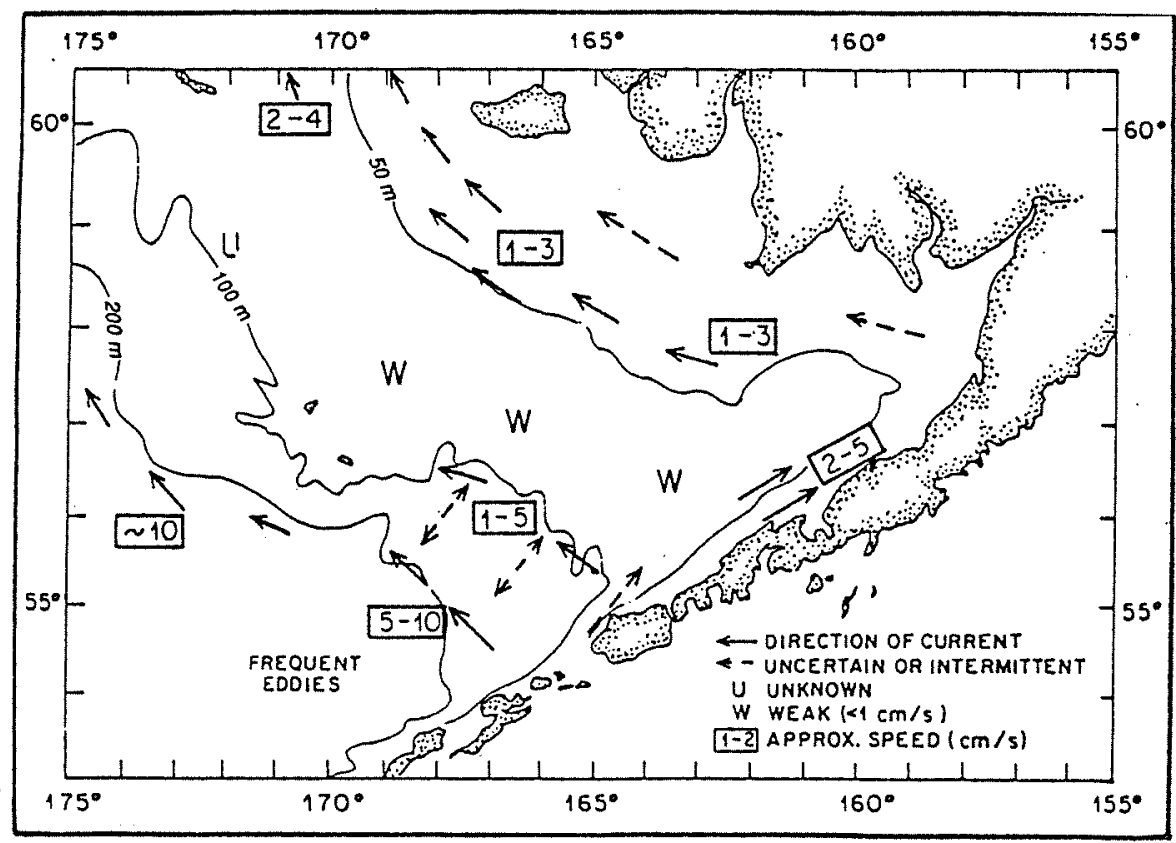

Figure 1.2. Long-term circulation patterns in Bristol Bay. Depicted are the long-term drift patterns of the waters of the Bristol Bay. These are fairly slow circulation patterns, especially along the coastal shelf. Primary (instantaneous) currents are tidally driven. Source: Bakkala (1993) as adapted from Kinder and Schumacher (1981). 
The middle domain, 50-100 m, is typically uniformly mixed in the winter; in summer it has a two-layered vertical structure with a shallow surface layer over a larger layer of cold, nutrient-rich water (Coachman 1986). The waters of this domain exhibit very sluggish net transport (Schumacher and Reed 1983). During the summer, these waters support high levels of primary production as occasional storms allow mixing of the productive bottom waters into the surface layer. The absence of large numbers of grazing zooplankton allows much of this production to sink to the bottom and support a high abundance of benthic animals, including crab and flatfish (Ackley et al. 1994).

The outer domain waters are also vertically stratified with a layer of shelf water above a layer of intruding oceanic water (Coachman 1986). The outer domain is subject to the highest rates of flow, generally along the shelf to the northwest (Schumacher and Reed 1983). Occasional mixing of nutrient-rich oceanic waters into the surface layer leads to high primary production. The presence of high numbers of zooplankton grazers does not allow much of this energy to reach the benthic community in this domain (Ackley et al. 1994).

A major seasonal component in the eastern Bering Sea is the pack ice, which can cover $\leq 80 \%$ of the shelf at its maximum extent during heavy ice years. Large year-to-year variations, fluctuating up to hundreds of kilometers, have been observed and are generally correlated with either wind fields or storm tracks (Niebauer 1983, Overland and Pease 1982). During heavy ice years, the storms typically track along a more southerly route, which leads to a greater proportion of cold winds from the north. This pattern causes greater ice production and pushes the ice further south to increase overall ice coverage in the region (Niebauer 1983). The opposite is generally true for light ice years where a more northerly storm track and fewer severe storms lead to a higher incidence of southerly winds and less ice production. On an annual scale, the boundaries of ice extension might be the most variable physical parameter of the eastern Bering Sea environment (Hsu 1987).

\section{General Behavior and Distribution of Red King Crab}

The red king crab, one of several species of crab fished in the Bering Sea, is considered to be a fairly shallow water species despite being found through a broad range of depths. It has been recorded from intertidal and shallow rocky habitat (Karinen 1985) to depths of nearly $250 \mathrm{~m}$ (Dawson and Yaldwyn 1985). Across this depth range, habitat utilization is often sex- or age-specific. These habitat specializations help to determine how the fishery impacts the crab population, and how the crab rely on the characteristics of the ecosystem.

As a point of reference, we begin with the first phase in a crab's life: the egg. Fertilized eggs are incubated by ovigerous females from fertilization through development, and are released in the spring, $\sim 1$ mo before spawning. In the southeastern Bering Sea, this is typically near the beginning of April, but the precise timing varies by up to $1.5 \mathrm{mo}$ from year to year, depending on water temperature throughout the incubation period (McMurray et al. 1984, Shirley and Shirley 1989). Planktonic larvae then pass through four zoeal stages, a single megalops, and a gluacothae, which is then competent to settle, and metamorphose into the first benthic instar (McMurray et al. 1984, Shirley and Shirley 1989). As with the length of incubation, the length of the planktonic phase is variable and largely influenced by sea temperature. McMurray et al. (1984) state that full larval development requires an average of 460 degree-days. ${ }^{1}$ However, the relation-

\footnotetext{
${ }^{1}$ Degree-days are a common indicator of the linear relationship between temperature and growth rate of an organism. For example, if an animal requires 100 degree-days for development, it would theoretically develop in 100 days at $1{ }^{\circ} \mathrm{C}, 50$ days at $2{ }^{\circ} \mathrm{C}, 25$ days at $4^{\circ} \mathrm{C}$, etc.
} 
ship between temperature and growth is not simply linear. Above $\sim 10^{\circ} \mathrm{C}$, larval growth is impaired, with earlier stages being more sensitive than later stages to high temperature. Laboratory studies suggest that steadily increasing sea surface temperatures through the planktonic phase result in the most rapid development as a result of slightly different requirements of the different stages. Optimal temperatures for zoeal development are $\sim 3^{\circ} \mathrm{C}$, and the greatest performance of later stages occurs close to $8^{\circ} \mathrm{C}$ (Nakanishi 1985). In Bristol Bay, this translates into a planktonic phase of $13-14 \mathrm{wk}: 10 \mathrm{wk}$ to pass through the four zoeal stages and another 3-4 wk before settling. Initially, these larvae will be located in the southern bay, along the Alaska Peninsula. As development progresses they are carried east and north by the prevailing currents (Fig. 1.3). The precise location of larval concentrations varies among years, reflecting variations in the precise location of breeding assemblages (Armstrong et al. 1993).

Peak settlement normally occurs in late July and August, predominantly in nearshore habitat. While reports exist of young-of-year red king crab being collected from depths $>100 \mathrm{~m}$ (Powell and Nickerson 1965), this appears to be uncommon. Sampling of the southeastern Bering Sea has failed to demonstrate any settlement below $50 \mathrm{~m}$, despite the existence of apparently suitable settlement habitat and the presence of competent larvae in the water column directly above (McMurray et al. 1984). Studies of red king crab in Kachemak Bay (Gulf of Alaska) found settlement restricted to $<27 \mathrm{~m}$ (Sundberg and Clausen 1977), and intertidal settlement has also been observed (Stone et al. 1993). Most important, settlement is restricted to specific habitats characterized by substrate quality and biotic assemblages. Settlement is known to occur in cobble to boulder habitat, as well as beneath shale outcroppings, and it is enhanced by the presence of biogenic structure. Common assemblages that enhance settlement include filamentous bryozoans (Flustrella spp., Dendrobeania spp.), erect colonial ascidians (Boltenia ovifera), erect sponges, tubicolous polychaetes, mussels beds, and filamentous algae (Sundberg and Clausen 1977, McMurray et

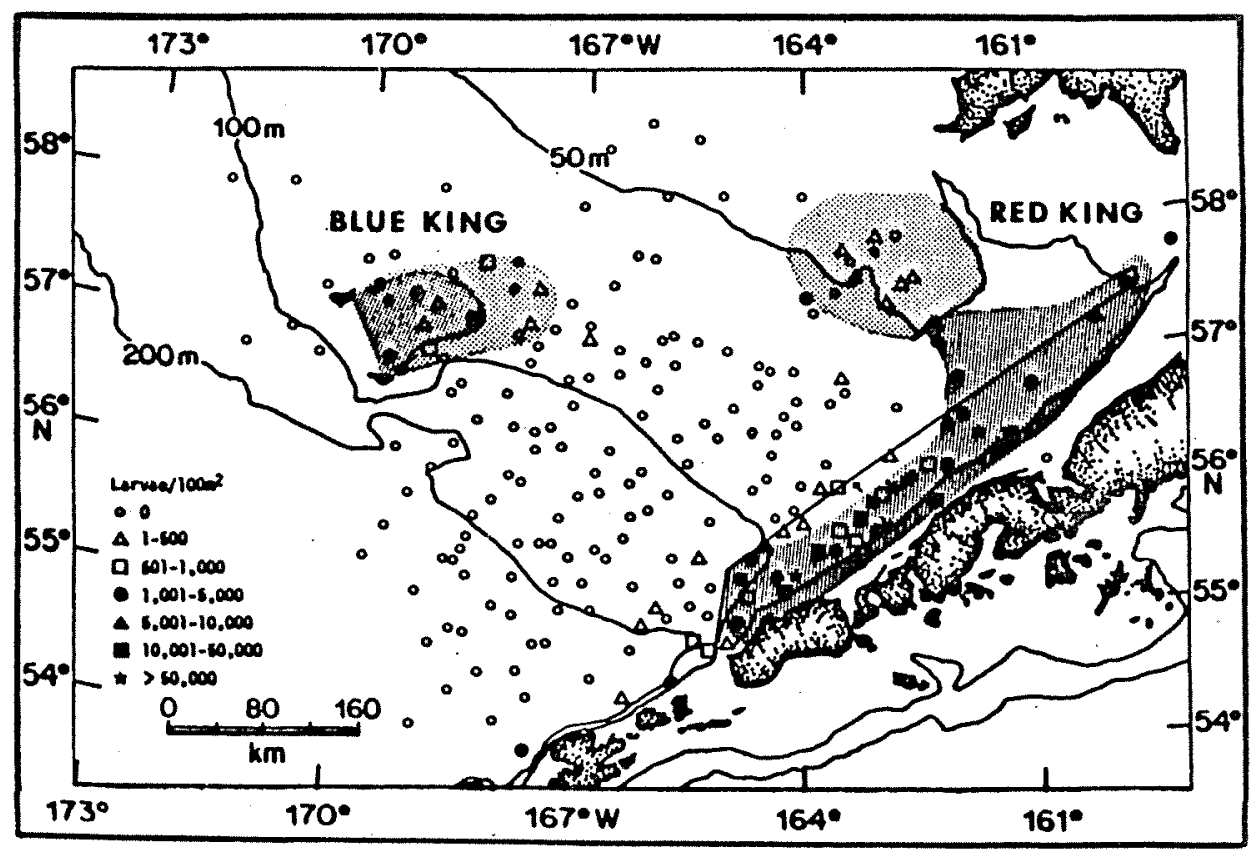

Figure 1.3. Distribution and abundance of red king crab larvae in Bristol Bay. Data include all years from 1976-81 throughout larval development. Note the pattern that indicates concentration of larvae along the inner frontal zone with east and northward drift through the summer. Source: Armstrong et al. (1981). 
al. 1984). These features provide physical refuge from predation, as well as a source of food. Cobble habitat, which may serve as important settlement substrate, appears to be limited and patchy, and is confined to three general regions in water $<50 \mathrm{~m}$ in depth: (1) on the north shelf near the mouth of Togiak Bay, (2) to the east in Kvichak Bay, and (3) along the southern shelf in the area of Port Moller (Armstrong et al. 1993). Figure 1.4 shows the location of such substrates and the location of early post-settlement juveniles in a typical year.

Red king crab remain cryptic and solitary in these fairly shallow water refuges through their first year and into their second (Karinen 1985, Stone et al. 1993). At $\sim 2$ years of age, however, they begin to move toward deeper water and aggregate. These aggregations become highly structured, resulting in deep piles of crab akin to haystacks, commonly known as "pods." Pods comprise almost exclusively 2-4-year-old individuals, and are thought to serve in predator defense (Dew 1990), though little quantitative work has been done to test this. The sex structure of pods is not fully understood either, with some researchers contending that pods are composed of single-sexed individuals, while others claim that mixed-sex pods exist. Podding aggregations in Bristol Bay are found seaward of settlement sites, nearer the central bay. Age 2 crab tend to be found near the 50-m contour while age 3 crab continue to move deeper, being located at $\leq 70 \mathrm{~m}$ (Fig. 1.5).

Organized pods begin to disperse at about age 4. While the distribution and behavior of 4- to 5-year-olds is not well understood, by age 5 sexual segregation begins to emerge. Aggregation is still common but can

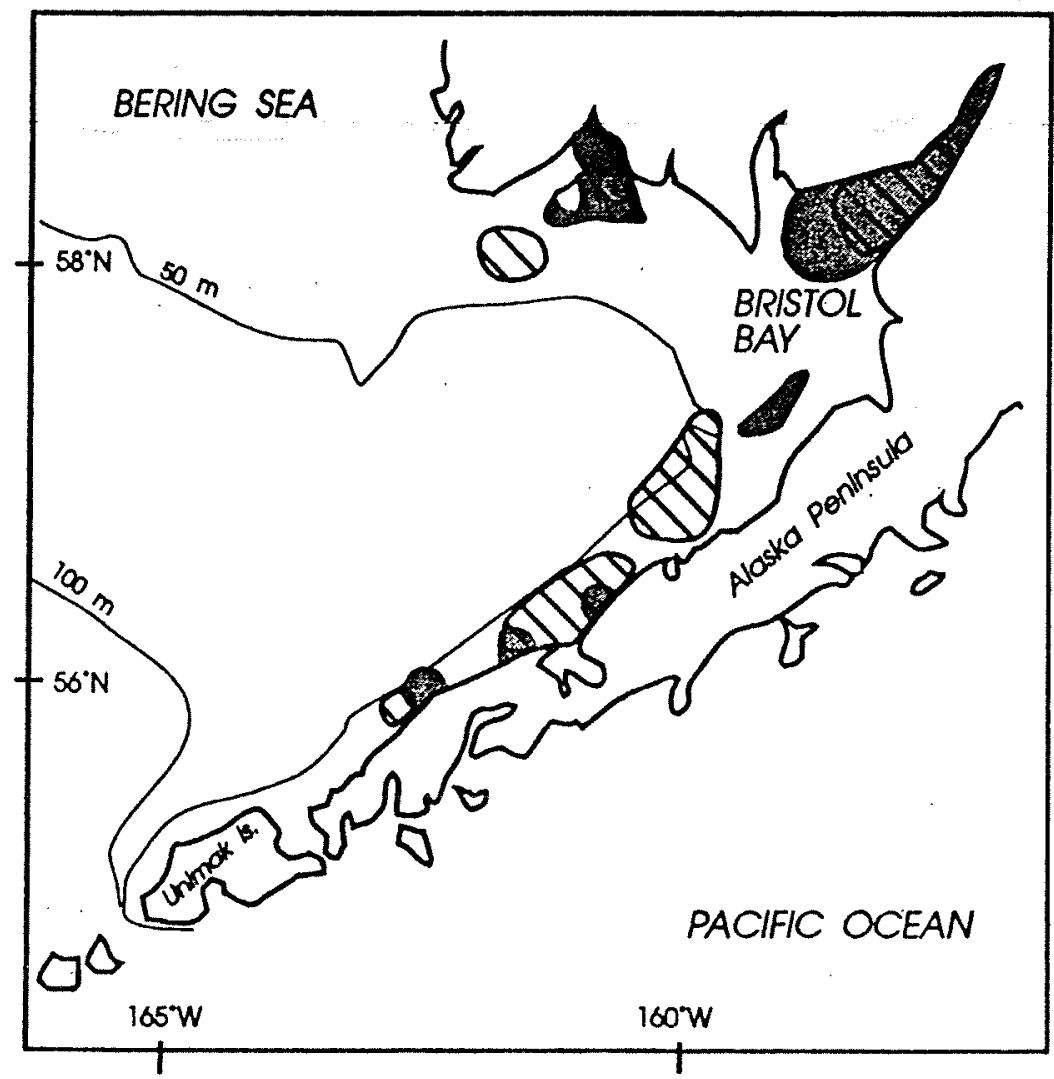

Figure 1.4. Location of gravel/cobble substrate in Bristol Bay. Shaded areas characterized by $\geq 10 \%$ gravel; striped areas represent juvenile distribution of red king crab in 1983. Source: Armstrong et al. (1993). 


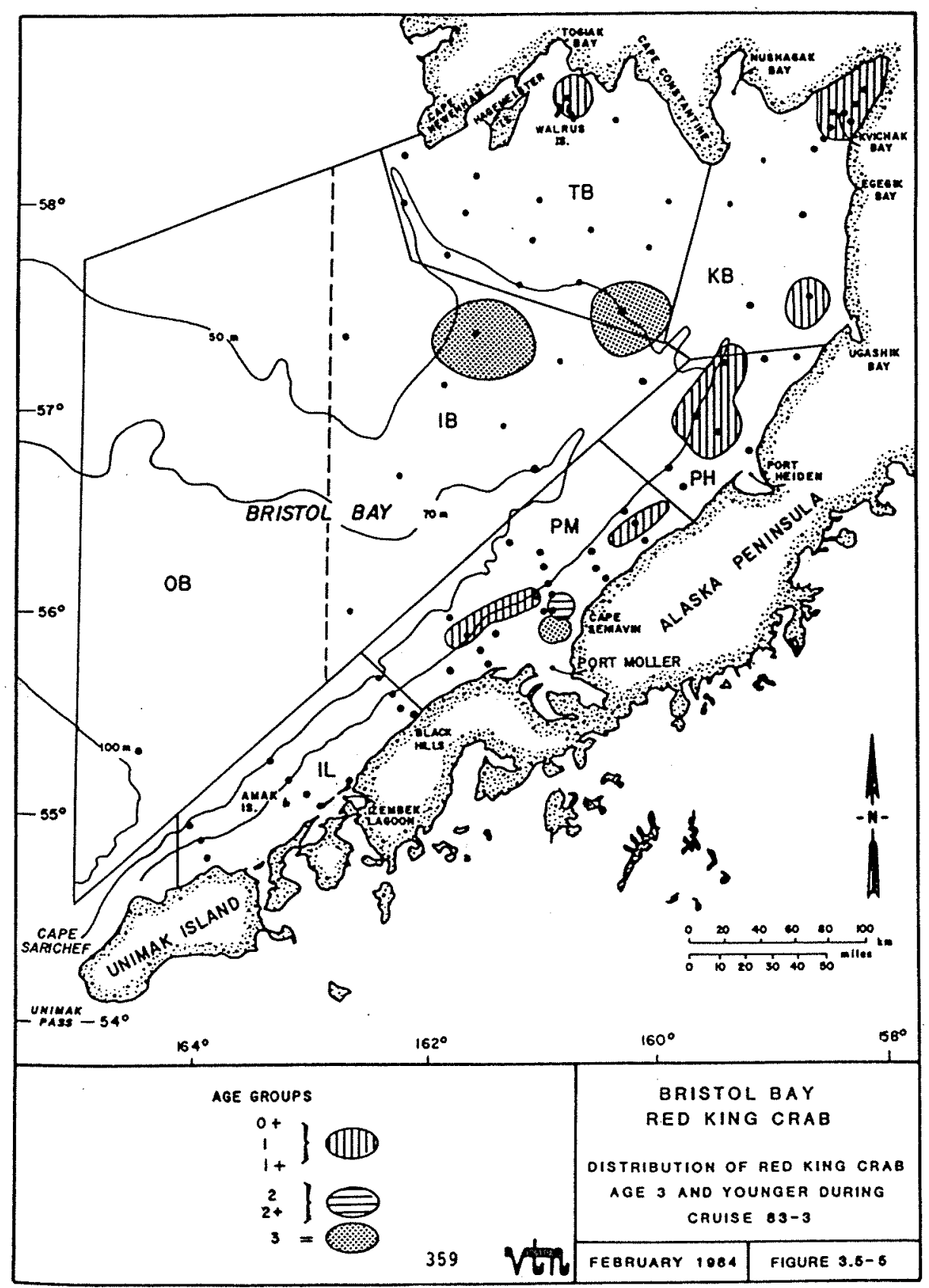

Figure 1.5. Distribution of juvenile red king crab in Bristol Bay. Data include early benthic phase (0-2 yr) and podding juveniles $(2+$ and $3 \mathrm{yr}$ ). Note that settlement occurs primarily in shallow nearshore waters with crab moving towards the 50-m isobath as they age. Source: McMurray et al. (1984).

be differentiated from podding in that such aggregations do not involve the piling of individuals on top of one another, or in cases where piling occurs there are rarely more than two or three layers of crab (Stone et al. 1993). Adult crab seem less prone to pile together on smooth, featureless substrates, but do so along reef and outcropping edges where aggregations may pile against rock surfaces while resting. This has been observed in ovigerous females, which are also known to rest partially buried on soft bottom (Stone et al. 1993). The distribution of these females is somewhat different from males. Females remain in shal- 
lower waters while mature males move into deep water. In the southeastern Bering Sea, mature females remain in waters near $4^{\circ} \mathrm{C}$, while males are subject to waters near $1.5^{\circ} \mathrm{C}$; this likely is an adaptation to the breeding state of the individuals. Mature females carrying incubating eggs must remain in warmer water to ensure that eggs will be ready to hatch prior to spawning, while males may conserve energy output by spending summer months in relatively cold water. What results is a regular yearly migration of mature individuals from deep water feeding grounds into shallow waters to molt and breed. Data collected on the migration of ovigerous females in Auke Bay, Alaska (Stone et al. 1993), indicate that these crab spend mid-June through mid-November in fairly deep water, below the established summer thermocline. When the thermocline breaks down, crab migrate back to intermediate depths where they remain until they have released the eggs fertilized in the previous spawning season. In May, females then move to shallow coastal areas to molt and spawn. Prior to molting, males leave their deep-water feeding areas to join females in shallow water. Males may choose mates at this point, after egg release but prior to female molting, and have been known to clasp and guard females for $\leq 16 \mathrm{~d}$ prior to spawning. Additional evidence suggests that males will clasp virgin females for much longer periods of time (Stone et al. 1993). Following spawning, adults migrate back to deeper water (Figs. 1.6 and 1.7).

\section{IMPLICATIONS OF THE GENERAL LIFE HISTORY}

The life history of the king crab suggests a number of critical stages in which the stock may be impacted by fishing. Traditional stock management models have often assumed a discrete stock-recruitment relationship based on a few discrete parameters describing the mortality of the species through time as it approaches recruitment to the fishery. For red king crab, individuals recruit to the fishery at $\sim 8$ years of age. Thus, significant mortality may occur at a number of different ages, and the agents of mortality may be very different at each life stage. Our failure to rebuild the stock suggests that we have incompletely considered the ecological ramifications of some limiting factor(s) within the life history of the species. Finding the "missing link(s)" in our understanding requires that we consider each relevant life stage, and the factors that may govern survivorship within that stage.

First, there are considerations regarding the spawning stock. What is the average fecundity within the breeding stock, considering energetic output, breeding behavior, and egg mortality factors? From this, we may estimate the basic larval supply, defined as the number of larvae that successfully reach settlement. Second, there are considerations of mortality occurring on benthic phases from settlement to recruitment. The factors that govern survivorship will likely be very different depending on what age group is studied; thus, analyzing similar year-classes together may be helpful. In this case, there appear to be at least six relevant age groups based on size, habitat use, and behavior: (1) incubating eggs, (2) larval stage, (3) early benthic phase (settlement through age 1+), (4) aggregating juveniles (age 2-4), (5) sub-adults (prefishery, approximately age 5-8), and (6) adults (recruited to fishery, approximately age 8+). Restrictions in any of these stages may result in reduced recruitment to the fishery. Our ability to enhance stock rebuilding hinges on identifying critical phases, especially those whose productivity may be limited by our activities. Critical intersections between crab life history and anthropogenic activities present us with the greatest opportunity to manage for positive effects on the stock. In the following text, we discuss these life phases and some of the possible limitations and impacts on each. 


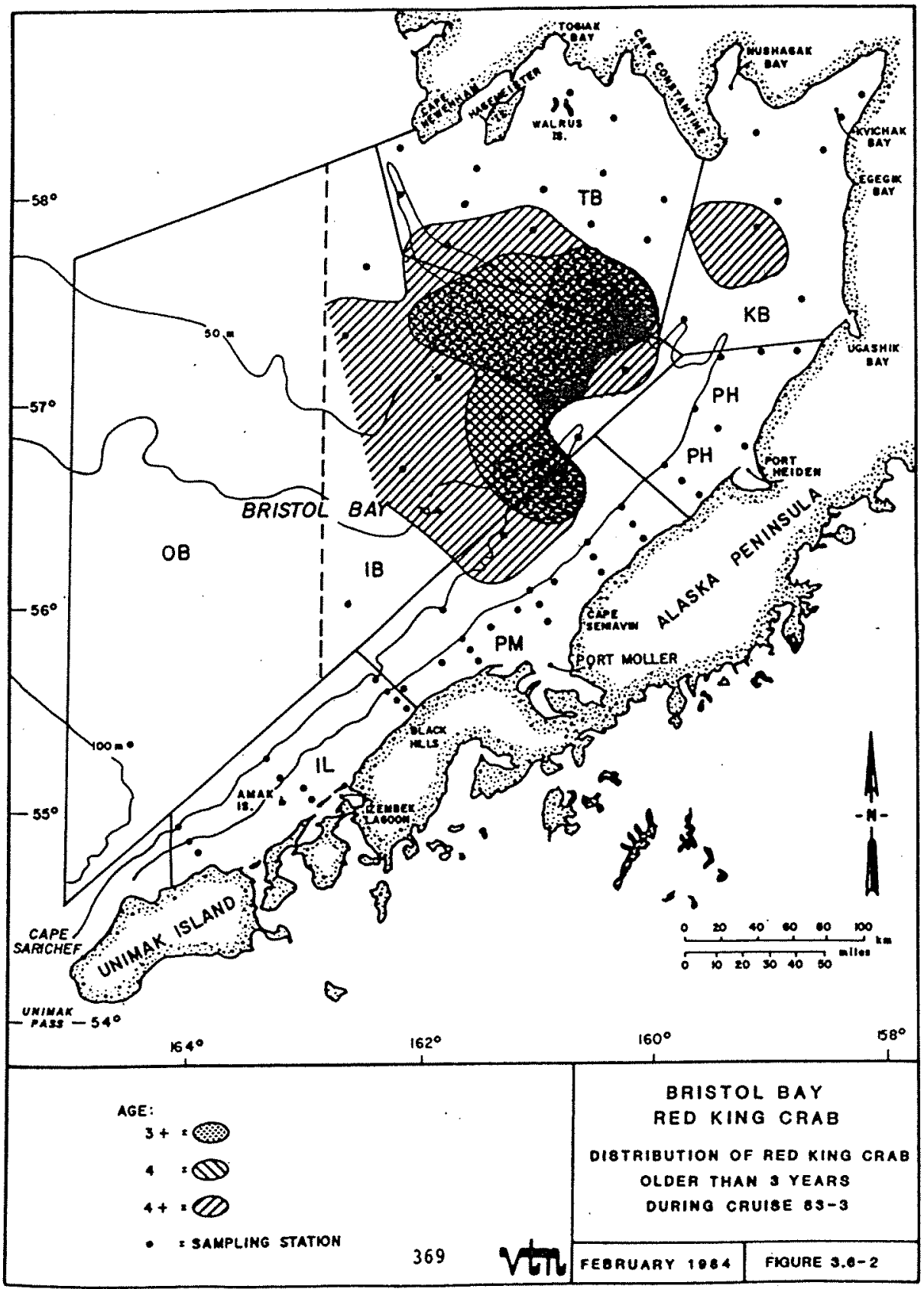

Figure 1.6. Distribution of adult and sub-adult red king crab in Bristol Bay. Data include pre-reproductive individuals ( $3+$ and $4 \mathrm{yr}$ ) as well as reproductive crab before and after entering the fishery (4+ yr). Note the use of greater water depths by crab as they age. Source: McMurray et al. (1984).

\section{Egg Supply}

Significant reduction in the number of eggs produced by the breeding stock may place limitations on the size of the future stock. This concept is one of the simplest to approach from a theoretical basis: you can not have more recruits than eggs. Determining what levels of egg production are actually limiting in a given stock, however, is somewhat more complex. How a species is characterized in terms of the stockrecruitment relationship can affect our interpretation of what constitutes "adequate egg supply." Accu- 

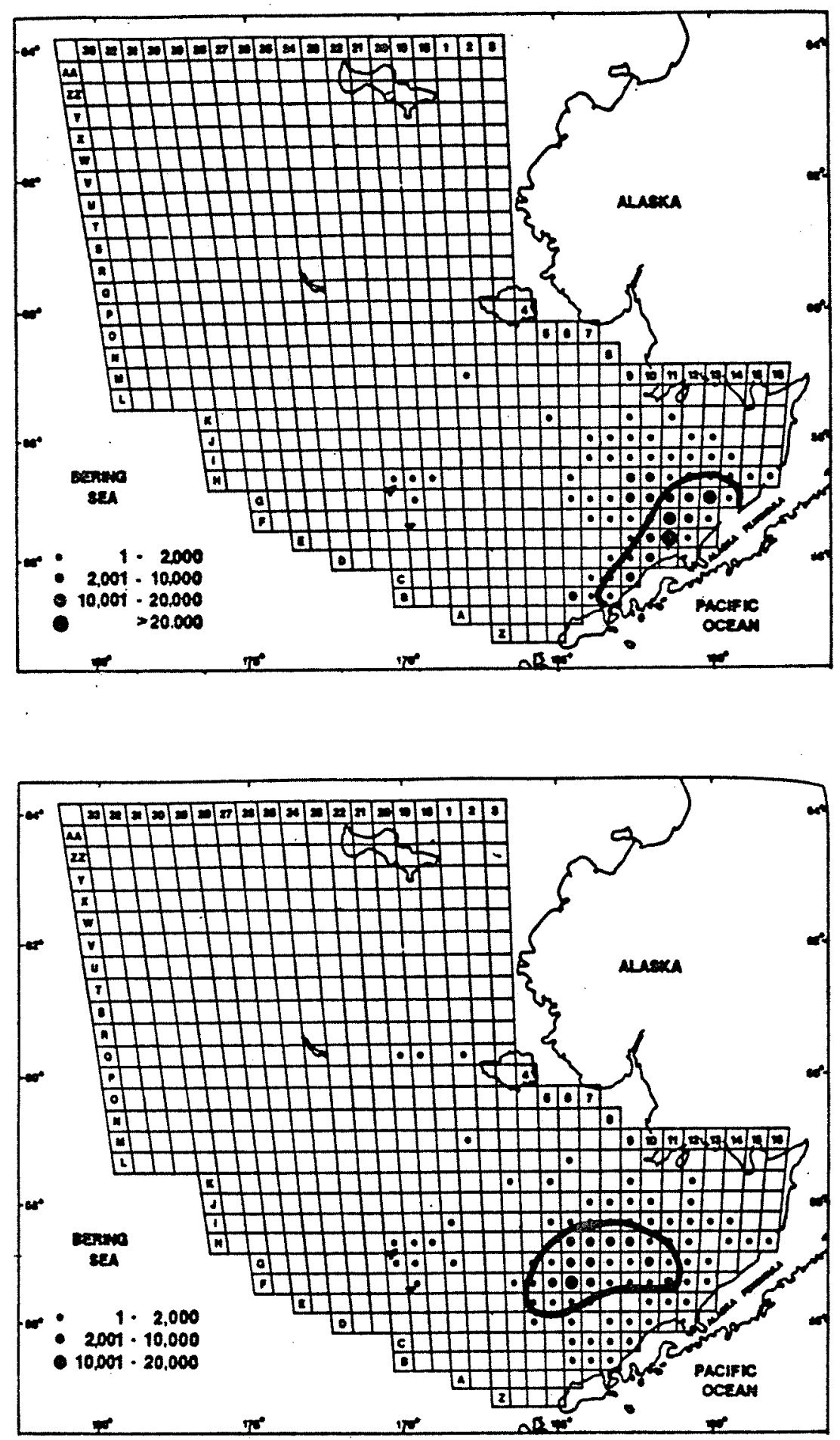

Figure 1.7. Sex-specific distribution of adult red king crab in Bristol Bay. Data reported for female crab $89 \mathrm{~mm}+$ carapace length, and male crab $134 \mathrm{~mm}+$ carapace length: upper panel shows concentration of females along southern shelf; lower panel shows greatest concentration of males in deeper water in the central Bay. Source: Armstrong et al. (1981). 
rately quantifying the true nature of stock and recruitment will remain an ongoing process in any management scheme. Within this framework, the stock may be defined not as total adult population, but alternatively as egg production.

Somewhat unique to crustacean fisheries is the ability to regulate the population in a sex-specific manner. The result may be a reduction in overall adult abundance without a reduction in egg production by harvesting that portion of the stock (in this case male crab) that is not "limiting" egg production in the hypothetical equilibrium population. In order to do this effectively, one must first consider the breeding ecology of the species to understand how perturbations in breeding stock may or may not result in changes in total egg production. Clearly, these are considerations that have been addressed in past management and will continue to be addressed in managing this species. The scope of this report limits us to a brief discussion of this life stage. We do not claim to fully understand which considerations have been addressed in the present management scheme, and which may warrant deeper examination. Instead, we discuss one factor that is important in managing for an appropriate breeding stock: the effects of breeding behavior on fecundity.

Since the total number of eggs hatched is the basic limiting factor of concern, the breeding success of the entire stock can be equated to the breeding success of females within the population. The total number of successfully hatched eggs produced by an individual female will be a function of (1) the total number of eggs that female produces within a season, (2) the proportion of those eggs that become fertilized and, (3) the proportion of fertilized eggs that successfully hatch. The number of eggs produced by a female will be related to the size of the female and her physical condition (Jensen and Armstrong 1989). In order to ensure an adequate level of egg production for the entire stock, we need to preserve an appropriate number of females large enough to spawn a sufficient number of eggs and maintain a male stock able to fertilize those eggs. The red king crab fishery has established a males-only harvest strategy, attempting to ensure the greatest possible female biomass, presumably comprising physically large individuals. The effect on the male population is the opposite: reduced numbers and smaller individuals. This should result in sex and size ratios biased in favor of females. Yet, if the male:female ratio becomes too small, the breeding potential of many females will not be realized. In order to determine what constitutes an appropriate ratio, one must first determine the actual breeding potential for each male in the stock. This can be accomplished by determining how large a male must be in order to fertilize a given female, and how many females a single male can mate in a breeding season. Research suggests that the male crab in a mating pair need not be as large as the female. A 1.7:1 ratio of female:male weight should, on average, result in 100\% fertilization. In addition, a study examining repetitive breeding success in sub-legal male red king crab (which will comprise the bulk of the breeding stock in a fully exploited fishery) determined that males may have the ability to fertilize multiple females in a single breeding season. Sub-legal males were able to fertilize $\sim 75 \%$ of an egg clutch in their first mating. This dropped to $38 \%$ in the second mating, and to $12 \%$ in third and fourth matings (Paul and Paul 1990). Armed with these data and a knowledge of female population structure, we may be able to ensure adequate spawning success by maintaining an appropriate male population structure.

However, some potential problems exist with this approach. One must also consider the subtleties of the species' breeding behavior in order to get a full understanding of the functional breeding success of mating pairs. For example, once a female has released any eggs she may have been carrying, a male may clasp her, guarding her from time of molt until breeding (McMurray et al. 1984). Extended clasping be- 
havior has ramifications on fecundity, which may not be considered in the present management framework. In order to fully understand how this behavioral pattern translates into functional breeding success, one must first understand how mates choose one another. Is there any evidence that mate choice occurs with regard to physical size, or do mates associate at random? Do males compete for females, and can subsequent males displace smaller males from their mates? It seems logical that small males may have difficulty in physically clasping and guarding significantly larger females. Furthermore, in an assemblage with essentially equal sex ratios some level of mate competition may ensure reasonable size matching within breeding pairs. But what dynamics exist in an assemblage where size and sex ratios have been altered by fishing pressure? Individual breeding success may be affected by changes in mate choice resulting from such an altered system, and fertilization success may be different than calculations would suggest. Furthermore, what effect does mate guarding have on male fecundity? Surely, any time spent guarding a mate will be time when the male will be unable to fertilize other females. If a male typically guards a female for extended periods before mating, how many mates can he actually access during the breeding season? Also, if energy expenditure occurs over this period without feeding, fertilization success may be reduced later in the breeding season. A full understanding of the potential mating success of multiple-spawning males and establishment of appropriate size and age ratios requires these and other questions to be answered.

Finally, regulating the size and composition of a breeding stock brings up questions with regard to genetic fitness and stability. Is individual fitness in some way related to size, and can you alter the genetic makeup of the population by altering the size structure within that population? As we apply pressure to only the largest males in the stock, we not only remove those with the greatest ability to fertilize females, but we may also be applying a selective pressure that favors smaller males and an earlier age at first reproduction. What are the ramifications of this? Some of these concepts will be addressed in later chapters.

\section{Larval Supply}

Once spawned and successfully hatched, the larval supply will be affected by another suite of impacts that reduce abundance in variable ways. Most immediately, larvae must avoid starvation and predation. Because early larval king crab are phytoplanktivorous, larval starvation is most directly affected by the availability of phytoplankton to developing larvae. This, in turn, is determined by absolute plankton biomass and by the location and timing of larval crab hatching. All of these events are largely determined by oceanographic conditions, as well as by the behavior of the spawning crab population. Various oceanographic conditions, including water circulation patterns and temperature, can affect the overall biomass and concentration of phytoplankton. Average water temperature also controls the length of the crab incubation period, suggesting that the resulting hatch dates may or may not correspond with phytoplankton blooms in the overlying waters. If the timing of phytoplankton blooms was similarly controlled by temperature, there may be limited potential for asynchrony between larval development and food supply. However, while hatching date is temperature-dependent and varies from year to year, phytoplankton dynamics are more commonly controlled by light levels and do not show much yearly variation (Shirley and Shirley 1989). Despite this fact, the effect of such asynchrony on larval supply appears minimal. From 1985 through 1988 Shirley and Shirley (1989) examined variations in phytoplankton-larval asynchrony and its effect on overall king crab larval supply in Auke Bay, Alaska. In 1985 and 1987, timing of the two populations was highly synchronous, while 1988 peak crab larval development preceded peak phytoplankton density. In all years, overall abundance of crab larvae was comparable with "all but the highest 
densities" recorded since 1969. Shirley and Shirley (1989) could find no correlation between timing of larval crab release and overall survival of larvae.

A more important factor in causing fluctuations in larval supply may be that of predation. A number of planktivorous fish species are known to feed on decapod zoea and megalops including Alaska pollock (Theragra chalcogramma), Pacific herring (Clupea pallasi), sockeye salmon (Oncorhynchus nerka), and yellowfin sole (Limanda aspera) (Kamba 1977, Livingston et al. 1993, Wespestad et al. 1994). The potential impact of these predators is increased when one looks at the intersection between life-history patterns of these species and those of the red king crab. As mentioned earlier, larval red king crab are commonly found in Bristol Bay from late April through early August at a time when Alaska pollock are also abundant in the area. Pollock, which spawn in the summer, produce a pulse of larvae that will also overlap larval crab distribution (Serobaba 1974). Early in their larval phase, pollock feed primarily on copepod nauplii, but as they age they begin taking larger and more diversified prey. A dietary study of larval and juvenile pollock in the waters off Japan (Kamba 1977) demonstrates the occurrence of decapod zoea in stomach contents after 3-4 mo growth. Pollock of this age should occur in Bristol Bay around June. Kamba's (1977) data also suggest that predation on decapod larvae may be preferential to other more numerically abundant prey. While decapod prey became more abundant in stomach samples from May through July, they were not increasing in abundance (in fact were not located at all) in plankton samples collected at the same time. All of these factors indicate the great potential of pollock predation to limit larval crab abundance.

A similar pattern may also occur with regard to Pacific herring. This species is not a year-round resident of the Bristol Bay area. Instead, it winters in aggregations farther offshore but moves into the bay in the summer in order to spawn. During the summer, these fish are commonly distributed throughout Bristol Bay and move onto the coastal shelf in somewhat smaller schools (Dudnick and Usol'tsev 1968). McGurk et al. (1991) have described the breeding behavior of this species in the area of Port Moller. From late April until mid-July, waves of herring move into the bay. As they spawn, their larvae are retained in converging currents, which impede their seaward transport. If these currents are capable of retaining and concentrating herring larvae, they must surely do so for crab larvae as well. This would subject the crab larvae to increased predation by planktivorous herring, both adult and larval.

The situation with salmon is somewhat more complex. Sockeye salmon, especially in recent years, are a very abundant seasonal resident of the Bristol Bay area and also present a significant potential source of predation on king crab larvae. Smolt are known to feed on king crab larvae and spring outmigrations of sockeye smolt, like the appearance of juvenile pollock and spawning herring, are timed to overlap crab larvae abundance. Wespestad et al. (1994) have modeled theoretical levels of smolt predation on crab larvae based on observations of smolt feeding rates and larval densities. Their model suggests that large year-classes of salmon smolt may significantly reduce larval supply in years of low zoeal abundance. Present effort is now being applied to address the importance of this impact in the Port Moller area (Don Rogers, Univ. Washington Fish. Res. Inst., Seattle, pers. comm.). What has not been addressed is the effect of the two-tier nature of variable salmon production on crab cohorts. Smolt are not the only life-history phase of salmon that feed on larval crab. Adults return to Bristol Bay to feed for $\sim 1$ mo before returning upstream to spawn and are known to feed on both king and Tanner (Chionoecetes spp.) crab zoea. While the number of adult salmon will be less than smolts, and the relative proportion of prey items will also likely be different, this still represents a significant biomass of predators and perhaps a non-trivial 
predation impact. Thus, with salmon, the factors that positively affect production within the freshwater phase (environmental, biological, and also management decisions) could negatively impact larval supplies of king crab not only during that year (during smolt outmigration) but again years later (when adults return to spawn). In addition, factors that impact marine survival of salmon may also effect larval crab supply.

The previous discussion considers the potential effects of planktivores operating at the surface and midwater, yet crab may face another gauntlet closer to the substrate. Livingston et al. (1993) report that yellowfin sole may be important predators on both newly settled king crab and also megalops. The fact that yellowfin sole are consuming megalops, which would not yet be fully benthic suggests that significant fish predation on larvae may occur in close proximity to the settlement surface. This is reported for only one species, yet the fish community in the area is likely to be complex and the number and abundance of potential predators great. In management, the general tendency is to consider only commercially important species, since these are the species we wish to harvest and manage. In our approach to the problems of king crab management, we acknowledge the need to consider the entire life cycle of the crab and how impacts intersect it. To fully understand the importance of an impact such as predation, we must also fully consider the entire suite of potential predators, whether traditionally considered important or not, and the entire life history of those predators as well. The bulk of food habit information focuses on larger individuals that are caught in sample gear adapted from commercial gear. For example, while market size halibut may not be observed feeding on crab megalops, it is likely that juvenile halibut nearing competence to settle to a benthic existence will be planktivorous. This same generalization may be true for many common species, thus amplifying the potential for impacts on larval supply.

\section{The Pre-Fishery Benthic Life Stages: Early Benthic Phase, Aggregating Juveniles, and Sub-adults}

Despite all of the potential factors resulting in variation in larval supply, the importance of such processes in limiting or determining recruitment into the fishery (subsequent adult numbers) remains ambiguous. While a negative correlation has been implied between potential salmon smolt predation and later crab abundance in the Bering Sea, direct data have not been collected. Salmon predation has not been established as a direct cause for this pattern. More study is needed to address whether high levels of pelagic planktivory result in discernible decreases in larval density and, furthermore, whether fluctuations in larval supply translate to fluctuations in year-class strength from settlement to recruitment. Studies on other commercially important crustacean species have failed to show such a relationship. A 6-year study of California Dungeness crab (Cancer magister) failed to find any correlation between larval abundance and year-class strength recruiting to the fishery (Shirley and Shirley 1989). Similarly, it has been a long-standing belief that recruitment of North American lobster (Homarus americanus) in the Gulf of Maine and Eastern Canada is limited by larval supply, but a closer examination of the existing data reflects no such correlation (Wahle 1991, Wahle and Steneck 1991). Instead, there appears to be a "bottleneck" in one critical life stage of the lobster that results in a fairly constant output of recruits passing through that stage.

Clearly early post-settlement lobster actively seek shelter and require complex substrate for successful settlement (Botero and Atema 1982, Cobb et al. 1983). Those settling on sedimentary substrate may burrow to avoid predation from benthic foraging predators such as fishes (Berrill and Stewart 1973), but the success of this strategy is probably quite low (Lavalli and Barshaw 1986, Barshaw and Lavalli 1988), and juvenile lobster are generally not found under natural conditions in such substrates (Wahle and Steneck 
1991). Instead, early benthic phase lobsters appear to be limited to cobble and heterogeneous rocky areas, which afford a refuge from predation by benthic fish and invertebrates.

The importance of spatial heterogeneity and refuges from predation in limiting species abundance and distribution in submerged aquatic ecosystems is clearly recognized in the ecological literature (Russ 1980, Choat 1982, Gilinsky 1984, Witman 1985, Ojeda 1987, Sebens 1991, Loher 1992). The limited availability of refuge habitat in conjunction with the discontinuous nature of such habitat is believed to be the "bottleneck" through which lobster stocks must pass, and appears to limit maximum annual recruitment (Wahle and Steneck 1991). Similar habitat limitation has been shown for other benthic crustacea including freshwater crayfish (Quin and Janssen 1989) and Caribbean stomatopods (Steger 1987).

McConnaughey and Armstrong (1991) claim that difficulties in correlating larval abundance with recruitment in Dungeness crab may be due to the confounding effects of multi-year-class fisheries and the nature of time lags between settlement and recruitment. In their study, they demonstrate a clear relationship between larval abundance and immediate post-settlement densities. However, these settlers were not followed through time and, in light of the nature of other crustacean stocks, an equally valid explanation for the lack of influence of larval supply on fishery recruitment could be a bottleneck at a critical life stage prior to age at fishery recruitment. We also believe that a similar process may, in recent years, be precluding the potential for high level recruitment of Bristol Bay red king crab and its subsequent rebuilding. Studies on the distribution of early juvenile red king crab (age 0-1+) in Auke Bay in southeastern Alaska (Karinen 1985), Kachemak Bay in the Gulf of Alaska (Sundberg and Clausen 1977), and Bristol Bay in the eastern Bering Sea (McMurray et al. 1984) demonstrate that settlement occurs in areas with heterogeneous rocky substrate such as cobble and boulder, especially when it supports epiphytic algal or invertebrate communities. As mentioned earlier, suitable settlement habitat for red king crab is limited in Bristol Bay (Fig. 1.5). Armstrong et al. (1993) further demonstrate that the availability of these sites varies from year to year. Since larvae are carried on currents throughout the pelagic phase and the location of spawning areas is not static, the precise location of larvae at the time of settlement is not consistent. In recent years, major spawning apparently has occurred further to the north within the central regions of Bristol Bay (Fig. 1.8), resulting in a presumably greater reliance on the settlement sites in the north bay. This may remain stable for some time; however, more southerly spawning in the future could result in a return of heavy settlement to more southerly settlement sites.

In addition to the importance of physical substrate type, biogenic assemblages have been demonstrated to be particularly important to successful settlement. Early juveniles are found associated with erect bryozoans, colonial tube-dwelling polychaetes, ascidians, and hydroids. They have also been successfully recruited to artificial beds of cobble and mussels as well as tube worms. In Kachemak Bay, the most important associations are with two species of erect bryozoans, sponges, filamentous red algae, hydroids, and even hydroid masses found drifting unattached on homogenous substrate. In fact, successful collection and survival of settling red king crab through one full year of growth has been obtained using mimics of filamentous communities constructed of wadded monofilament line (Donaldson et al. 1992). These structures not only provide physical refuge from predation, but also provide food. Juvenile crab have been observed feeding on hydroids, bryozoans and various worms (McMurray et al. 1984).

These epifaunal communities appear to be important to the survival of red king crab through their first benthic phase, yet these communities may be highly impacted by local fishing effort, a problem compounded by the limited nature of cobble beds and the year-to-year variability previously discussed. The shelf areas 


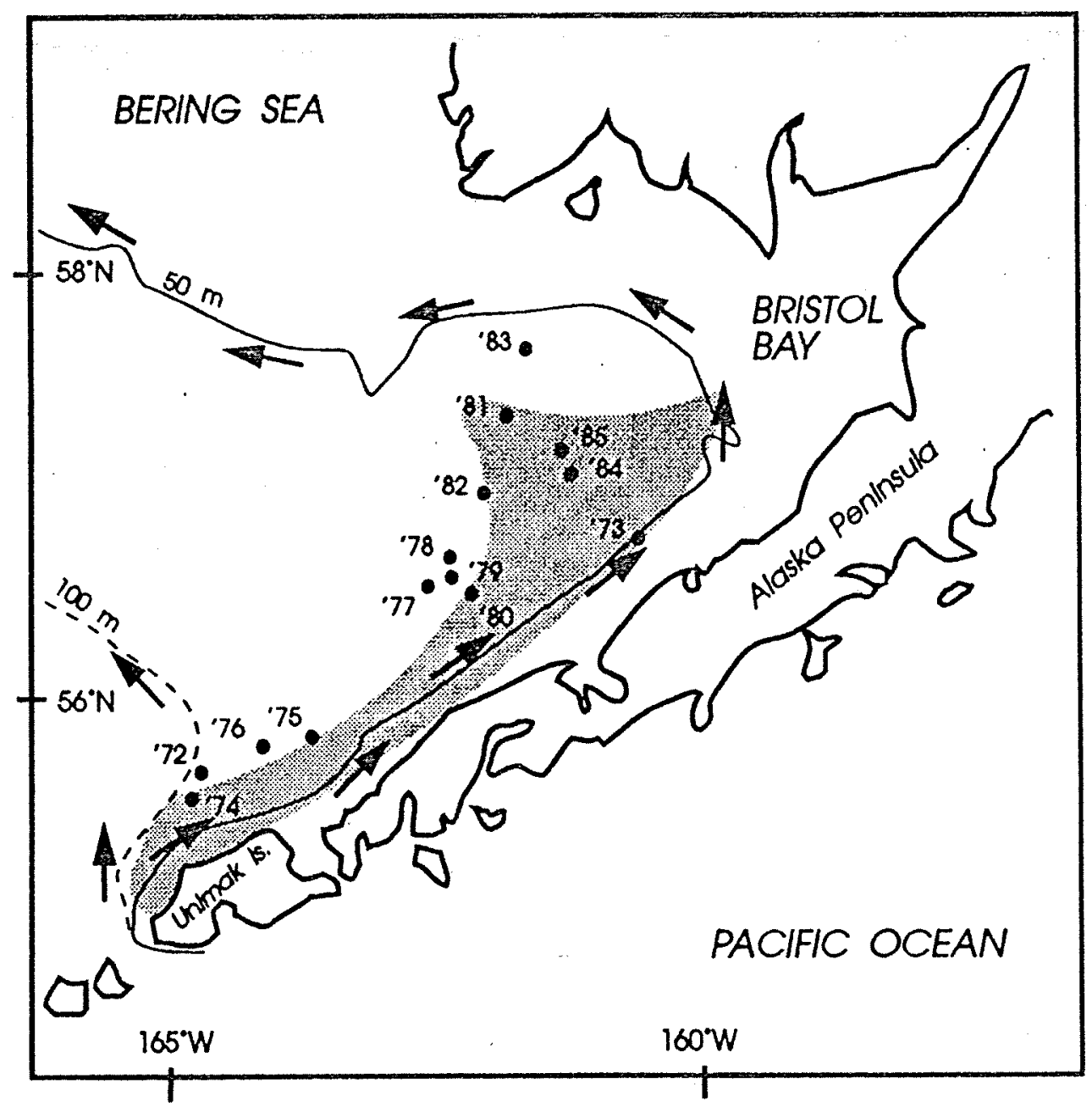

Figure 1.8. Location of breeding concentrations of Bristol Bay red king crab. Circles are the estimated central abundance of egg hatching and spawning, with years indicated. Note the use of more southwesterly areas in the mid-1970s, and a shift to the northeast by the mid-1980s. Source: Armstrong et al. (1993).

of Bristol Bay have traditionally been subjected to bottom trawling for various groundfish species. The effects of bottom trawling on benthic community structure have been in debate for hundreds of years (deGroot 1984), yet study on this topic is clearly incomplete and the results of such studies are often contradictory. However, existing evidence indicates that the nature of the impacts depends on the type of community considered. Trawling may have little short-term effect on the composition and abundance of benthic infauna in soft substrates (Graham 1955, VanDolah et al. 1991), yet the effects to epifaunal assemblages may be severe. Protruding epifaunal species, which require some form of anchorage to a hard substrate, will likely be more susceptible to damage from passing gear. Infaunal species may be displaced by scour from tickler chains and trawl doors, but are likely more resistant to such processes. Soft-bottom communities are typified by homogenous spatial complexity, where community composition is maintained, and species diversity enhanced, through bioturbation and disturbance (Dayton and Hessler 1972). In a rocky subtidal community, structure is more dependent on initial colonization patterns, competition, persistence, and spatial complexity of the substrate (Sebens 1991). Trawling on soft bottom can be viewed as a form of bioturbation (albeit more extensive than most) to which the community is adapted to with- 
stand. Such disturbance is less common on subtidal rocky substrate and, thus, epifaunal species are more susceptible to damage from passing gear.

Significant trawl damage has been reported for sabellid polychaete tubes (Caddy 1973) and erect sponges (VanDolah et al. 1987). An analysis of long-term trends in benthic community composition of the Wadden Sea indicates recent total elimination of two communities formerly associated with reefs of a tubicolous sabellid polychaete (Sabellaria sp.) and with subtidal seagrass beds (Zostera marina) (Reise 1982). It is believed that the complete elimination of these areas was caused by the shrimp trawling industry. In a study on impacts of trawl gear in the North Sea, deGroot (1984) reports that "damage to Tubularia [an erect hydroid] species ... was great ... The meshes of the trawl were equally filled with or without the use of tickler chains. We must assume that nearly all Tubularia in the trawl path will be destroyed by any tow net used." While tickler chains on hard-bottom beam trawls are assumed to cause more damage to the bottom than other gear types, it is important to note that the belly of the net, as well as roller bobbins, trawl doors and excessive warp may also impact the benthos (Main and Sangster 1979, 1981; deGroot 1984). It is precisely these types of epifauna that have been demonstrated as important habitat for early benthic phase red king crab. Additionally, indirect effects of trawling, in the form of increased predation in the wake of tows, may result in further loss of crab. Increased foraging efficiency of flounder and other predatory fish is known to occur in association with bottom disturbance (VanBlaricom 1982), and fish and crab are known to be attracted to trawl and dredge paths following the disturbance (Caddy 1973, Kaiser and Spencer 1993). Predation impacts of groundfish and invertebrates on early benthic phase crab may be severe.

At this point, we must acknowledge the management efforts that have been established with regard to the potential impacts of trawling. Trawl exclusion zones have been established within the Bering Sea, and are discussed in later sections. However, the effects on bottom habitat have not been monitored (Brad Stevens, Alaska Dep. Fish and Game [ADFG], Kodiak, pers. comm.). It is unknown whether biogenic structure is significantly different within exclusions than outside them, or if juvenile recruitment and abundance has been enhanced or not. The data to quantify these questions simply do not exist. Our discussion of trawling impacts, like most others, has been predominantly theoretical. Accordingly, it is prone to skepticism and debate as any theoretical discussion should be. The only way to rectify this situation is to collect the data required to asses the validity of trawl exclusion.

Trends and characteristics of the groundfish community in the Bering Sea are discussed in the following chapter, but it seems appropriate at this point to provide a review of potential predators on juvenile king crab. This is, by no means, intended to be a complete treatment of all potential predators, which is well beyond the scope of the paper, and also beyond the knowledge and understanding of the scientific community as a collective. The reader's awareness of omitted species should only strengthen our argument that predation on this phase of the red king crab is probably significant. Potential fish predators include a number of commercially important species such as Pacific cod (Gadus macrocephalus), Pacific halibut (Hippoglossus stenolepis) and sablefish (Anoplopoma fimbria); a number of flatfish species such as Alaska plaice (Pleuronectes quadrituberculatus), yellowfin sole, flathead sole (Hippoglossoides elassodon), arrowtooth (Atheresthes stomias) and Kamchatka (Atheresthes evernanni) flounder; and commercially ignored fishes such as eelpout (Lycodes palearis), skates (Raja spp.), sculpins (various genera of the family Cottidae), and snailfish (Liparis spp.). The relative importance of these predators will depend upon a number of factors, including the particular dietary habits of each species, distribution and 
abundance of the predators relative to red king crab stocks, seasonal changes in dietary patterns, and size of predators relative to the prey.

Predators of early post-settlement crab are likely to be the smaller species, since the feeding habits of fishes are often gape limited and foraging efficiency is increased by consuming larger prey. Simply put, large fish with large mouths will tend to seek large prey. Fish with smaller mouths will be limited to somewhat smaller prey such as early benthic-phase crab. A number of the flatfish species of the Bering Sea shelf fit this description. Yellowfin sole are fairly small fish whose diet is known to be quite broad and generally focused on polychaetes, bivalves, echinoderms, decapod crustaceans, and amphipods (Tokranov 1990). The diet of flathead sole is similar. In Puget Sound they are known to feed on pea crab (Miller 1970) and might be expected to feed on small king crab in areas where the distribution of the two species overlap. Alaska plaice are also generalists, but their consumption of decapods in the eastern Bering Sea may be fairly low (Zhang 1988). Thus, the impact of various species within this group of fishes may not be equal. Factors that favor increases in yellowfin sole, for instance, may increase predation pressure on small crab more than if Alaska plaice were a more abundant member of the community.

Another largely ignored group may also have a great impact on crab survival: commercially unattractive species such as skates, sculpins, and snailfish. Diet, biomass, and distributional studies of these species are clearly lacking. Since these species are not a sought-after commodity and present little economic incentive for study, groundfish surveys are not designed with regard to their collection. Collection methods will not likely be designed in order to capture snailfish in an unbiased manner, and the extant data are not reported in groundfish survey reports. Yet the small amount of existing information suggests that these species may be very important with regard to their impact on crab stocks. Table 1.1 is a compilation of data showing diet composition of a number of species feeding in the southeastern Bering Sea. Consumption of decapod prey seems trivial for only one sculpin species (bigmouth sculpin, Ulca bolini), whereas crab comprise a very large proportion of the diet for many other species. If these predators' abundance relative to crab recruitment levels is significant, they alone could remove a large fraction of the stock each year. Note, however, that the studies from which these data were compiled concentrated on impacts of fishes on snow crab (Chionoecetes spp.) and the data reflect only those prey. Nonetheless, we believe the data indicate the potential importance of the impact of commercially ignored fishes on red king crab. Any activities or conditions that enhance the stock of non-commercial species may have ramifications that should be considered. A similar case can be made for benthic invertebrates. As a single example, the sea

Table 1.1. Consumption of crab by non-commercial fish in the southeastern Bering Sea. Data are from Jewett (1982) and are reported for consumption of Chionoecetes spp.; "\% weight" refers to volume of all prey consumed, by weight, which was crab.

\begin{tabular}{llc}
\hline Common name & Scientific name & \% weight \\
\hline Sculpin & Myoxocephalus spp. & 40.5 \\
Sculpin & Malacocottus zonaurus & 36.3 \\
Yellow Irish lord & Hemilepidotus jordani & 54.1 \\
Spinyhead sculpin & Dasycottus setiger & 29.1 \\
Bigmouth sculpin & Ulca bolini & $<1$ \\
Polkadot snailfish & Liparis cyclostigma & 24.5 \\
Wattled eelpout & Lycodes palearis & 28.4 \\
Alaska skate & Raja parmifera & 27.4 \\
Bering skate & Raja interrupta & 40.4 \\
\hline
\end{tabular}


star, Asterias amurensis, also feeds on decapods with three species of crab, presumably small individuals, appearing in just over 7\% of sea stars analyzed (Feder and Jewett 1978).

The impact of large commercial species is more thoroughly documented. One such predator, cod, has received much attention with regard to crab stocks. In the Gulf of St. Lawrence in the western Atlantic, cod (Gadus morhua) have been proposed as a significant regulator of snow crab (Chionoecetes opilio) abundance. Correlating crab catch with cod abundance 3-6 years earlier (to account for lag time before recruitment to the fishery) displays a negative trend: high crab catches have been recorded since the drop in cod abundance in the mid-1970s. Researchers believe that this relationship is not spurious and that cod actively limit crab abundance (Bailey 1982). Pacific cod have also been shown to prey significantly on red king crab in the southeastern Bering Sea. Livingston et al. (1993) propose that cod predation could have been responsible for a loss of between $4 \%$ and $14 \%$ of total female biomass during the summer months between 1987 and 1989. Their study also illuminates a number of nuances with regard to the nature of predation and how it may impact the prey population. The most obvious observation relates to the earlier discussion, which is that predators of different sizes impact different segments of the population. Adult cod were shown to feed on larger crab and will impact the stock at juvenile or adult stages, but probably not impact the early benthic phase. Younger cod will be expected to have more impact at earlier stages. This was certainly demonstrated for halibut. Those $>80 \mathrm{~cm}$ in length feed primarily on age 1,2 or older crab, while smaller halibut feed on age 1 and age 0 crab (Fig. 1.9).

Thus, these larger fish may present a problem for crab at a somewhat different stage of development, perhaps as they move out of protected settlement habitats and attempt to join aggregations. As mentioned earlier, at approximately age 2 red king crab move from shallow rearing habitat to more offshore areas to form "pods." These assemblages are thought to provide a level of protection from predation (Dew 1990). Essentially, these animals have left the spatially complex world of the rearing habitat that previously afforded shelter from predators, and they must adopt behavioral changes in order to compensate for this loss. However, in order to benefit from this behavior, the outmigrating crab must survive long enough to find a pod. A low number of available pods and low spatial complexity in the environment between settlement sites and podding grounds in conjunction with an abundance of intermediate-sized predators may leave these isolated individuals at high risk of predation and may be yet another gauntlet through which the population must pass.

Further, the majority of prey preference studies are conducted during the summer. This is not surprising, considering conditions in the Bering Sea during winter, but it does have some potential implications. For the previously reported studies of cod, halibut, sablefish and arrowtooth flounder, stomach contents were collected during cruises from May through August. Novikov (1968) reports that halibut feed throughout the winter months, and the same may be true for other species that have not been studied during this period. Diets often show large, distinct seasonal changes. For example, during the summer in the Gulf of Maine, herring may represent an abundant prey resource for Atlantic cod. When available, this prey can constitute $>90 \%$ of cod diet; yet, in the winter cod display virtually no piscivory at all, feeding almost exclusively on ophiuroids, decapod crustacea and polychaetes (T. Loher and J.D. Witman, unpubl. data). If the benthic piscivorous predators of the Bering Sea shelf overwinter in these areas and are not presented with seasonally available prey such as herring and pollock, at what level do they feed and what prey constitute their diet? Seasonal and interannual variations cannot be ignored. 
$30-59 \mathrm{~cm}$

a)

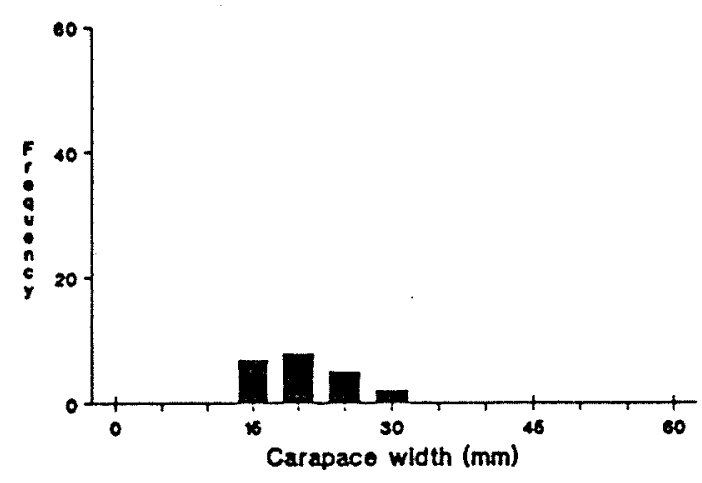

b)

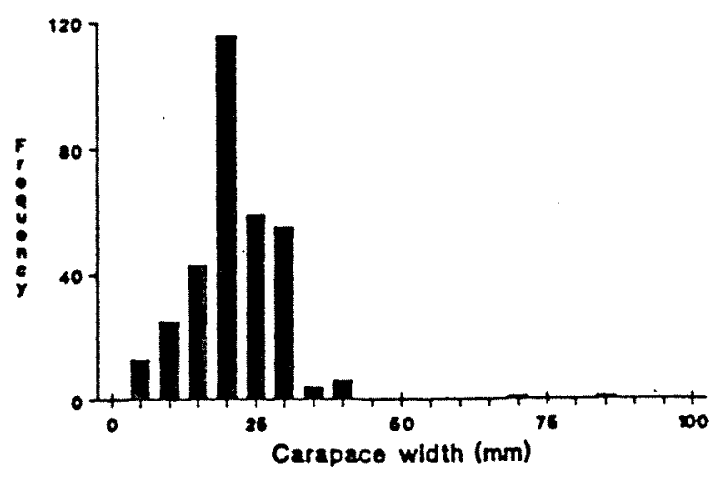

1989

c)

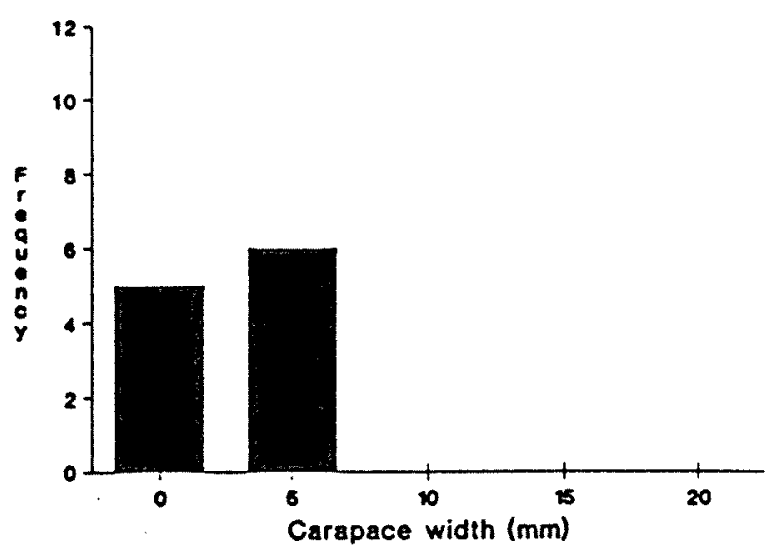

$.60 \mathrm{~cm}$

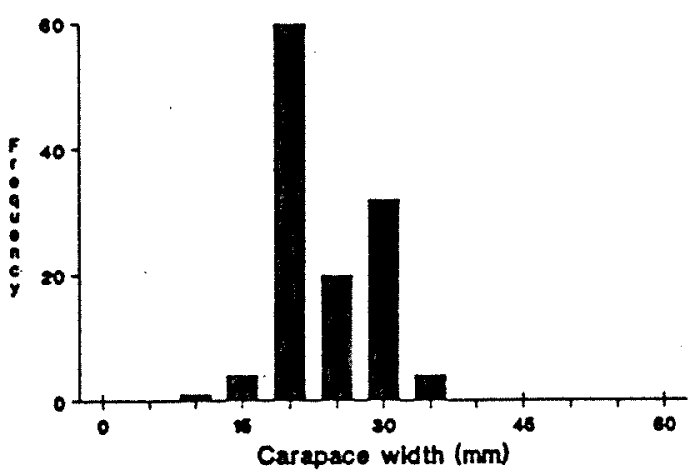

1989

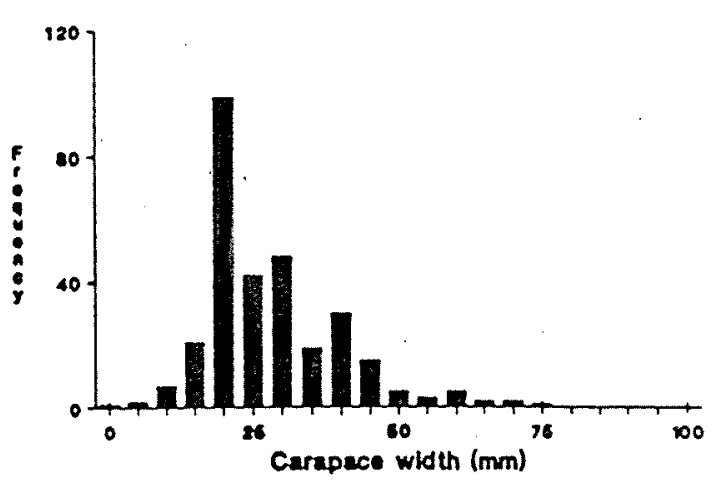

1989

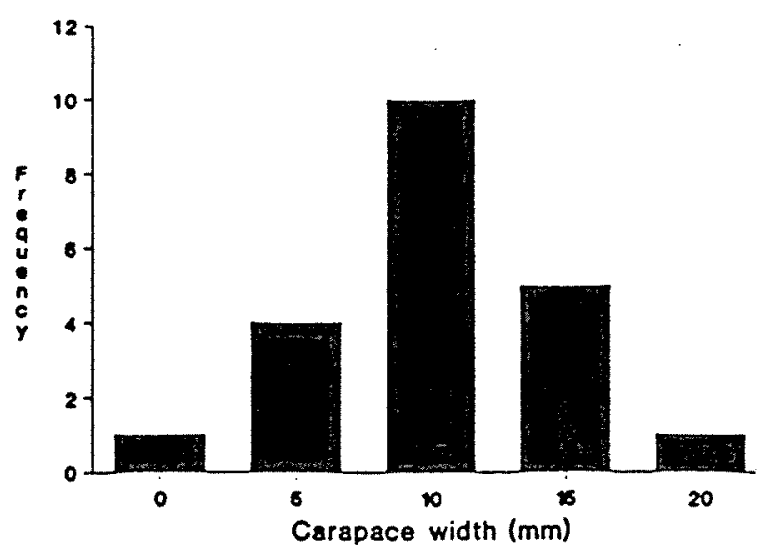

Figure 1.9. Size distribution of crab prey in selected groundfish species in 1989: (A) Size of crab in two size classes of Pacific halibut in 1989; (B) size of crab in two size classes of Pacific cod; (C) size distribution of crab prey in yellowfin sole (left) and flathead sole (right). Source: Livingston et al. (1993). 
Returning to considerations of predator size, piscivory is more prevalent in large cod, halibut, and perhaps sablefish than smaller individuals (Livingston et al. 1993). This consideration is very important for assessing the potential impacts of another numerically abundant fish on the Bering Sea shelf, the arrowtooth flounder. This species is reported to be predominantly piscivorous (Livingston 1993, Livingston et al. 1993), yet most of the study on the diet of this fish addresses the feeding behavior of adults. Considering that the young of many benthic and epibenthic species are more generalist feeders and concentrate on slower benthic invertebrates, the potential for young arrowtooth to impact crab stocks must be considered.

Finally, the data from Livingston et al. (1993) suggest another potentially troubling situation for crab. On the basis of timing, size, and location of crab found in cod gut analyses, the authors postulate that nearly all of the large crab consumed were soft-shelled (immediately post-molt) females. A female would normally molt immediately following egg release and immediately preceding breeding. At this time it would not be uncommon for a male crab to clasp her. The presumed advantage of being clasped by a male is that it affords a level of protection, and the energy expended by the male is rewarded with the opportunity to mate with the female once she has hardened. The high level of soft-shelled female predation reported in the study would suggest that this guarding is either ineffective, or does not exist for a large segment of the female population subject to cod predators. It seems unlikely that such behavior would be ineffective now, after millions of years of predator-prey interactions, but it is quite reasonable to think that the process is simply not occurring owing to the nature of the crab fishery itself. Once again, there may be a problem inherent in the males-only management strategy: not enough males to guard the females during molting. The result may be a natural reduction of female biomass by predators to establish something closer to the male:female ratio of an undisturbed stock. In other words, protecting the females from one predator (man) may simply leave them vulnerable to another (cod).

\section{Post Fishery-Recruitment Adults}

Natural mortality at this stage is considered low (Kruse 1993). At older ages the greatest mortality will probably come from within the red king crab fishery and other fisheries. Loss due to natural predation is possible, especially from very large cod and halibut, but the previously discussed studies of predator impact found little predation on crab of this size. Considering the nature of our fisheries, this is not surprising. Fish species that attain a size large enough to feed on large adult red king crab are commercially important, and the nature of processing and management advocates the removal of the largest and oldest members of these species. As we remove large predators from the community, natural mortality of adult red king crab from these sources will drop. What may be a far more important source of mortality at this age is bycatch (Alverson et al. 1994), which is discussed in Chapter 3. Bycatch mortality may be significant not only for adults, but for any age class subjected to this pressure. A determination of impact first requires an analysis of the age distribution of the crab impacted by the subject fishery, and then a consideration of overall catch and mortality within those year-classes. At this point, we simply wish to acknowledge it and make the reader aware of our concern about this issue.

\section{CONCLUSION}

In summary, levels of adult king crab abundance have remained at apparently stable low levels since the stock decline around 1980. Many may view this as indicative of general stock failure, but we do not. We believe that this represents the current maximum level of yearly recruitment to the fishery. We suggest 
that a bottleneck presently exists within the life cycle of the red king crab that is not allowing large numbers of recruits to pass to the next life stage. This bottleneck may be occurring at any of a number of important life stages: egg supply, larval supply, early benthic phase, juvenile, or adult (Fig. 1.10). Considerations of limited larval supply may be valid, but our understanding on this topic is clearly in its infancy. Low levels of recruitment may be maintained by limited availability of suitable settlement habitat, degradation of the biotic assemblages associated with nursery habitat, and high fish predation on early benthicphase and young juvenile (approximately age 2) king crab attempting to move from shallow settlement areas to deeper water. Additionally, a more complete understanding of breeding dynamics in this species may indicate that breeding potential and adequate larval supply can be maintained under a different harvest scheme that protects the genetic integrity of the stock. Finally, bycatch problems may have significant impacts on adult stock. Some of these concepts are expanded upon in the following chapters.

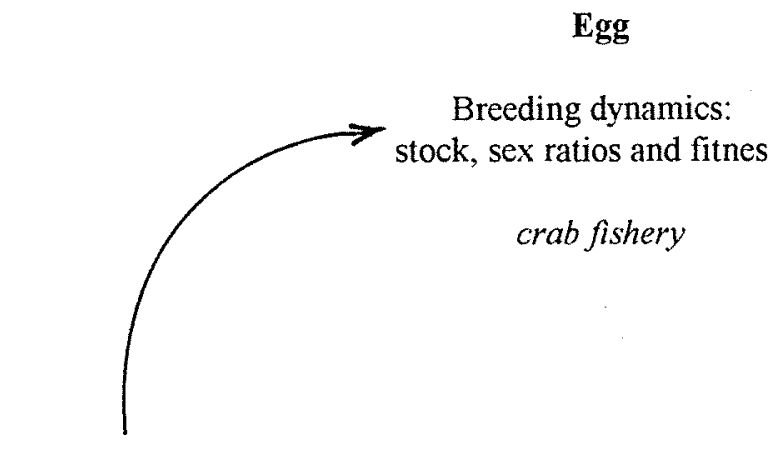

Adults

bycatch

crab fishery

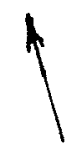

outmigrating juveniles

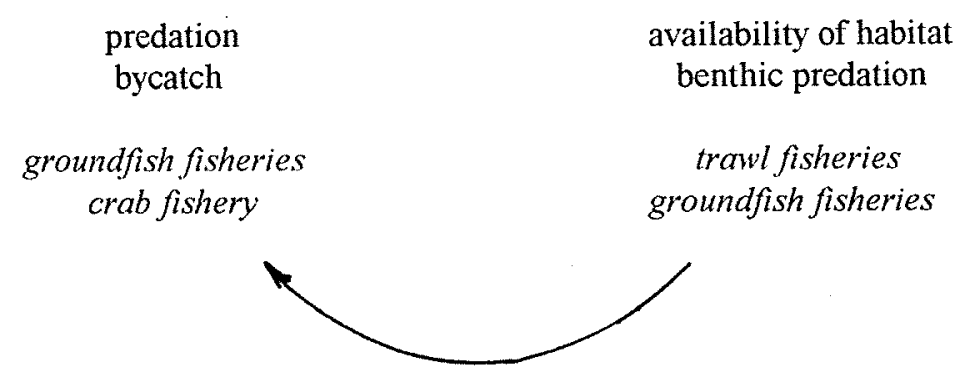

Larval

predation pelagic piscivore

fisheries

oceanographic factors

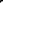




\section{CHAPTER 2. RESTRUCTURING OF THE BERING SEA ECOSYSTEM?}

\section{History of Fishing In the BerING SEA}

The Bering Sea ecosystem has a long history of intensive resource exploitation, beginning with the virtual elimination of whales and large numbers of seals. Then the long-lived Pacific ocean perch was greatly reduced in numbers. The fisheries of the Bering Sea continued to evolve as the discovery and depletion of new resources in turn removed large amounts of yellowfin sole, sablefish, halibut, king crab, and finally pollock from the system.

Figure 2.1 demonstrates the history of commercial landings of fishery resources in the eastern Bering Sea (R. Otto, NMFS, Kodiak, Alaska, unpubl. data). In the 1950s, the Japanese and Russian distant water trawl fleets began to intensively exploit the region. From 1958-62, an average of 404,000 metric tons (mt) per year of yellowfin sole were caught, with the highest catch of 554,000 mt in 1961. During this period, the fleets expanded their areas of operation to encompass most of the eastern Bering Sea and fished throughout most of the year (Bakkala 1993). Pacific ocean perch catch peaked at 47,000 $\mathrm{mt}$ in 1961, sablefish at 26,000 $\mathrm{mt}$ in 1962, and halibut at 12,400 mt in 1963. In the 1960s, large catches for these species apparently exceeded sustainable yields: large reductions in catch since that time have only allowed the stocks to recover to a fraction of their 1960 estimated biomass levels. The development of a Japanese longline fishery led to the continued exploitation of the sablefish resources in the late $1960 \mathrm{~s}$.

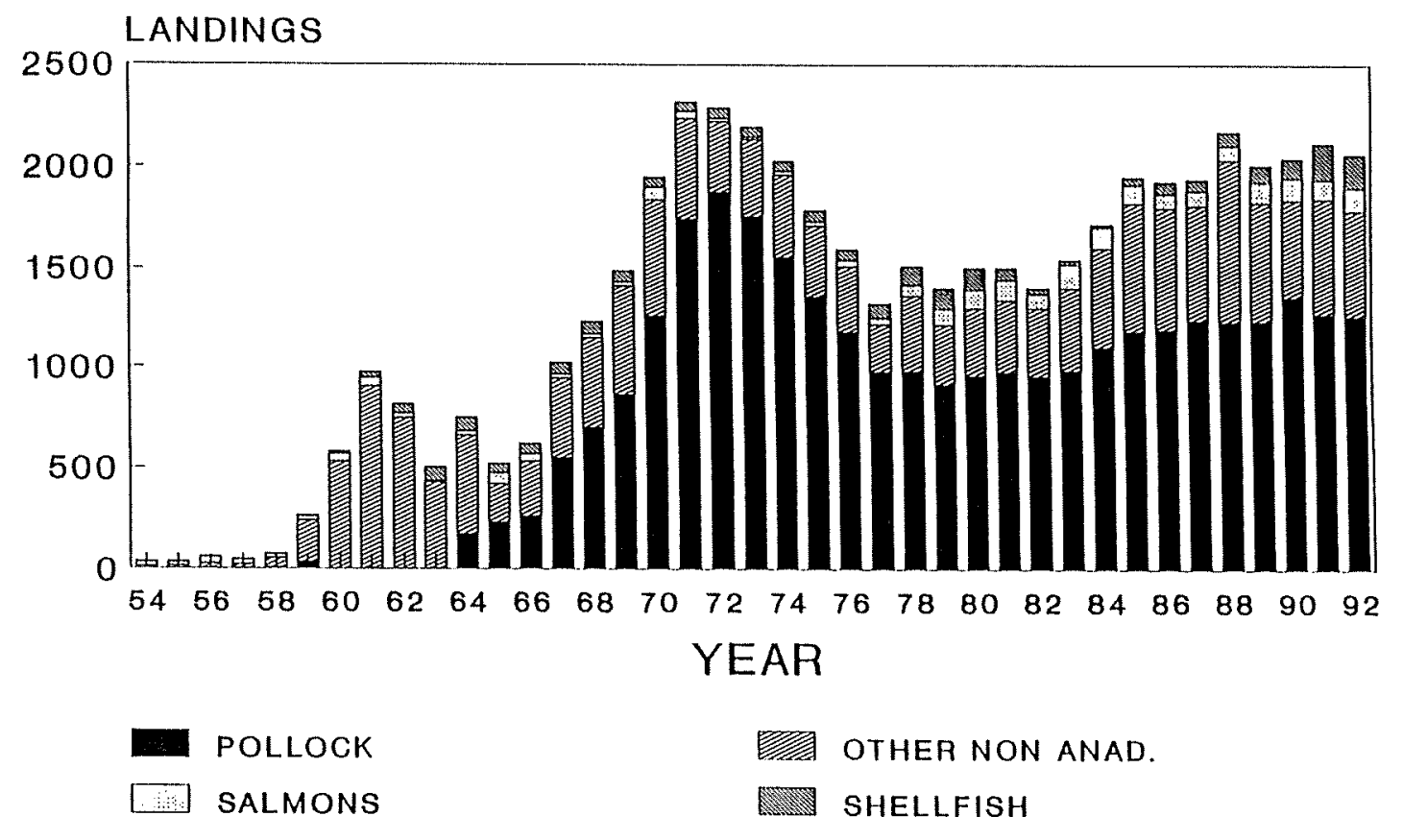

Figure 2.1. Commercial landings from the eastern Bering Sea (1000s mt), 1954-92. Source: R. Otto (NMFS, Kodiak, Alaska, unpubl. data). 
The invention of shipboard surimi processing in 1964 and an expanded Japanese market led to heavy pollock exploitation, with a peak of nearly 1.9 million $\mathrm{mt}$ in 1972 (Bakkala 1993). During the 1970s the eastern Bering Sea sustained intensive fishing effort as other nations (Korea, Taiwan, Poland, and Germany) commenced trawling operations in the area. Passage of the Magnuson Fisheries Conservation and Management Act in 1976 paved the way for the Americanization of the Bering Sea fisheries. The eastern Bering Sea groundfish resources have been subjected to relatively intensive levels of exploitation since 1960 , with average commercial catches of $\sim 1.6$ million mt per year during 1970-81 (Bakkala 1993). The highest recorded catch of groundfish was 2.25 million $\mathrm{mt}$, occurring in 1972.

Exactly what effect this prolonged anthropogenic stress has had on the Bering Sea ecosystem is an important issue when attempting to properly manage current and future fisheries. Stress applied to an ecosystem may reduce the stability, the species diversity, or the average physical size of dominant species in the system, and could cause a shift in species composition towards shorter-lived species (Apollonio 1994). Mann (1988) has suggested that even rather small fluctuations in system variables may cause an ecosystem to experience drastic structural changes. An example of this restructuring behavior was seen in the English Channel in the 1930s when a major change in the species composition occurred. For nearly 3 decades, a very different mix of species thrived until the late 1960s when the structure of the system reversed itself and the previous mix of species, including the gadoids and flatfish, returned (Mann 1988). If the Bering Sea ecosystem has reorganized to a new structure, then trying to manage its fisheries to obtain historical catches may be a futile attempt. The system simply may no longer be able to sustain populations of certain species at their historical levels. The questions management should ask, then, are as follows: Do the recent changes noted in the eastern Bering Sea constitute a restructuring of the ecosystem, and what impact does this have on the ability to rehabilitate the stock of Bristol Bay red king crab?

\section{VARIATION IN THE ABUNDANCE OF RED KING CRAB}

Since the 1960s, the abundance of red king crab in the eastern Bering Sea has varied nearly tenfold. Good population estimates from limited area trawl surveys for the period from 1957-60 indicate 20 million commercial size male crab at that time (Hayes 1983). A complete time series of trawl surveys (Fig. 2.2) provides a perspective of the abundance of commercial-size male red king crab in the eastern Bering Sea from 1969 through 1994. The peak abundance in 1978 was followed by a collapse in the stock. The stock recovered slightly during the late 1980s and early 1990s, possibly owing to management restrictions including a total fishery closure during the 1983 season and the establishment of a no-trawl zone in 1987 to protect the area encompassing the adult population center. Recent declines again caused a closure of the directed fishery in 1994 and an expansion of the no-trawl zone in 1995. The total abundance estimate for red king crab in 1994, which includes pre-recruit males and females, was the lowest since the inception of the eastern Bering Sea trawl survey assessment program in 1969 (NMFS Crab Plan Team 1994).

The reasons for the collapse have not been firmly established though a number of explanations have been offered, including overfishing, competition, predation, disease, and environmental change. Overfishing seems an unlikely cause because of the conservative nature of management for this fishery (Otto 1986; W. Wooster, Univ. Washington School of Marine Affairs, Seattle, unpubl. data). Similarly, as harvest rates have been low since the collapse, it is unlikely that overfishing (including bycatch in other fisheries) is continuing to hold the population in check, implying that other factors may be operating. Recent evidence 


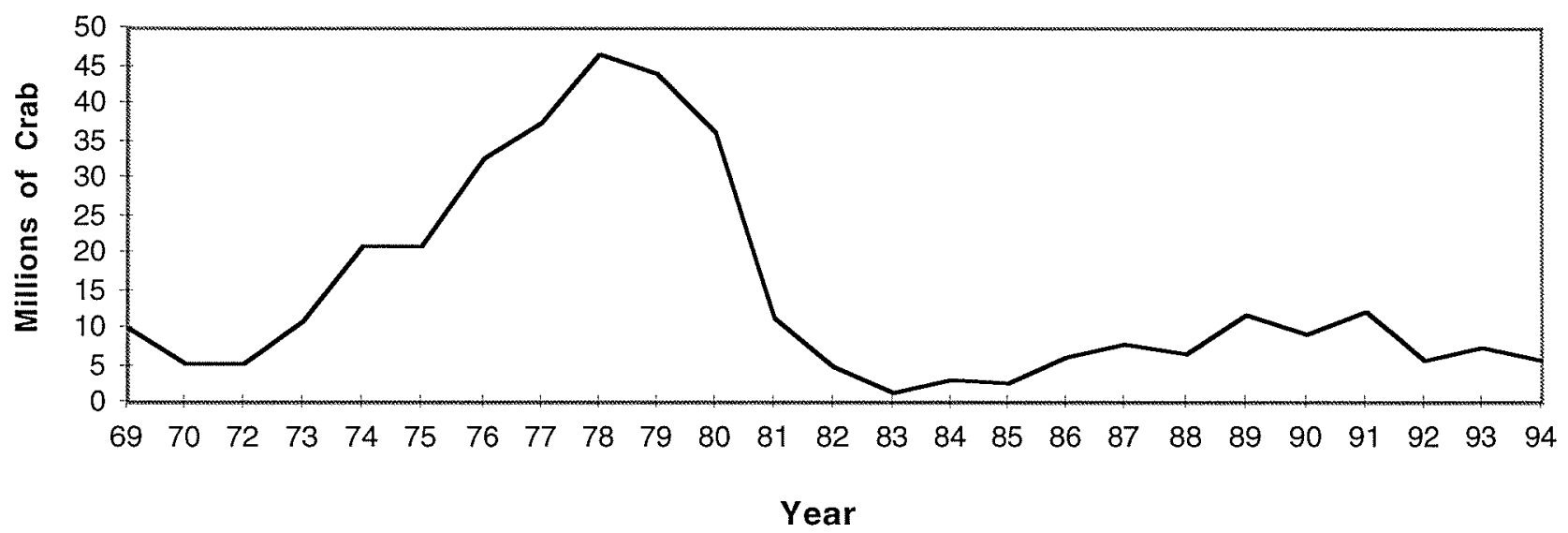

Figure 2.2. Abundance of legal sized male red king crab from annual NMFS trawl surveys in the eastern Bering Sea, 1969-94. Data for 1971 were omitted because the survey was incomplete. Adapted from NMFS Crab Plan Team (1994), Stevens et al. (1992).

indicates that bycatch rates of red king crab in the eastern Bering Sea crab fisheries are substantial (Beers 1991; ADFG, Anchorage, unpubl. data). Reeves (1993a) suggests that the actual exploitation rates of the red king crab may be considerably higher than previously believed when accounting for discards and assuming a moderate to high mortality rate for the discarded crab. The actual mortality rate of discards is largely unknown and requires further study; however, experimental evidence suggests handling mortality in pot fisheries may be minimal (Zhou and Shirley 1994). Chapter 3 entails a discussion of the issue of handling mortality in greater detail.

Could the current abundance of red king crab be normal for the eastern Bering Sea? Rothschild (1986) developed abundance trajectories for two hypothetical stocks (Fig. 2.3). The observations for both populations date back 50 years and imply that both populations have collapsed. However, only one population has collapsed. The other population had been at unnaturally high levels and shortly after the observation period began, started returning to its normal level of abundance. The population appeared to collapse because of the limited observation period. The observation period for crab dates back to 1955, with a continuous time series (from the NMFS crab surveys) only dating back to 1969. The high abundance of crab in the 1970s appears to have been an anomaly. This could have resulted from one or several very large year-classes caused by a variety of factors (beneficial environmental conditions, high fishing pressure on predator or competitor species, random chance, etc.) operating in the late $1960 \mathrm{~s}$ or early $1970 \mathrm{~s}$. The population may currently be back at its normal abundance.

Alternatively, the red king crab may simply be undergoing natural population fluctuations. Large natural fluctuations in fish populations are known to occur in the absence of fishing. Fish scale deposits in layered anaerobic sediments in the Santa Barbara Basin were used to demonstrate large natural fluctuations in anchovy and sardine populations, clearly unrelated to fishing (Soutar and Issacs 1974). More recent investigations in the same basin have extended the database back more than 16 centuries. In performing a spectral analysis, the data from the high frequency end of the spectrum indicate both anchovies and sardines have fluctuated over $~ 60$-year cycles (anchovies exhibit a 100-year fluctuation also). More importantly, when comparing the low frequency dynamics of the populations to a proxy for climate change, we note that both populations appear to have responded similarly to large-scale climatic factors (Baumgartner et al. 1992). 


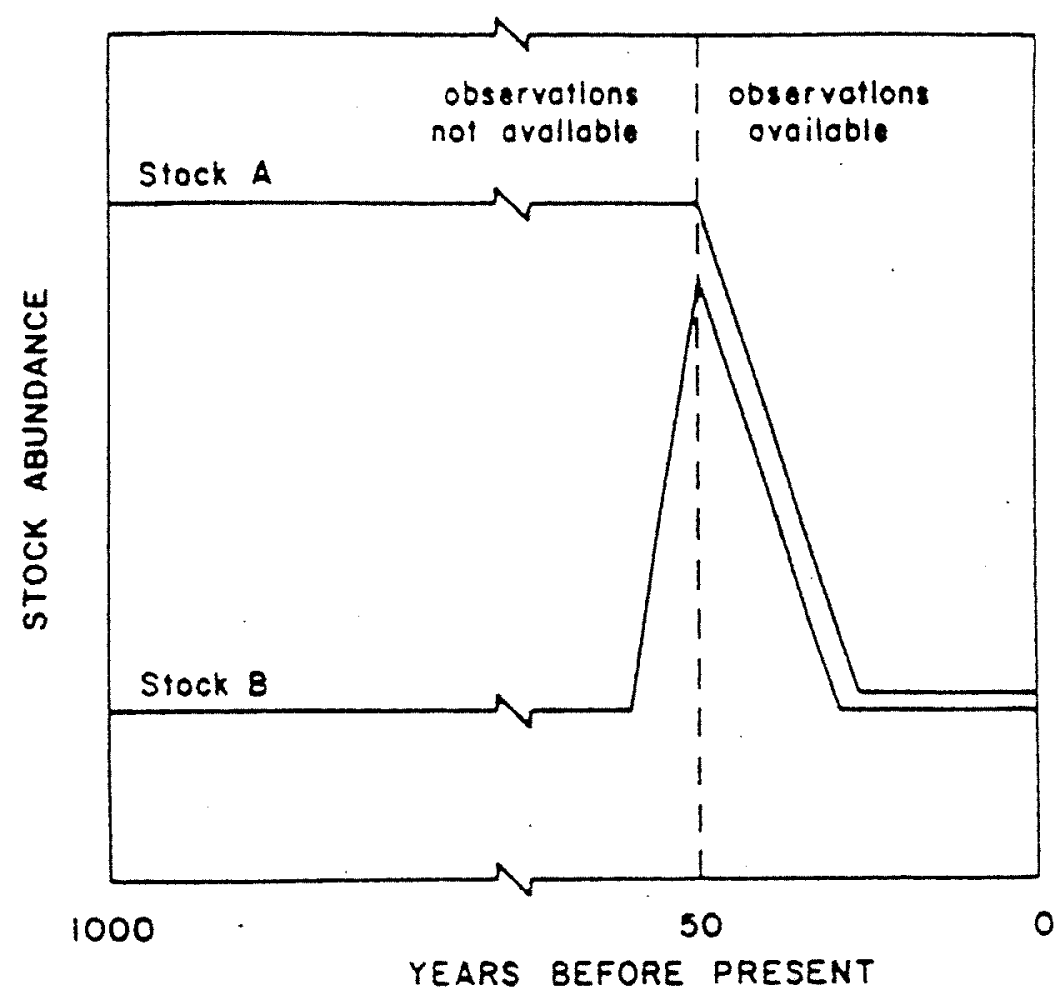

Figure 2.3. Population trajectories for two hypothetical stocks. Source: Rothschild (1986). Reprinted by permission of the publishers from Dynamics of Marine Fish Populations by Brian J. Rothschild, Cambridge, Mass: Harvard University Press, Copyright $\odot 1986$ by the President and Fellows of Harvard College.

\section{ENVIRONMENTAL EFFECTS}

A workshop entitled "Climate variability and its impact on the Northwest" was convened on February 1 , 1995, at NOAA's Pacific Marine Environmental Laboratory in Seattle. Along with other topics, participating researchers discussed variation in large-scale ocean/atmosphere processes and the implications for fishery management. Participants generally agreed that detecting a large-scale event, such as EI Niño, as it occurs is not difficult. However, the ability to predict how it will affect the eastern subarctic Pacific, which includes the eastern Bering Sea, remains inadequate (J. Parkhurst, Washington Dept. Fish and Wildlife, Olympia, pers. comm.). Fishery managers then are faced with the dilemma of managing resources under highly variable conditions with low predictability. The ocean environment varies on all scales. The scales of variation that must be considered are seasonal, annual (ice extent), large-scale and short-term events (El Niño), or large-scale and long-term events (regime shifts).

The abundance of red king crab has remained at low levels for well over a decade. During this period, little evidence suggests red king crab stocks are recovering in both the eastern Bering Sea and Gulf of Alaska (B. Otto, NMFS, Kodiak, Alaska, pers. comm.). As there has been considerable interannual environmental variation during this period (such as wind, water temperature and ice coverage), it appears the year-to-year variability is likely not the factor controlling crab abundance. Instead, large-scale environmental forcing may be a contributing factor to the continued low abundance. The changes in the environment may be directly affecting crab recruitment or they may be favoring competitor or predator species, which in turn are having a deleterious effect on the crab population. 
Brodeur and Ware (1992) studied subarctic Pacific Ocean zooplankton collections from two periods (1956-62 and 1980-89) and demonstrated a doubling of zooplankton biomass between the two periods along with a concurrent increase in pelagic fish and squid abundance. They proposed that the increased production resulted from enhanced atmospheric and oceanic circulation in the 1980s, which led to greater enrichment of the euphotic zone. During the winter of 1976-77, between the two periods studied by Brodeur and Ware, a climatic regime shift occurred in the North Pacific (Miller et al. 1994).

Francis and Hare (1994) recently examined rapid decadal-scale shifts in the abundance of salmon in the northeast Pacific, and how they relate to similar atmospheric and ocean climate shifts. Using time-series analyses and proxies for the intensity of the winter Aleutian Low and sea surface temperature from 1925 to 1992, they detected regime shifts in 1947 and 1977. Alaskan salmon production (using catch as a proxy) was found to correlate well with the 1977 regime shift (Fig. 2.4), with higher catches of salmon occurring after the shift. Francis and Hare suggest a significant and coherent linkage between the regime shift in the northeast Pacific and a biological response (increased salmon production) to that shift. Although year-to-year variation has continued, beginning in 1977 the climate in the eastern Bering Sea has tended to be warmer and winter Aleutian lows have tended to be more intense (lower). If the regime shift of 1977 is somehow affecting crab production, then the survey abundance of adult males would begin to display this effect in the early 1980s. This coincides fairly well with the decline in crab abundance.

Hollowed and Wooster (1992) demonstrated that winter ocean conditions in the eastern north Pacific exhibit a decadal pattern of variation. They noted alternating environmental regimes (or eras) back to 1932 and identified distinctions between warm and cool eras. Warm eras are characterized by more intense Aleutian lows, warmer seawater temperatures, higher sea levels, onshore advection in the Gulf of Alaska, and reduced upwelling off California. The onset of the latest warm era began in 1977 with an El Niño event. During 1977, a number of groundfish stocks in the eastern subarctic Pacific, from California to Alaska, experienced synchronous strong recruitment (Hollowed and Wooster 1992). In addition, Bakkala (1993) showed that a number of groundfish species in the eastern Bering Sea experienced stronger-thanaverage year classes during 1977 and 1978. Eastern Bering Sea groundfish species in this list include sablefish, Greenland turbot (Reinhardtius hippoglossoides), pollock, Pacific cod, yellowfin sole, rock sole (Pleuronectes bilineatus), and flathead sole (Hippoglossoides elassodon). As demonstrated in Chapter 1, most of these species interact with the red king crab at some point during its life cycle. The data indicate that an underlying large-scale change in the Bering Sea environment may be directly (e.g., environment causing high mortality on the early life stages of the crab) or indirectly (e.g., environment favoring competitor or predator species) affecting abundance of the red king crab. Shortly after the 1977 regime shift we see increased zooplankton production, increased salmon production, higher abundances of a large number of the crab's predators and competitors, and lower abundances of a number of Alaska's crab resources. The decline of the Bristol Bay red king crab appears to be associated with a geographically large scale shift in ecological conditions that had its genesis in the late 1970s and was unfavorable to shellfish stocks in general (B. Otto, NMFS, Kodiak, Alaska, pers. comm.). Climate-driven regime shifts can cause major reorganizations of ecological relationships over vast oceanic regions (Francis and Hare 1994). 

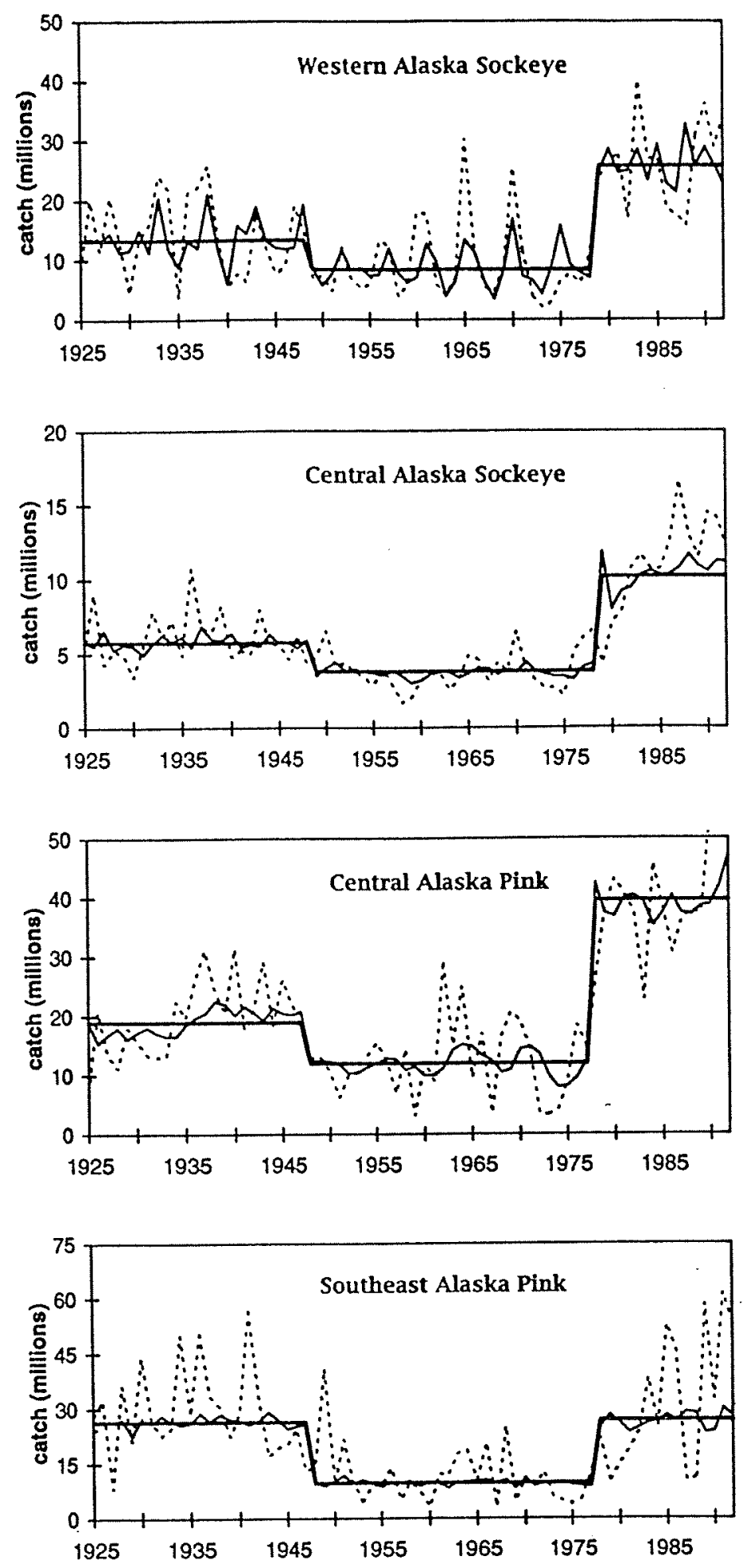

Figure 2.4. Salmon production and intervention model fits from 1925 to 1992 displayed with regime shifts of 1947 and 1977: $\cdots . . .=$ salmon catches; $-=$ intervention model fits, and $-=$ estimated interventions. Source: Francis and Hare (1994). 


\section{Changes in Species Abundance in the Eastern Bering Sea}

We now turn our focus to changes in species composition that have occurred in the recent history of the eastern Bering Sea. Learning more about these changes will allow us to assess how they will affect king crab, possibly via increased predation or competition for habitat or food. The documented changes are likely due to a mixture of reasons. It is difficult, though, to tease out whether the changes in relative abundance of species are due to intense fishing pressure, to climatic changes, or to natural fluctuations in the populations of the eastern Bering Sea. In addition, it is difficult to determine whether the noted changes are reversible or if the system has reorganized to another state. Analyzing the major changes, however, will allow us to make inferences concerning potential effects on the red king crab.

In an effort to determine whether observed variability in species abundance in the eastern Bering Sea could be indicative of stress-induced change in the system Ackley et al. (1994) examined trends in the biomass of individual species and the diversity of species within trophic guilds. The species were grouped into three trophic guilds, as determined by a similarity in food habits. The biomass estimates from 1979 through 1993 were then analyzed; these estimates are considered to be the longest unbiased time series available for the Bering Sea. Members of the "offshore pelagic fish consumer" guild feed primarily on small pelagic or bathypelagic fish in the 80 - to $250-\mathrm{m}$ depth zone near the continental slope. Members of the "crab and fish consumers" guild feed primarily on crab and fish in the 80- to 250-m depth range. Members of the "inshore benthic infauna consumer" guild feed primarily on the benthic infauna and brittle stars in the depths $<100 \mathrm{~m}$.

In general, measures of species diversity (the number of species) and evenness (the distribution of species abundance) were fairly stable throughout the time period for all three guilds. No dramatic shifts in species composition were observed over the 1979-93 period (Ackley et al. 1994). Pollock likely have not always dominated the pelagic fish consumer guild as much larger populations of whales, birds, and other mammals were present prior to the beginning of the time series. Thus, it is possible that the offshore pelagic guild already reflects a dramatic change in species composition of the eastern Bering Sea (Ackley et al. 1994). The pollock biomass increased as the 1977 and 1978 year-classes entered the system and decreased as they either died naturally or were fished from the system (Fig. 2.5). As discussed in Chapter 1, pollock are known to consume red king crab larvae, so their increased abundance through the 1980s would have increased predation pressure on the pre-settlement life stages of the crab.

Another significant change to the pelagic offshore guild is the decline in the Greenland turbot biomass and concurrent increase in arrowtooth flounder biomass. Moreover, the amount of increase in arrowtooth flounder biomass is much larger than the decrease in turbot (Fig. 2.6). The life history of the two species is similar, with juveniles inhabiting the shelf waters. However, at approximately age 4 , the turbot move to the deeper waters of the continental slope while a substantial portion of arrowtooth flounder remains in the shelf waters through age 9, and some remain indefinitely (Bakkala 1993). The increase of these predators may be having an adverse effect on the juvenile and adult king crab inhabiting these waters. Comparison of the distribution of arrowtooth flounder between 1985 and 1991 shows they have increased their range northeast along the Alaska Peninsula into Bristol Bay (Bakkala 1993, Goddard and Zimmerman 1993), which may increase their interactions with juvenile crab. The very low exploitation rate of the arrowtooth flounder (Fig. 2.7) may allow their abundance and range to increase in the future, thereby amplifying the potential effects on the red king crab. 


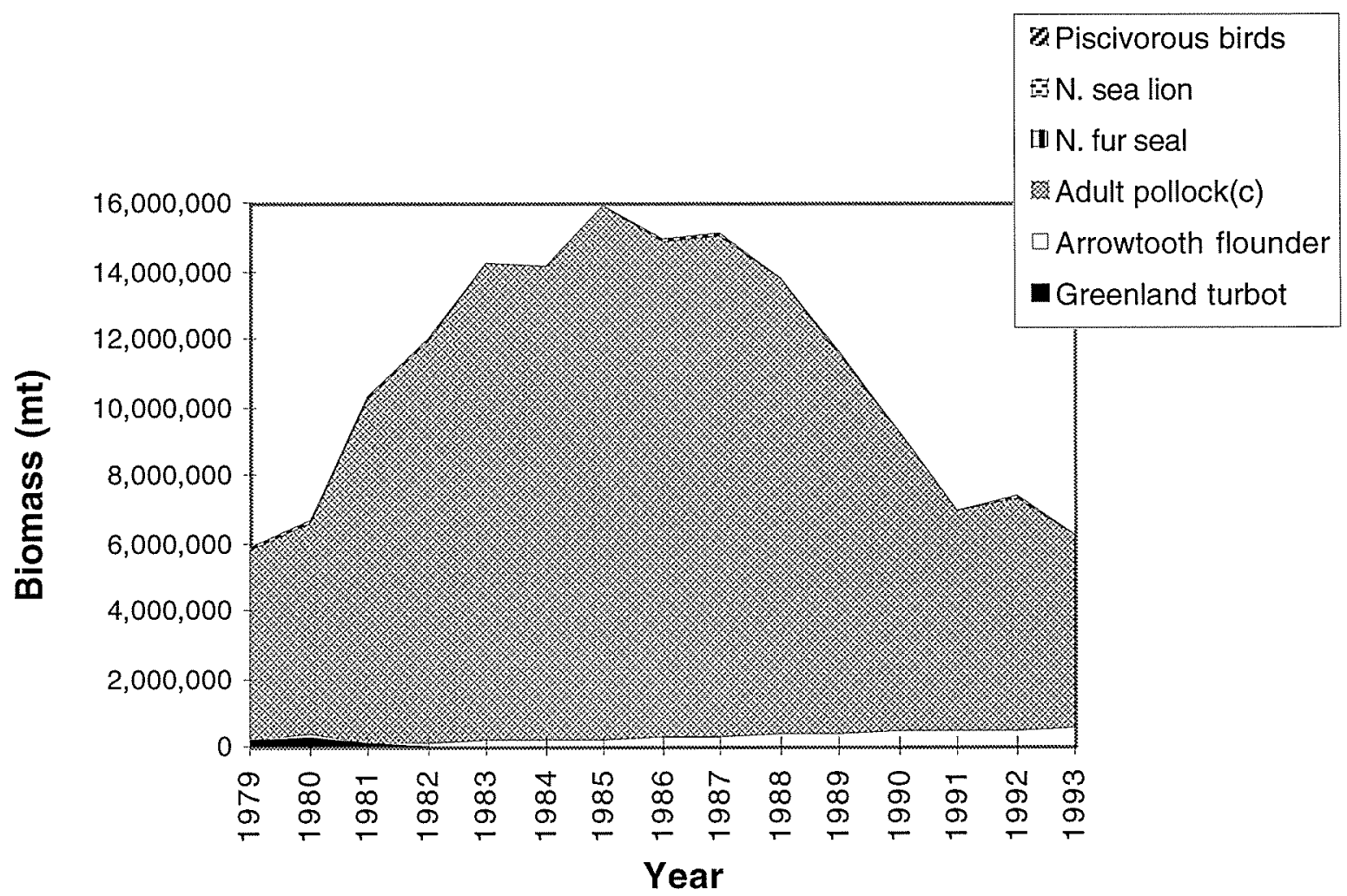

Figure 2.5. Biomass of the offshore pelagic fish consumer guild in the eastern Bering Sea, 1979-93. Source: Ackley et al. (1994).
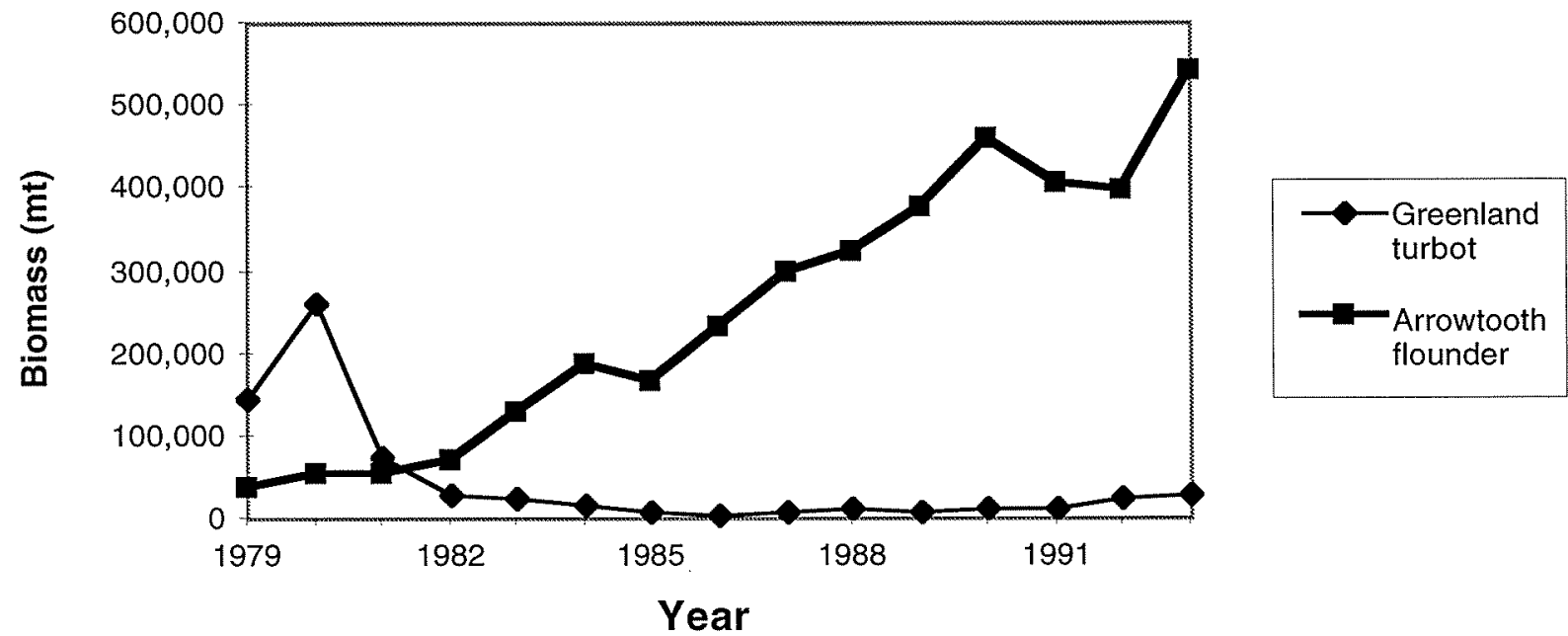

Figure 2.6. Biomass of Greenland turbot and arrowtooth flounder in the eastern Bering Sea, 1979-93. Source: P. Livingston, L.-L. Low, R.J. Marasco, NMFS, Seattle, unpubl. data. 


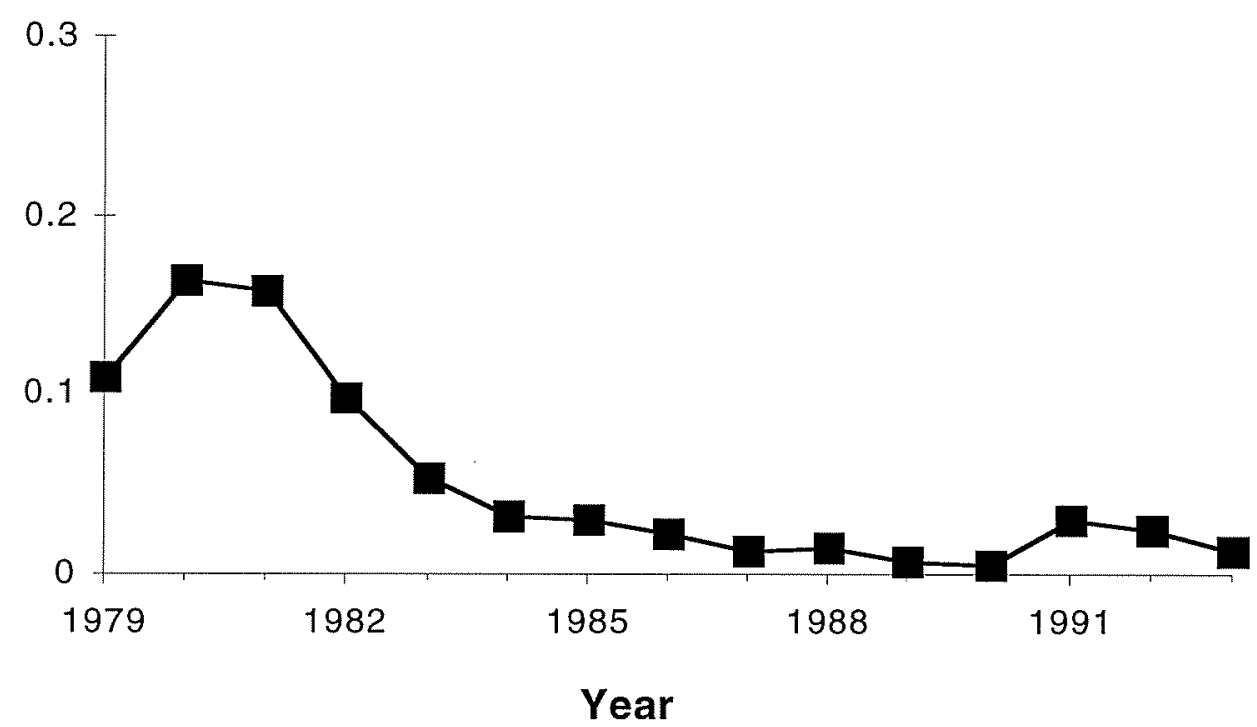

Figure 2.7. Exploitation rate of arrowtooth flounder in the eastern Bering Sea, 1979-93. Source: P. Livingston, L.-L. Low, R.J. Marasco, NMFS, Seattle, unpubl. data.

Total biomass in the crab and fish consumer guild was highest during the middle of the 1979-93 period, largely owing to the increase in Pacific cod at that time (Fig. 2.8). Thompson and Methot (1993) indicate that cod biomass is undergoing another increase due to strong year-classes from 1989 through 1992. Bakkala (1993) showed that skate biomass increased dramatically in the 1980 s after a long period of relatively low estimates dating back to 1965 (Fig. 2.9). Pacific cod and skates inhabit red king crab habitat and are both known predators of the crab. This implies their increasing abundance is likely increasing the level of predation on the crab. Fishers recall employees working the offshore processing line having to shovel piles of juvenile red king crab (removed from the stomachs of the cod) overboard while fishing for Pacific cod in the early 1980s (P. Richardson and B. Lamoreux, fishers, Dutch Harbor, Alaska, pers. comm.). However, these fishers may have mistaken juvenile Tanner or snow crab, which are found quite abundantly in cod stomachs, as red king crab.

Referring again to Figure 2.8, we note the biomass of two genera of sculpin (Myoxocephalus sp. and Hemilepidotus sp.) has remained fairly stable during 1979-93. As seen in Chapter 1, members of the sculpin family (Cottidae) are known to consume decapod crustaceans. Historical survey data suggest the sculpin family has remained relatively stable since 1965, with a substantial dip in the biomass during the 1970 s and a low occurring in 1975 (Bakkala 1993). This could have led to decreased predation on juvenile crab at the time when red king crab abundance increased.

The total biomass of the inshore benthic infauna consumer guild, of which the red king crab is a member, increased over 1979-93 (Ackley et al. 1994). Much of this increase is due to growing populations of rock sole and flathead sole (Fig. 2.10). As one can see, the red king crab biomass is relatively small when compared with the biomass of other species components within the guild, flatfish in particular.

Data on the eight most abundant species of groundfish encountered in the eastern Bering Sea U.S.-Japanese bottom trawl survey of 1979 (Bakkala 1993) and U.S. eastern Bering Sea bottom trawl survey of 1991 (Goddard and Zimmerman 1993) illustrate increasing flatfish abundance (Table 2.1). The propor- 


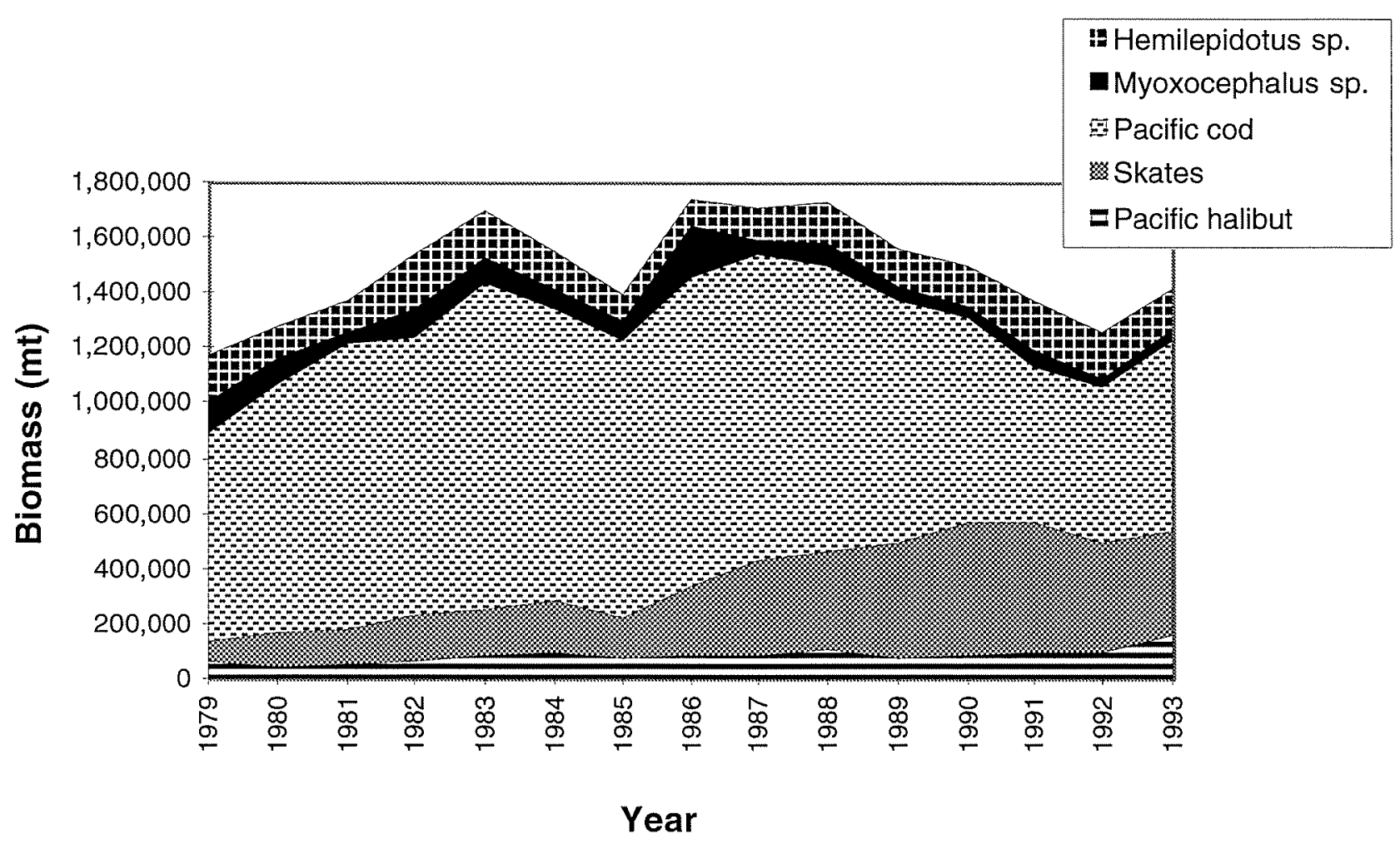

Figure 2.8. Biomass of the crab and fish consumer guild in the eastern Bering Sea, 1979-93. Source: Ackley et al. (1994).

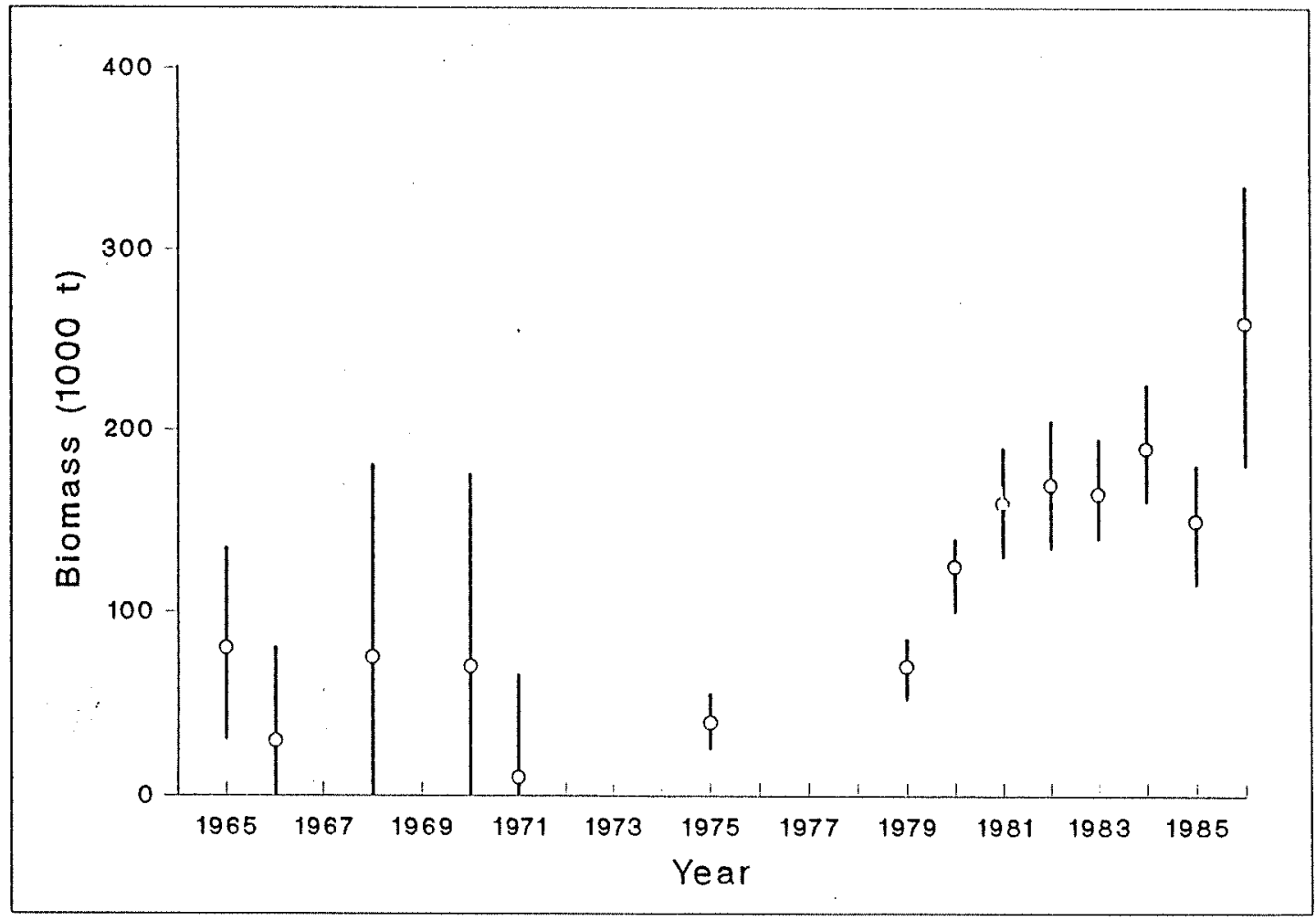

Figure 2.9. Skate biomass in the eastern Bering Sea, 1965-86. Source: Bakkala (1993). 


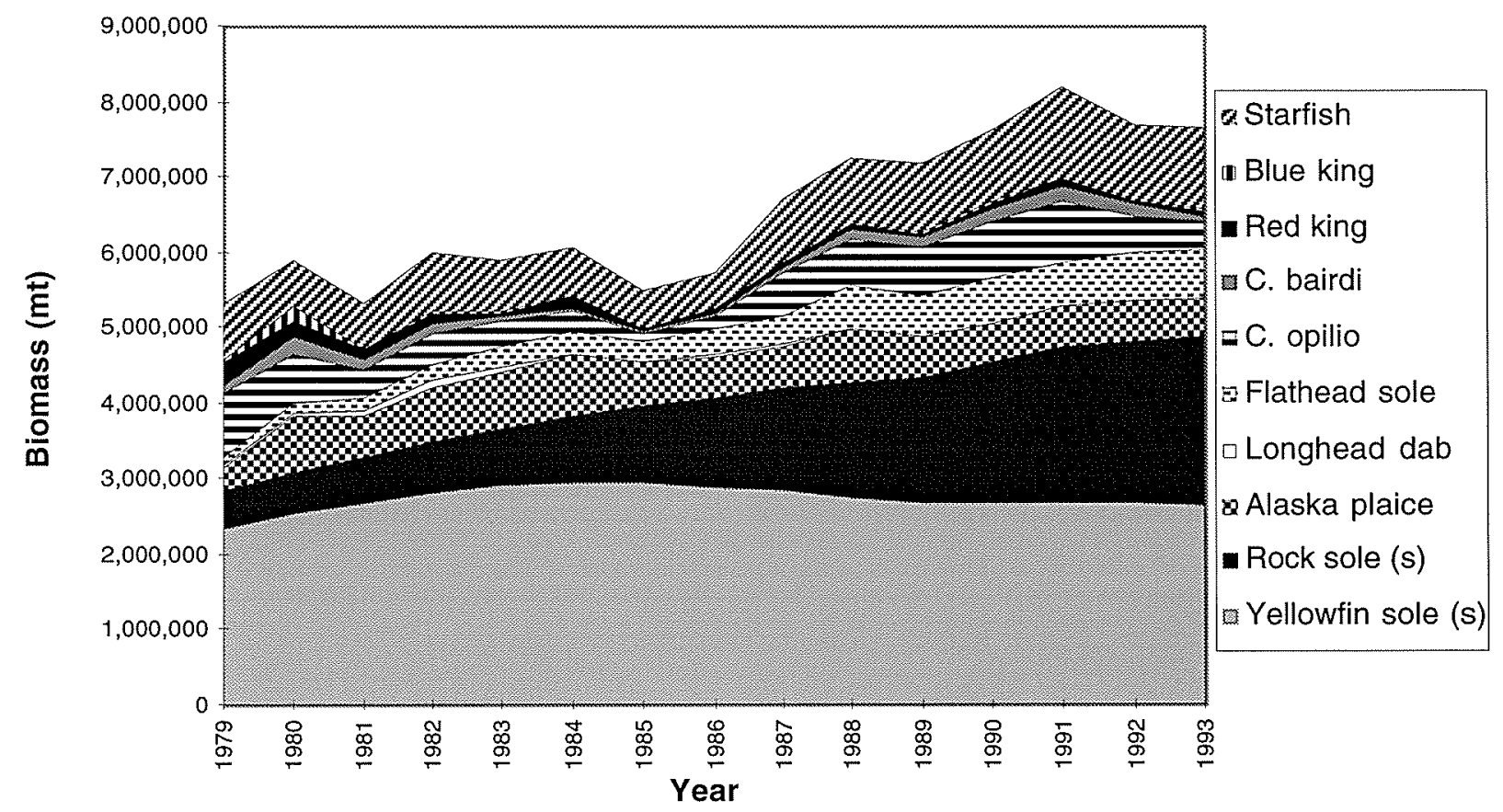

Figure 2.10. Biomass of the inshore benthic infauna consumer guild in the eastern Bering Sea, 1979-93 (Ackley et al. 1994).

tions listed in the table refer to the proportion of total groundfish biomass estimated from the survey data, and the species are listed in order of decreasing relative abundance. The rank column refers to the change in rank of the relative abundance of the species between 1979 and 1991. Positive values display increases in relative abundance. For example, a value of +5 indicates that species has moved up ahead of five other species in its rank of relative abundance.

The differences noted between the 1979 and 1991 survey data indicate the trend of increasing relative abundance of flatfish. In 1979, flatfish comprised $\sim 31 \%$ of the estimated total fish biomass compared with 1991, in which flatfish combined to make up nearly $45 \%$ of the total estimated fish biomass of the eastern Bering Sea ( $>45 \%$ if skates are included). More importantly, yellowfin sole and rock sole represented $68 \%$ of the estimated fish biomass in waters $<50 \mathrm{~m}$ in depth (Goddard and Zimmerman 1993). Furthermore, abundance estimates prior to 1979 indicate that the populations of several flatfish species, yellowfin sole in particular, had already increased by 1979 (Bakkala 1993). How does this great increase in flatfish biomass affect juvenile red king crab and their habitat?

Disproportionately high biomasses of predator species could have great impacts on the trophodynamics of the marine ecosystem and shift the species composition (Ackley et al. 1994). The abundance of flatfish species in the eastern Bering Sea has increased from 2.8 million $t$ in 1979 to $>6.7$ million $t$ in 1994 . Whether the increase in biomass is due to beneficial environmental conditions or relatively low exploitation rates is not clear. Figure 2.11 displays the low flatfish exploitation rates of the mature portion of the stocks (except for the heavy foreign fishing pressure on the yellowfin sole during the 1960s) in the eastern Bering sea. The low exploitation levels on the various flatfish species may be allowing their abundance to increase, thereby creating greater predation pressure on either the red king crab or their prey. 
Table 2.1. The eight most abundant species in 1979 (Bakkala 1993) and 1991 (Goddard and Zimmerman 1993) trawl surveys.

\begin{tabular}{lcllcc}
\hline \multicolumn{1}{c}{1979} & & & \multicolumn{2}{c}{1991} & \\
Species & Prop. & & Species & Prop. & Change in Rank \\
\hline Walleye pollock & .394 & & Walleye pollock & .388 & 0 \\
Yellowfin sole & .243 & & Yellowfin sole & .203 & 0 \\
Pacific cod & .100 & & Rock sole & .119 & +5 \\
Eelpouts & .042 & & Alaska plaice & .052 & +2 \\
Sculpins & .039 & & Flathead sole & .053 & +4 \\
Alaska plaice & .036 & & Pacific cod & .042 & -3 \\
Greenland turbot & .035 & & Skates & .035 & +5 \\
Rock sole & .025 & & Arrowtooth flounder & .030 & +3 \\
\hline
\end{tabular}

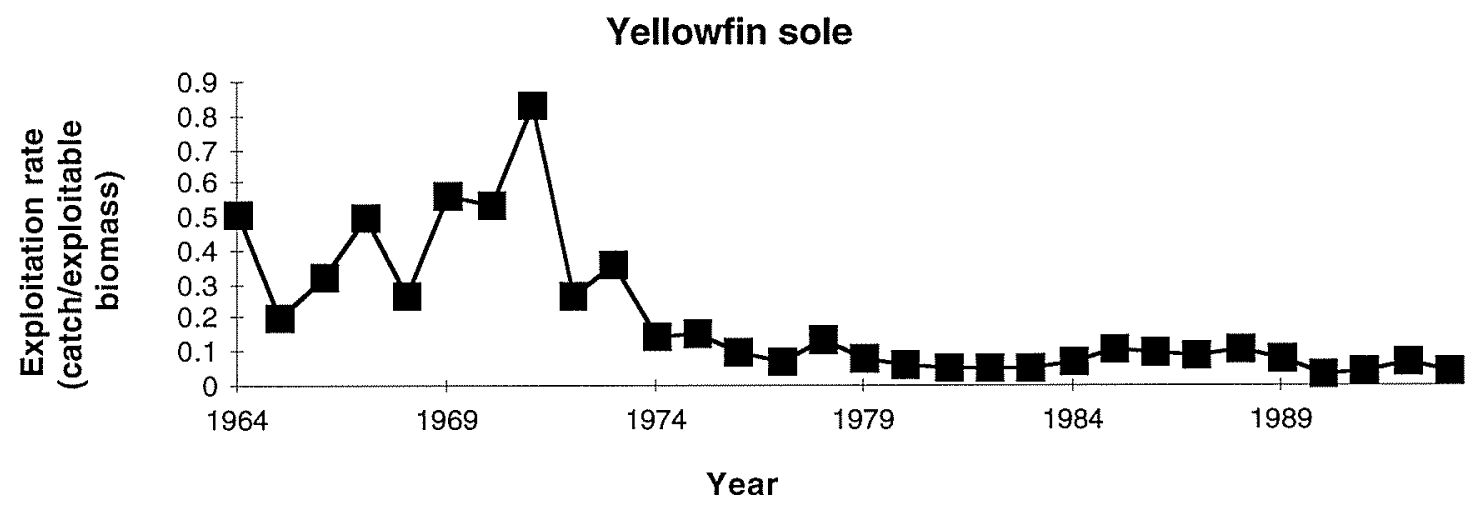

Other flatfish

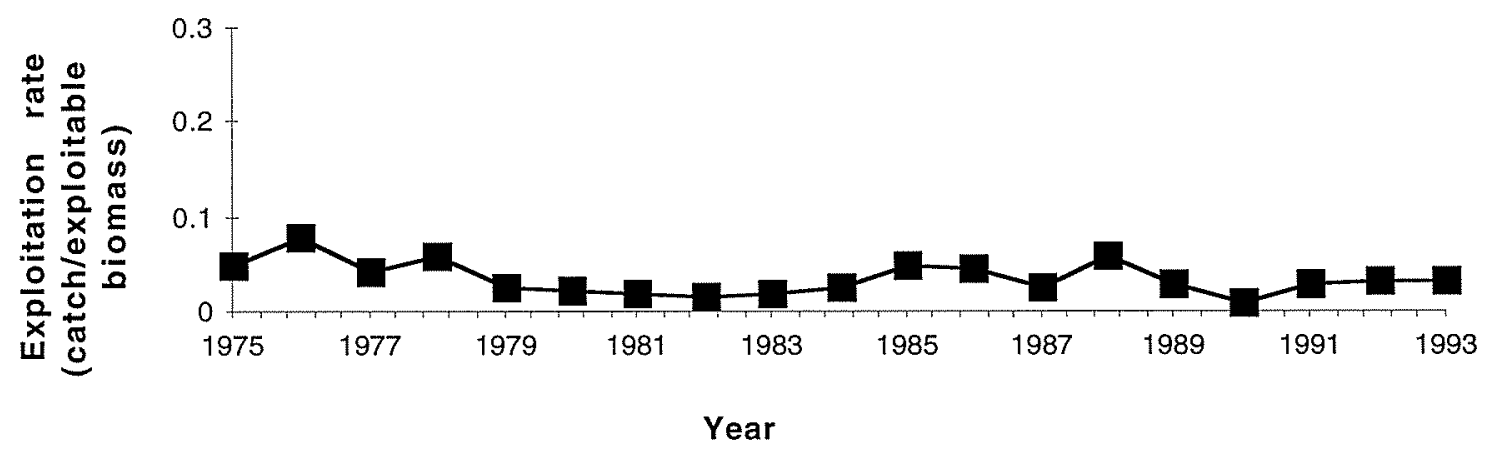

Figure 2.11. Exploitation rate of yellowfin sole (1964-93) and other flatfish (1975-93) in the eastern Bering Sea. Source: P. Livingston, L.-L. Low, R.J. Marasco, NMFS, Seattle, unpubl. data.

Yellowfin sole are known to consume red king crab megalops larvae (Livingston et al. 1993) and yellowfin predation could be a mechanism affecting crab recruitment. For 1970-93, a significant positive correlation exists between the number of age 6 male crab (an index for recruitment) and the exploitation rate of yellowfin sole in the crabs' birth year, and a significant negative correlation exists between yellowfin sole biomass lagged 6 years behind the number of age 6 male crab (Fig. 2.12). These findings suggest higher yellowfin sole abundances could lead to lower king crab survivorship. 
In a food habits study, Brodeur and Livingston (1988) reported a king crab (it is uncertain whether it was a red or blue king crab) in the stomach sample of a rock sole. In the same study, Alaska plaice and rock sole were found to have a high degree of diet overlap, which indicates that Alaska plaice may also have a predatory relationship with king crab. However, a subsequent and more complete food habits study (Livingston et al. 1993) failed to display this predation on king crab. Nonetheless, we want the reader to be aware of this potential source of predation on newly settled king crab. R. Otto (NMFS, Kodiak, Alaska, unpubl. data) demonstrated the relationship between mature red king crab abundance and shallow water flatfish biomass (Fig. 2.13). Comparison of graphs displaying the distribution and relative abundance of yellowfin sole (from 1976 survey) and rock sole (from 1979 survey) to the 1991 survey data shows that both species have increased their abundances in prime juvenile crab habitat (Bakkala 1993,
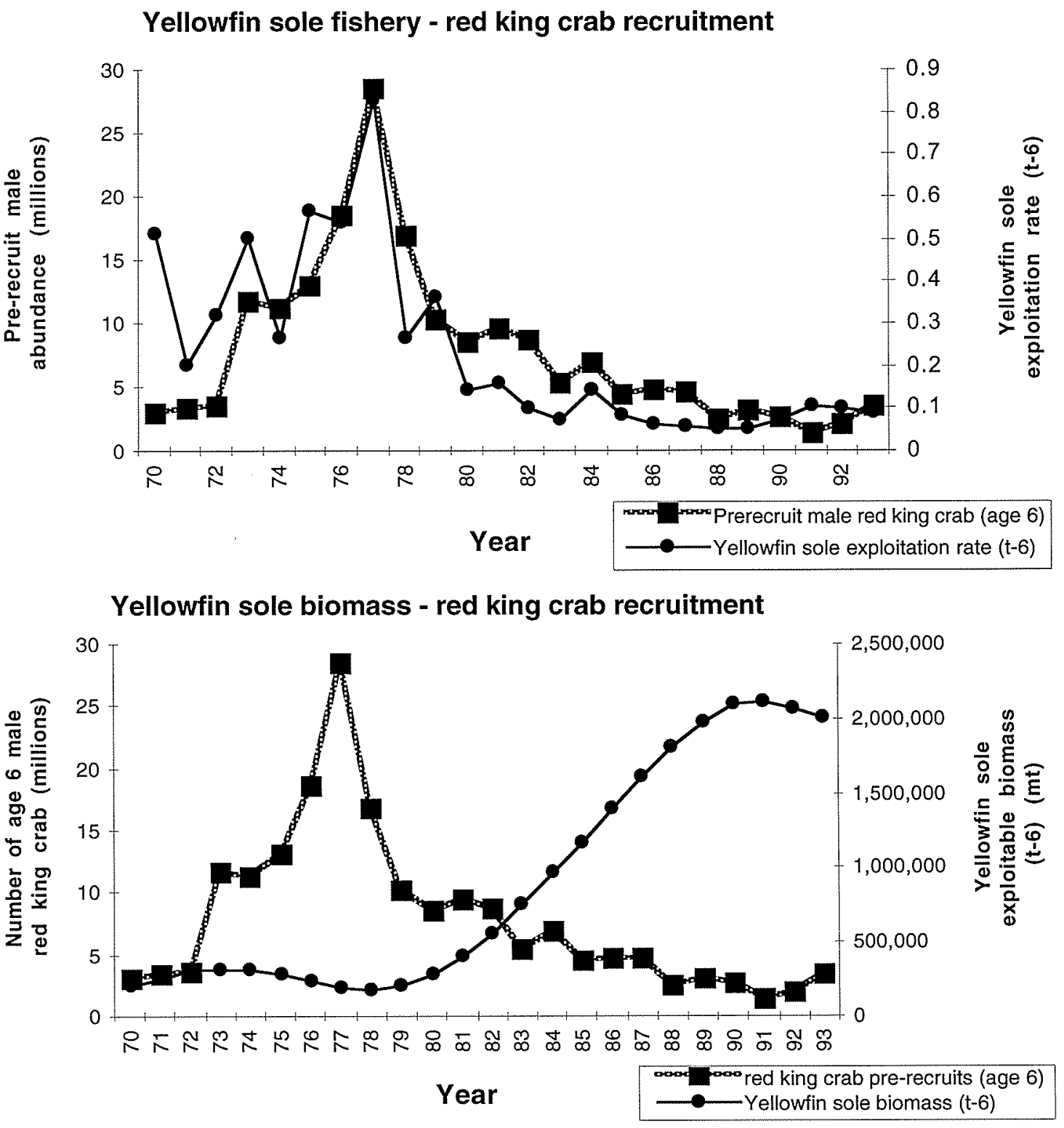

Figure 2.12. Yellowfin sole exploitation rate and biomass versus red king crab recruitment in the eastern Bering Sea, 1970-93. Source: P. Livingston, L.-L. Low, R.J. Marasco, NMFS, Seattle, unpubl. data. 


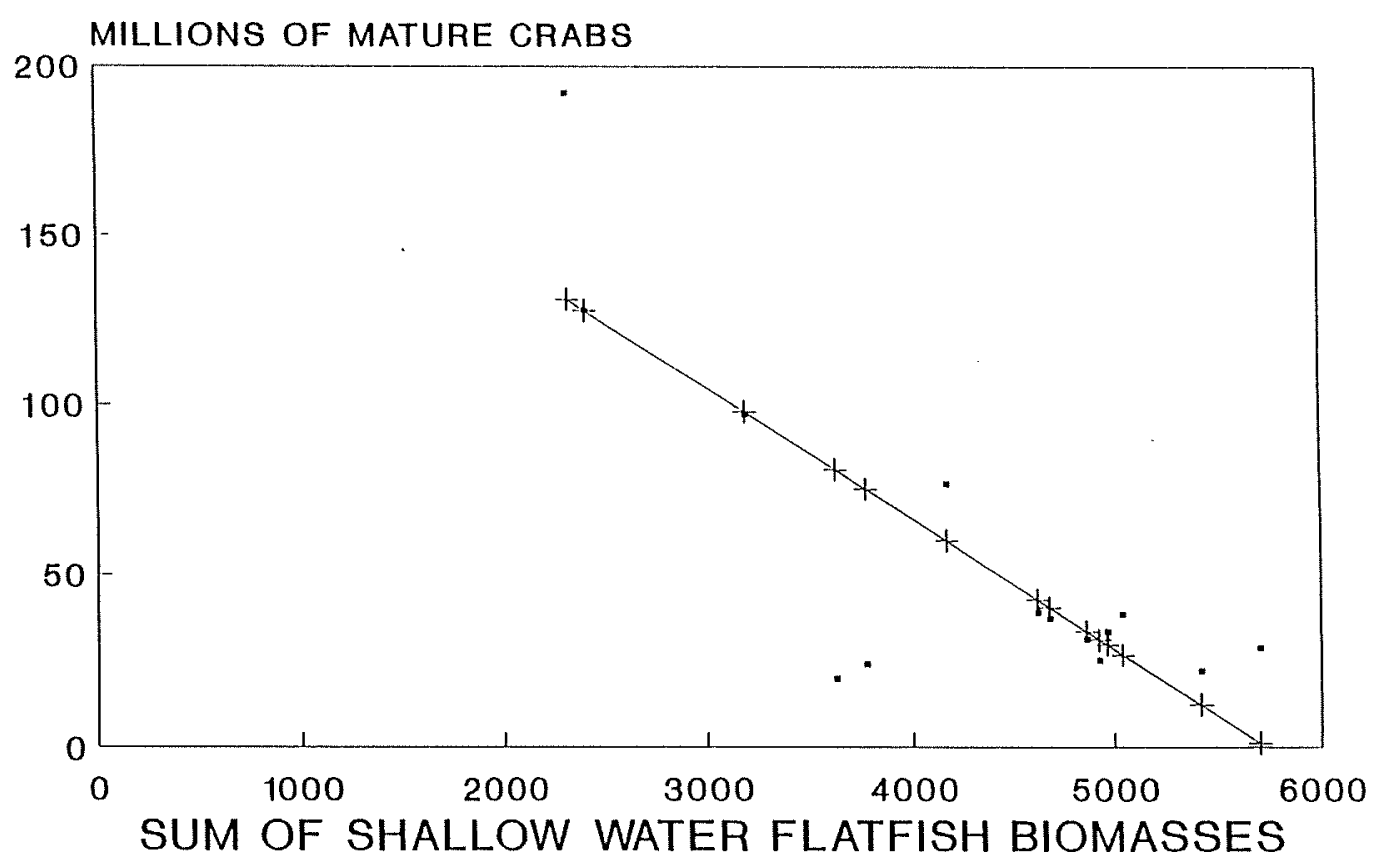

Figure 2.13. Relationship between red king crab abundance and shallow water flatfish abundance in the eastern Bering Sea. Source: R. Otto (NMFS, Kodiak, Alaska, unpubl. data).

Goddard and Zimmerman 1993). Evidence suggests that the increasing abundance of flatfish species could be a contributing factor to poor recruitment of red king crab in recent years. Clearly, more definitive predation studies need to be performed in settling areas during times of settlement.

Livingston et al. (1993) showed an apparent decreasing trend in mean size at age for rock and yellowfin sole, particularly for rock sole in the years after 1985 (Fig. 2.14). After performing an ANOVA, the authors stated the observed decline in fish size appeared to be a density-dependent response to increasing rock sole biomass. If this is the case, then food resources could be a limiting factor for members of the inshore benthic infauna consumer guild. Limited food availability for adults and sub-legal crab in conjunction with increased predation on the recently settled larvae and juveniles could be a severe impediment for the king crab.

A final point to make about the benthic infauna consumer guild is the increasing biomass of starfish (Fig. 2.10) between 1979 and 1993. The purple-orange sea star was the fourth most abundant species encountered on the eastern Bering Sea shelf in the 1991 bottom trawl survey (Goddard and Zimmerman 1993), behind only pollock, yellowfin sole, and rock sole. If the benthic infauna consumer guild is indeed food limited, then an increase in starfish biomass would be yet another competitor for scarce food resources and, as mentioned in Chapter 1, another predator on newly settled king crab.

\section{CONCLUSION}

Significant changes are apparent in the red king crab's guild since 1979. Aside from a decrease in crab abundance, other important components of the guild have increased or maintained their abundance over the time period. The crab population is being maintained at relatively low abundances relative to levels 


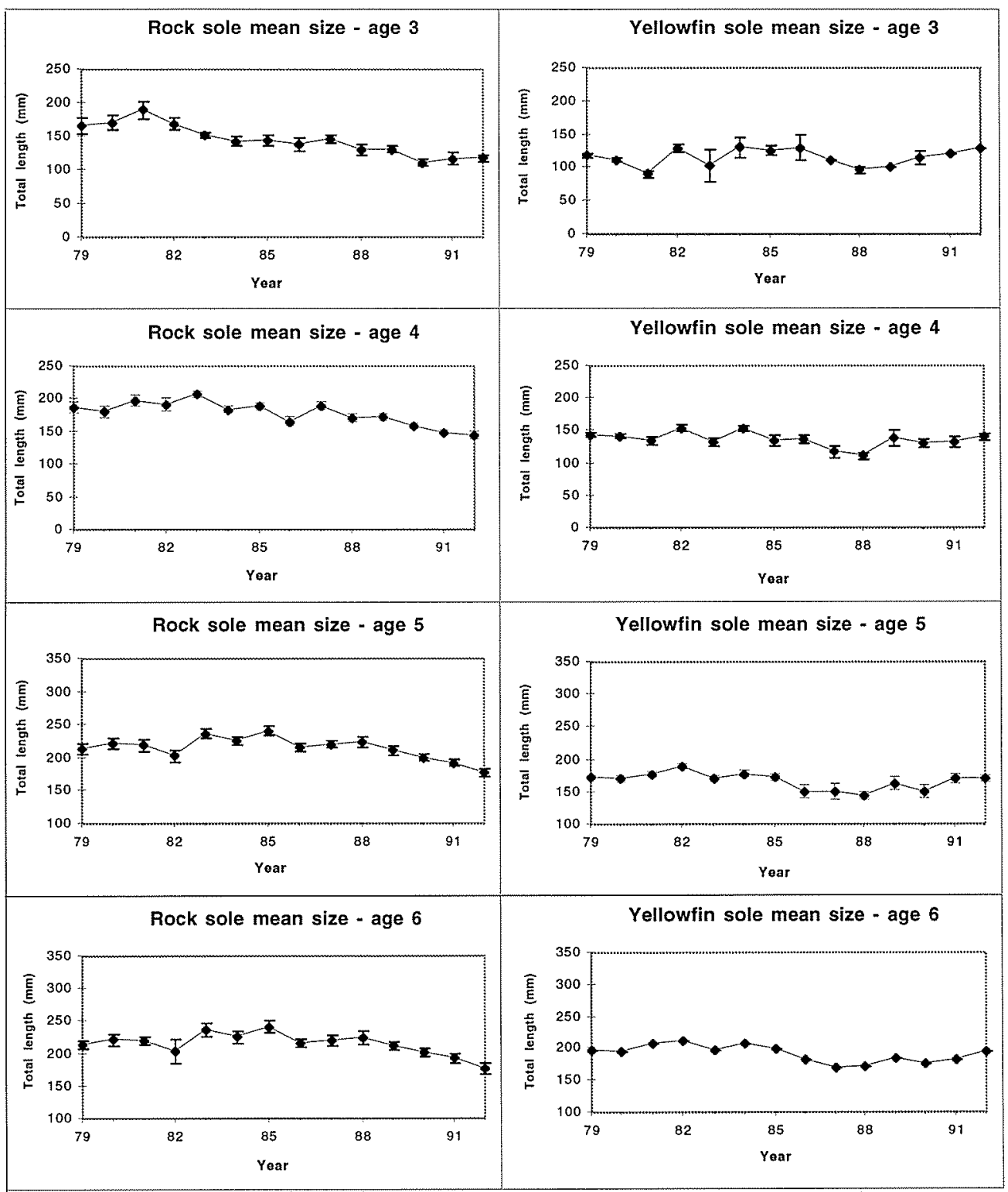

Figure 2.14. Length-at-age for rock sole and yellowfin sole (fish aged 3 through 6) in the eastern Bering Sea, 1979 93. Source: P. Livingston, L.-L. Low, R.J. Marasco, NMFS, Seattle, unpubl. data.

attained in the recent history of the eastern Bering Sea. If food resources are indeed limited, competition for these resources will increase as populations of other guild members continue to increase. We have also demonstrated increases in a large number of crab predators since the late 1970s, such as Pacific cod, Alaska pollock, sockeye salmon, skates, and arrowtooth flounder. The specific reason, or reasons, behind the documented changes are difficult to unveil. It is also unclear whether the noted species changes are reversible or if the recent trends constitute a transition to a new ecological structure of the eastern Bering Sea ecosystem. Nonetheless, larger numbers of these predator species in conjunction with possibly poor crab survival conditions (habitat or environmentally related) are likely adversely affecting the crab. 
We should note that the red king crab does not fall neatly into the guild in which Ackley et al. (1994) have placed them. As shown previously, different species intersect with the crab at different stages of its life history. Throughout its life a crab encounters a changing set of predators, has various habitat requirements, consumes different types of prey, and is affected by man differentially. Consider environmental variability (annual and long-term), and it is not surprising that the sources and causes of crab population variation are not well understood. 


\section{CHAPTER 3. RED KING CRAB MANAGEMENT IN BRISTOL BAY, BERING SEA, ALASKA}

The management of red king crab can best be understood in the context of ecosystem management when all of the factors affecting the resource are analyzed. These complex factors determine how scientific information and knowledge of the stock are translated into management actions that determine the nature of the crab fishery. Once these factors are understood, the question arises of how much weight to give each factor when making a management decision. This is the key difficulty in determining the optimal management plan. The two fisheries that have the greatest direct impacts on the crab population are the groundfish trawl fishery and the crab fishery itself. The management bodies are the Alaska Department of Fish and Game (ADFG) and the North Pacific Fishery Management Council (NPFMC). The authority for the day-to-day management of the crab fishery is delegated to ADFG, which monitors the fishery and declares the seasonal closures. NMFS cooperates with ADFG in the assessment, survey, biological data collection, and management of the red king crab fisheries (Otto 1986, Reeves 1993b). The Council's role is oversight of the state's actions. In 1989, the Council developed the Fishery Management Plan for the Commercial King and Tanner Crab Fisheries in the Bering Sea/Aleutian Island. Outlined in this plan is the division of jurisdiction for the fulfillment of the Plan and the Magnuson Act. The Council represents the regional perspective and considers the views of non-Alaskans. Joint management ensures that both Alaskan and non-Alaskan crab fishers are represented in management decisions. The Council also is directly responsible for managing the groundfish fishery.

Historically, the red king crab fishery in Bristol Bay has been volatile in nature. Russian and Japanese fishers intensively harvested red king crab in the late 1950s and early 1960s. Foreign harvesting continued at a declining level through the 1960s until all foreign fishing ended in 1974 (Otto 1981). Intensive domestic fishing began in the late 1960s. Common stories among the fishers at the time relate a sense of massive abundance to the point of waste. The crab were caught at such high levels that the processors were not able to handle the incoming loads. In Dutch Harbor, sometimes the unprocessed crab died on the docks while waiting to be processed, or they died on the boats while waiting to be unloaded (B. Lamoreux, fisher, Dutch Harbor, Alaska, pers. comm.). These dead crab, called deadloss, are wasted because they cannot be processed. In the 6 years before 1981, the amount of deadloss ranged from 730,279 1bs in 1977 to $3,555,891 \mathrm{lbs}$ in 1979 (ADFG 1994), compared with the total harvest in 1993 of 14,628,639 lbs (ADFG 1994). Additional accounts of huge gear losses compound the amount of waste generated during those years (lost gear continues to fish, commonly called ghost fishing). Lost gear has been estimated to be $10 \%$ of the annually deployed pots (Armstrong et al. 1993). Overcapitalization was prevalent because everyone wanted to participate in the second most valuable Alaskan fishery (after salmon) (Matulich et al. 1988).

Throughout the 1970s, the United States led the world in crab production, Bristol Bay and Kodiak Island being the main production areas. In 1982-83 the red king crab stock in Bristol Bay collapsed. In 1982, crab fishing produced the lowest catch on record and, in 1983, ADFG ordered a complete closure of the fishery for that season. According to the NMFS trawl survey abundance index, the populations of both legal males and mature females had dropped dramatically. In 1980, the abundance index was 36.1 million legal males and 67.5 million mature females; by 1983 these numbers fell to 1.5 million legal males and 
9.7 million mature females (ADFG 1994). J. Reeves (NMFS Alaska Fisheries Science Center, Seattle, unpubl. data) showed the dramatic decrease in crab catches between 1980 and 1983, and the current state of the fishery (Fig. 3.1). The specific causes of the crash are unknown, although it is easy to point to the red king crab fishery and its management. In reality, the situation is much more complex: "Management failed to prevent recent declines in landings because causes of declines in abundance are not related to fishing, and hence largely beyond control"' (Otto 1986).

\section{Objectives of Managing the Red King Crab Fishery}

The goals of the NPFMC and ADFG for the optimal management of red king crab are both social and biological:(1) a sustained fishery for both commercial and subsistence fishers, and (2) maintenance of healthy crab stocks. A viable long-term fishery is dependent on maintaining healthy stocks. In addition, seven specific objectives have been outlined in the NPFMC's Fishery Management Plan (FMP). "These objectives relate to stock condition, economic and social objectives of the fishery, gear conflicts, habitat, weather and ocean conditions affecting safe access to the fishery, access of all interested parties to the process of revising this FMP and any implementing regulations, and necessary research and management" (NPFMC, Anchorage, unpubl. data). Determining what management measures allow both healthy stocks and a viable fishing industry is the next step toward realizing these goals.

\section{Methods of Managing the Red King CRAB Fishery}

\section{Sex-Size-Season Management}

ADFG uses two basic methods to manage red king crab to achieve NPFMC's objectives: Sex-Size-Season (3-S management) and exploitation rate management. Sex-Size-Season management dictates that (1) only males are retained in the fishery, (2) 6.5-in carapace width (which equates to a carapace length of $135 \mathrm{~mm}$ )

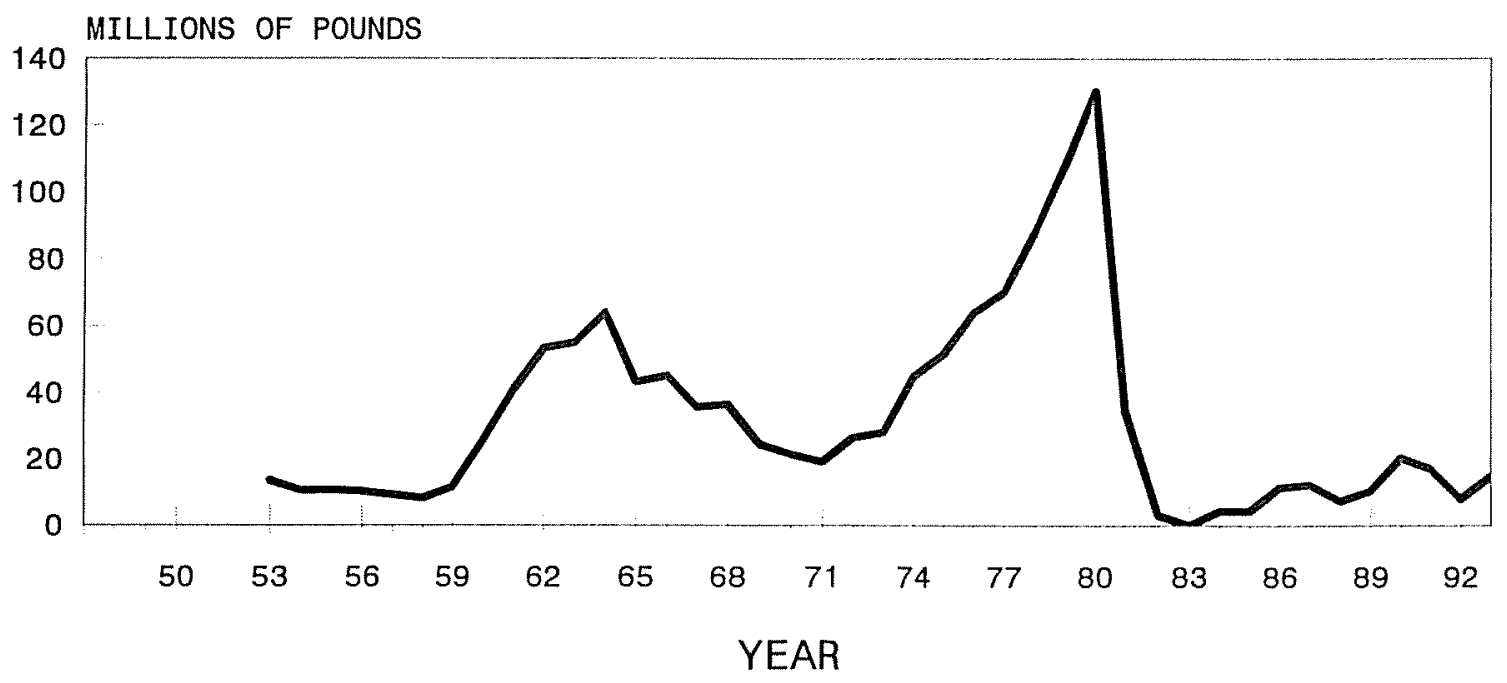

Figure 3.1. Bristol Bay red king crab catches: Bering Sea, Aleutian Islands (J. Reeves, NMFS Alaska Fisheries Science Center, Seattle, unpubl. data). 
is the minimum retainable size, and (3) harvesting is prohibited during molting and mating times when the crab are most vulnerable and of the poorest quality. The 3-S strategy does not impose a quota. Therefore, it is used only where abundance estimates are not available. Exploitation rate management is added to 3-S regulations by establishing a pre-season quota of the exploitable biomass, set according to annual crab surveys conducted by ADFG and NMFS. Then, during the season, the catch per unit effort (CPUE) is used to update the amount of exploitable biomass. Once the quota has been reached, the ADFG closes the fishery by issuing an emergency order. Both the 3-S and exploitation rate management systems utilize the same tools to control the fishery. These tools are "legal gear, permits, onboard observers, management and registration areas, pot limits, reporting requirements, vessel tank inspections, and provisions for gear placement, removal, and storage" (Kruse 1993).

\section{Exploitation Rate Management}

In the Bristol Bay red king crab fishery, the main management strategy is exploitation rate management. For red king crab, the exploitation rate management strategy establishes a pre-season guideline harvest level (GHL) based on the exploitation rate of $20 \%$ of mature male crab $>120 \mathrm{~mm}$ carapace length (Witherell 1995). The "GHL . . is set before the fishing season. The fishery is closed by emergency order-determined by catch per unit effort (CPUE) and soft-shelled condition of crab" (Matulich et al. 1988). The emergency order is declared by ADFG $1 \mathrm{wk}$ before the fishery is closed. The GHL is a biological estimate of sustainable harvest: the number of crab which can be harvested without damaging the population. The GHL is adjusted during the season by the reported CPUE. Some years the season is only 2-3 wk long. The 1994-95 season was completely closed, mainly to protect the record low numbers of female crab. ADFG justified the 1994-95 closure as follows: "The total estimated abundance for juvenile, pre-recruit and legal male crab and small and large females is 28.3 million crab, the lowest combined stock abundance for these sex-size components since the inception of the eastern Bering Sea trawl assessment program in 1969" (Steven et al. 1994). The trawl survey in June 1995 determined that the 1995-96 season would be closed owing to female fecundity.

During the winter, red king crab are in the optimal condition for harvesting, prior to molting in the late winter and early spring. During the months before they molt, the crab meat is at its maximum quality and density, and the shell is harder. This is better for the processing industry, because larger, higher-quality crab command a higher price. Also, the harder shell is better for the crab because they suffer less handling mortality. A major drawback is the great danger of fishing in the Bering Sea in the winter: crab fishers suffer more casualties and accidents than any other group of fishers (Richards 1995).

\section{ANALYsis of MANAGEMENT MEASURES AND AlteRnatives}

\section{Sex-Size-Season Management}

The 3-S strategy, or a variation thereof, is ingrained in crab management throughout Alaska and the North American West Coast. It is traditional crab management, using biological theories dating back to the pre1940s. However, the principles of 3-S management have been questioned by contemporary crab biolo-

gists, who have developed new theories, based on abundance estimates, that are contrary to the traditional 3-S principles. Replacing the 3-S rules with techniques based on these new theories will be difficult until abundance estimates for all stocks are available on a regular basis. 
One new theory suggests harvesting both females and smaller males. As discussed in Chapter 1, the biological concerns of continuing to harvest only the largest males include altering genetic diversity and reducing the potential mating age of males. The current size limit excludes females because the vast majority do not reach the legal size of males. Females will be excluded by the current size limit $(\sim 135 \mathrm{~mm}$ carapace length) because they are smaller overall. Therefore, to allow the harvest of females, we need to either lower the legal size or create a separate size limit for females.

The male-only fishery could damage the long-term health of the stock. Currently, the red king crab stocks are volatile and susceptible to crashes. Part of the volatility may be due to the single-sex fishery. Thus, harvesting both males and females might increase the population's stability. Although there is no evidence of this in Bristol Bay, harvesting only the males might reduce the male/female ratio and, therefore, reduce the reproductive potential of the population (Kruse 1993). Actually, having too many females may lead to reduced recruitment (J. Reeves, NMFS Alaska Fisheries Science Center, Seattle, pers. comm.) and the population might increase if both males and females were harvested (Kruse 1993). As discussed in the first chapter, the dynamics of a natural biological ratio help to ensure high fecundity and reproduction: "Female harvest, particularly at high population levels, should be considered because it may lead to less variability in production and higher long-term yield" (Kruse 1993).

To strengthen the stock, we might consider implementing a plan to increase the diversity of harvested crab by lowering the size limit and harvesting females. "Harvesting females may, hence, be a viable option from a biological stand point and may actually increase yields" (Otto 1986). Increasing the catch diversity allows some older, larger males to survive, acting as a "buffer against population crashes in unfished stocks" (Kruse 1993). At the same time, bycatch will be reduced and this will increase the CPUE for the fishing vessels. The stock will also be strengthened by the decreased harvest of the largest, most virile males. Increasing the diversity of the harvest does not mean increasing the exploitation rate; the exploitation rate will remain the same and only the composition of the catch will change.

Increased utilization (IU) of the red king crab stock by including mature males and females with a $>120$ $\mathrm{mm}$ carapace length can increase the CPUE, benefiting the fishers, and decrease bycatch and handling of the stock, benefiting the crab population. This reduced size would not drastically impact the stock because male red king crab mature at $119 \mathrm{~mm}$ and only a small portion of mature females reach $120 \mathrm{~mm}$ (see Fig. 3.2). In an economic study of IU, P. Hill (Univ. Washington School of Marine Affairs, Seattle, unpubl. data) determined that "with a $120 \mathrm{~mm}$ size limit the 1993 level of revenue could have been achieved at a $30 \%$ reduction in effort and $>2.0$ million less crab affected by the gear." In determining these figures, Hill assumed a constant ex-vessel price per pound of $\$ 3.80$. Using a sensitivity analysis, Hill further determined that by lowering the ex-vessel price per pound for crab under the current $135-\mathrm{mm}$ size limit to $\$ 2.00$, IU still increased CPUE and the strategy remained economically viable for the fishers. The analysis omitted consideration such as the effects on processors and the lowering of the price per pound for large crab due to the influx into the market of more, smaller crab. IU will result in a small reduction in legal crab size and, therefore, have a small effect on ex-vessel price, but it is a viable management option for reducing fishing effort and the impacts of fishing on the red king crab stock.

However, the processing industry opposes reducing the retainable size because they want only the highly valued, large male crab. Smaller crab yield less meat per unit cost than larger crab, although the meat is the same quality. Therefore, the processors earn less profit processing females and smaller males (Matulich 1988). It will be a trade-off between the vessels, who benefit from increasing the catch composition, and 


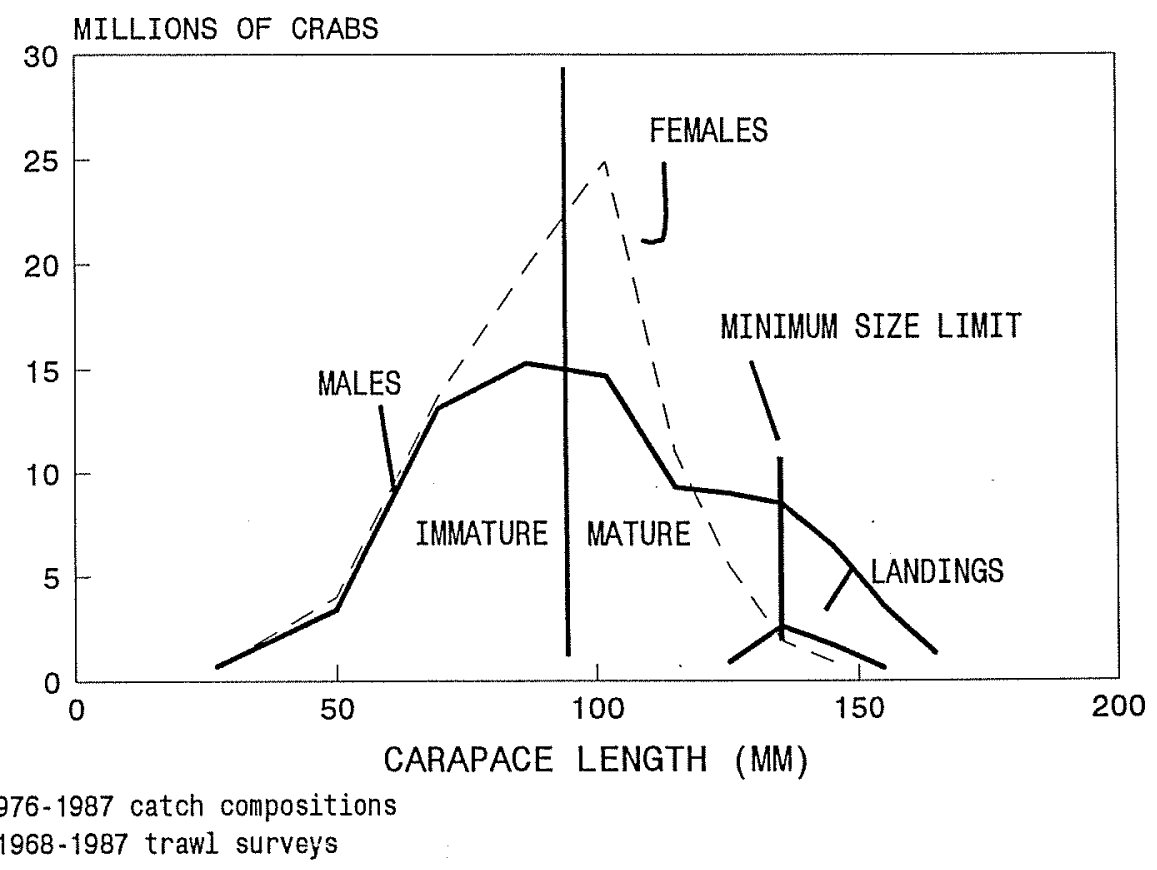

Figure 3.2. Bristol Bay red king crab: representation of average size composition (J. Reeves, NMFS Alaska Fisheries Science Center, Seattle, unpubl. data).

the processors, who benefit from large crab. Getting the processors to change will be difficult, but, as the amount of large crab decrease, it is inevitable that changes in the 3-S system will occur. Until the processors accept smaller crab, discards will continue owing to market forces. Fishers will discard crab that processors will not or are not forced to buy. Incentives or regulations that promote utilization of smaller crab must occur simultaneously with changes in the catch composition. Currently, the lack of concrete information concerning the benefits of these changes to the population is a major inhibitor to action ( $\mathrm{J}$. Reeves, NMFS Alaska Fisheries Science Center, Seattle, pers. comm.). At the same time, there is no biological reason not to implement modified versions of the 3-S strategy, such as allowing harvesting females and reducing the legal size.

We do recommend keeping the timing of the season because it is vital for the health of the population to reduce handling mortality during mating and molting. Harvesting females and smaller males should not be interpreted as increasing the amount of the overall harvest; rather, it would spread the allowable harvest over a broader size and sex range of the population (see Fig. 3.2). Currently, the harvested crab are to the right of the minimum size limit line. Moving the line to the left would open up a wider range of crab to harvesting, while keeping the same quota would decrease the pressure on the large males.

\section{Exploitation Rate Management}

The strong point of exploitation rate management is that it rapidly adapts to fluctuations in the stock size regardless of the causes of these fluctuations. Compared with other fisheries, the GHL sets a conservative estimate, of the amount of fishing pressure the stocks can sustain. This rapid response, however, has not produced stable, plentiful stocks. The current management scheme does not control access or limit effort. Therefore, it has produced an unstable, derby-type fishery. Effort has increased substantially after the clo- 
sure in 1983 (Fig. 3.3) as compared with the increase in crab catches (Fig. 3.1). Fishers never can predict when the season will be closed, how much income they will be able to earn in a season, or whether they will be able to break even. The fishery operates $24 \mathrm{~h} /$ day when it is open. Therefore, the fishers are forced to fish as fast as they can, overcapitalize by using as much technology and gear as they can, and fish in all types of weather. Independent Fishermen for Fair Quotas, a group that advocates fishing vessel quotas, criticizes the current system by saying it gives fishers two alternatives: face financial ruin, or face damage and loss of vessel and life from winter fishing. A vessel that capitalizes on size, uses advanced technology, sets the maximum number of pots, and goes out in all weather has a better opportunity to earn a higher profit during a limited number of fishing days than a vessel that does not maximize at every stage of harvesting. This type of derby fishery also discourages "clean" fishing practices, practices that reduce the large amount of bycatch.

Current management has led to intensive harvesting effort by the red king crab fleet during the limited season. Effort can be determined by the number of pot lifts made per season. Effort can be controlled by gear restrictions, specifically, a limit on the number of pots a vessel is allowed to set at one time. Currently, each vessel $>125 \mathrm{ft}$ has a limit of 250 pots; vessels $<125 \mathrm{ft}$ have a limit of 200 pots (Witherell 1995). This does limit effort, but it also reduces soak time per pot (the time a pot spends on the bottom). When a vessel only has 250 pots, it can rotate these pots faster. The longer the soak time, the better chance undersized crab have to escape. Thus, with shorter soak time the smaller crab do not have a chance to escape, and must be discarded after they are hauled on deck. The result is shorter soak times and higher bycatch per pot. The optimal soak time would be long enough for the bait to fade away so the smaller crab would lose interest and leave the pot.

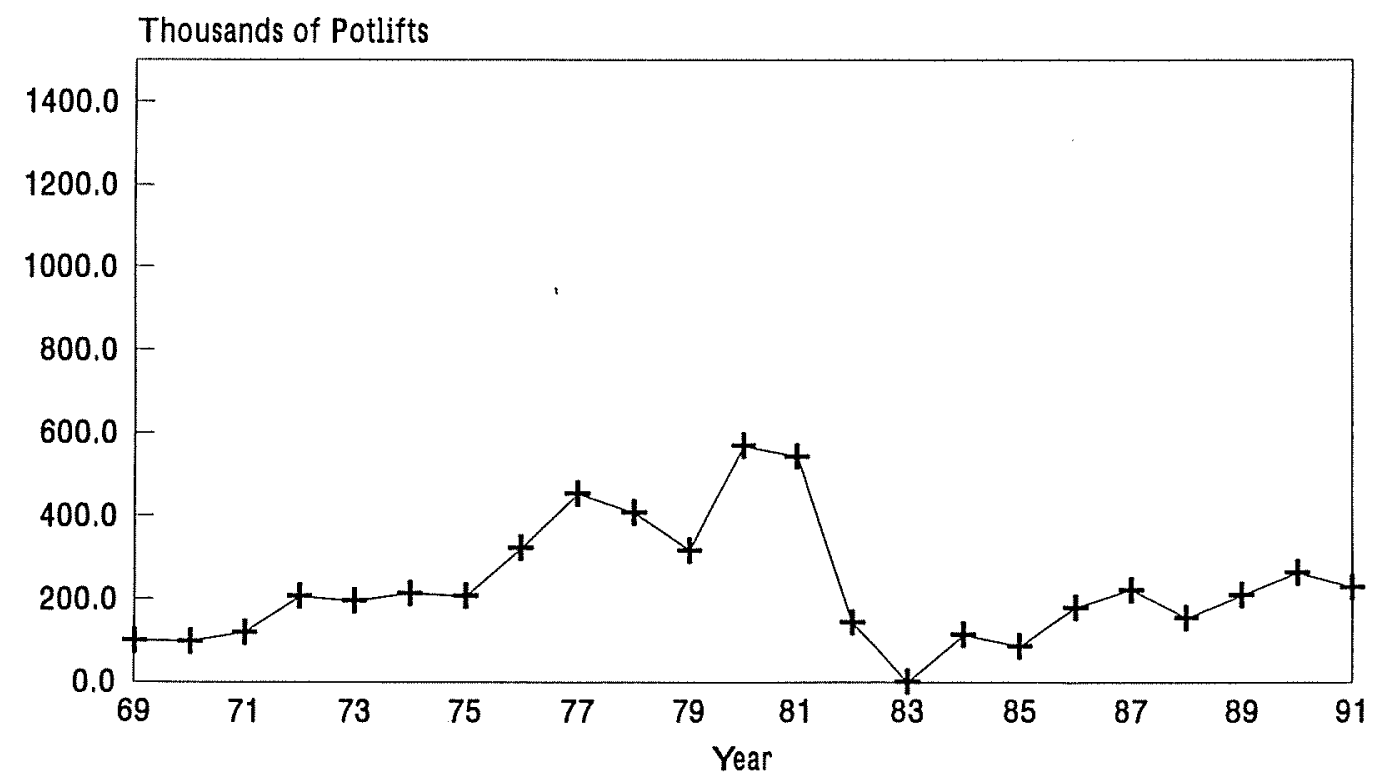

Figure 3.3. Composition of fishing effort for red king crab in Bristol Bay/Aleutian Islands (J. Reeves, NMFS Alaska Fisheries Science Center, Seattle, unpubl. data). 


\section{ByCATCH IN THE RED KING CRAB FisheRY}

A major difficulty in managing the red king crab fishery revolves around its extremely high level of bycatch, which consists of female and sub-legal male crab. Relatively low bycatch of other species occurs in the red king crab pot fishery. The large amount of bycatch in the red king crab fishery was documented with the introduction of observers in 1988 on the joint-venture vessels and on catcher/processors. One hundred percent observer coverage is now required by ADFG on all catcher/processor boats. Retaining bycatch is illegal; therefore, all crab except legal males are thrown overboard. Discard numbers range from $20 \%$ to $40 \%$ of the estimated crab population, some years the estimate is as high as $80 \%$. "Discards may have done much to shape current stock conditions" (Alverson et al. 1994). The percentage of bycatch and its composition vary yearly, reflecting the composition of the species. An example of the bycatch rates for 1993 (Fig. 3.4) illustrates the potential severity of the problem. One difficulty in determining the effects of discards on the population is determining how many of the discarded crab die, and the number of crab repeatedly caught and discarded. This is the crux of the problem. If the bycatch mortality rate is high, then this will add significantly to the total fishing mortality and thus fishing may have a tremendous effect on the health of the population. Alternatively, if the mortality of discards is low, then fishing impacts a fairly small percentage of the population.

\section{BYCATCH MORTALITY}

Few studies have been conducted to determine the handling mortality on red king crab discards. Crab bycatch discards are either killed (by crushing, desiccation, exposure to extreme temperatures, or dropping), or become handicapped (reduced vigor, increased predation, reduced growth and feeding rates, loss of limbs, decreased reproductive potential, or bacterial infections). The most extensive study was conducted by Zhou and Shirley (1994) at the University of Alaska Fairbanks in Juneau. "In our study . . females and sub-legal-sized male red king crab displayed few acute or chronic responses to laboratory handling treatments designed to mimic handling occurring during sorting in the commercial fishery" (Zhou and Shirley 1994). However, they qualify their findings by saying that actual conditions in the fishery

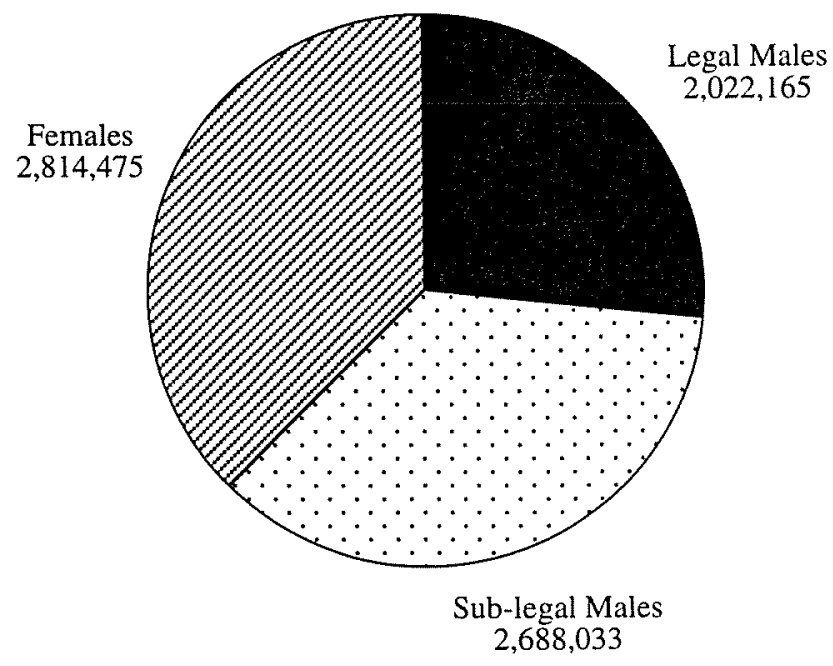

Figure 3.4. Composition of crab catches based on 1993 data from ADFG. 
might be worse than those in the lab, and that many red king crab die during molting, 47-120 $\mathrm{d}$ after being exposed to cold air in the laboratory (Kruse 1993). Uncertainties exist because only a portion of the whole process can be simulated in the lab .

More research needs to be done on bycatch mortality. If the situation is as the Zhou and Shirley (1994) study suggests, then bycatch is not a major problem and does not significantly impact the crab population. The bycatch mortality rate is directly affected by the season in which they are caught and the gear type and fishing methods used. Red king crab are vulnerable to bycatch mortality during molting and mating seasons. "Gear designs may promote handling mortality that may exacerbate stock declines" (Kruse 1994). Reducing the bycatch to a more moderate level is achievable with relatively simple measures. Gear modifications to allow juveniles to escape, such as escape holes in pots and longer soak times, would reduce the level of bycatch. Reducing bycatch benefits the fishers because it reduces the time and effort spent on hauling up the pot, sorting through the catch, and then discarding the sub-legal and female crab.

\section{Red King Crab Bycatch in Other Crab Fisheries}

Red king crab are found in the bycatch of other fisheries as well. In Bristol Bay, two fisheries impact the red king crab: pot fishing for Tanner crab (Chionoecetes bairdi) and bottom trawling for groundfish. In 1993, ADFG closed the critical red king crab habitat east of $163^{\circ} \mathrm{W}$ to Tanner crab fishing for the 1994 season (Stevens et al. 1994) (see Fig. 3.5). This closure has eliminated a large amount the red king crab bycatch in the Tanner crab fishery. ADFG took such a drastic measure because of the continually poor condition of the red king crab stocks and the high bycatch in the Tanner crab fishery.

\section{GroundFish TRAwl Fishing EFFECTS ON RED KING CRAB}

The bottom trawl groundfish fisheries use non-selective harvesting techniques, catching salmon, halibut, and crab, in addition to catching their target species. When restrictively managing one fishery to the direct benefit of another, equity conflicts arise that are difficult to solve when the costs and benefits are not easy to quantify. "A conflict occurs when bycatch is thought to impact measurably the resources available to another fishery. Bycatch management attempts to balance the effects of various fisheries on each other" (Pautzke 1995). To balance these effects, it is necessary to quantify them. The groundfish fisheries have been adversely affected, and the groundfish fishers claim unfairly, by attempts to eliminate the impacts of the groundfish fishery on king crab. Although many studies have been done to determine the effects of trawling on the seabed and benthic community (Thompson 1993), restricting bottom trawling is difficult to justify because there are no concrete scientific findings that directly link trawling with the decline in the red king crab population. Yet, substantial evidence exists that indicates the health of the red king crab fishery might depend on restricting the groundfish fishery from important red king crab habitat.

In 1987, the first no-trawl zone in Bristol Bay was established for the domestic fleet; this zone comprises the waters south of $58^{\circ} \mathrm{N}$ and between $160^{\circ}$ and $162^{\circ} \mathrm{W}$, excluding nearshore waters $<25 \mathrm{fm}$ deep (Armstrong et al. 1993). The rationale behind prohibiting bottom trawling is twofold: (1) red king crab are a component of trawl bycatch, and (2) bottom trawling crushes crab and has a disastrous impact on the benthic habitat that supports the red king crab (Armstrong et al. 1993). (Please refer to Chapter 1 for details concerning the red king crab and its habitat.) Bottom trawling is believed to destroy the plant life and 


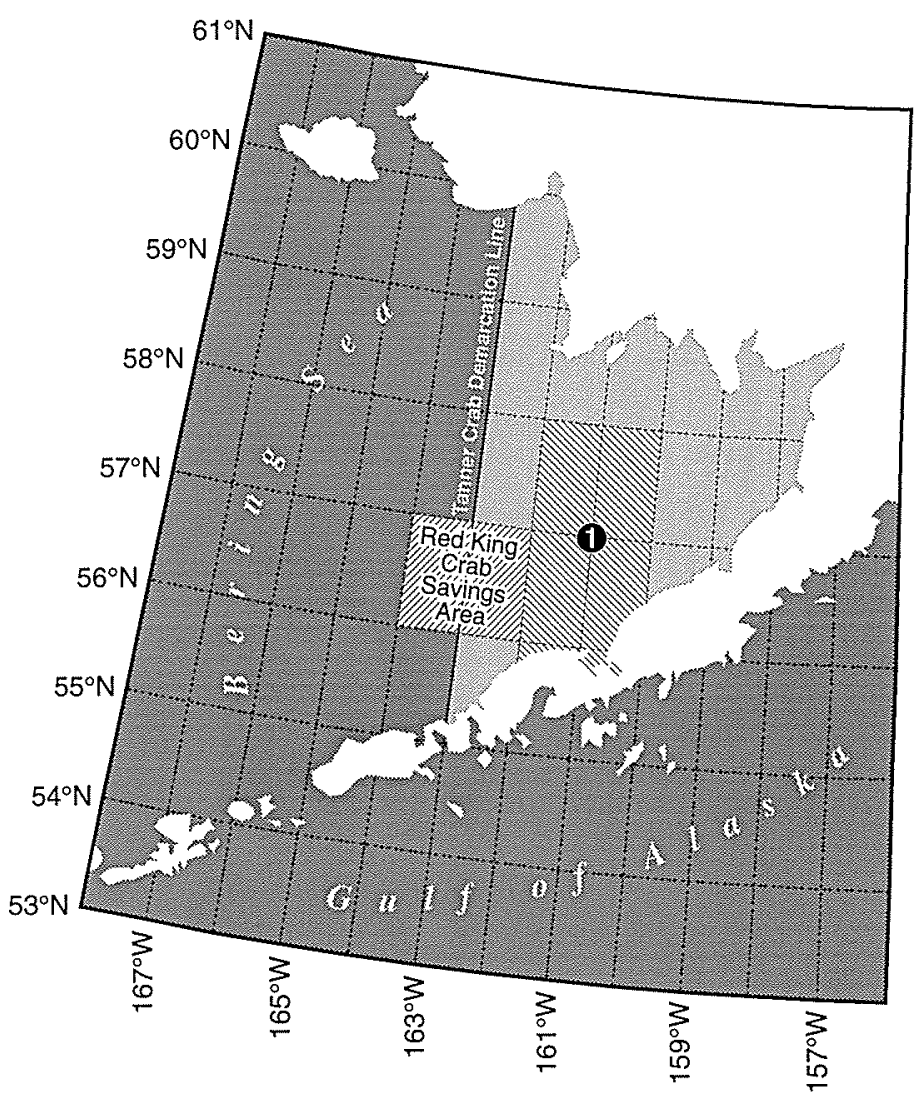

Figure 3.5. Current NPFMC no-trawl zones and Tanner crab demarcation line. Zone $1=$ no-trawl zone. Tanner crab fishing is prohibited east of $163^{\circ} \mathrm{W}$. Source: NPFMC (Anchorage, unpubl. data), Stevens et al. (1994), and Armstrong et al. (1993). (Map generated by B. Feist.)

bottom structures that the crab depend on for protection from predators. Also, the act of dragging the net and trawl doors over the bottom could crush, mangle, and kill the crab in their path. Thus, the drawback to the current no-trawl zone is that it does not include the habitat of the vulnerable juveniles.

It is difficult to assess the relative importance of trawl bycatch of crab. The relative number of red king crab caught as bycatch in groundfish trawls is small compared with the bycatch in the crab fishery. Conversely, the mortality of these crab is high: $\sim 80 \%$ of the crab die (Armstrong et al. 1993). The amount of bycatch and associated mortality is based on observer data and differs for each species of groundfish targeted. The rock sole fishery has the highest bycatch of red king crab compared with the other groundfish fisheries. Bycatch rate in the bottom trawl fisheries depends on a variety of factors, from the time of the year to the location of the fishery, and is susceptible to yearly fluctuations.

Currently, there is a prohibited species cap (PSC) of 200,000 red king crab on the groundfish fishery (Witherell 1995). The PSC dictates that the target fishery is closed when the cap is reached for the prohibited species. With the PSC in effect, it would appear that red king crab are protected from excessive destruction by trawling. The establishment of no-trawl zones, therefore, assumes that bycatch is not the important issue in closing areas to trawling. Instead, habitat destruction and crushing are the justifications for closing areas to trawling. 
Currently, there is limited monitoring to observe the effectiveness of the no-trawl closure areas. We suggest that the monitoring of the no-trawl areas be increased in order to quantify the effectiveness of the closures. Improved monitoring would include comprehensive surveys at regular time intervals in trawl and no-trawl zones. These surveys would be directed at measuring the effects of trawling versus the absence of trawling on both the crab population and benthic substrate. When the benefits can be quantified, it will be easier to justify the closures to protect the red king crab fishery. Alternatively, the data might show that no-trawl zones do not produce the desired effects and other alternatives should be implemented to rebuild the crab population.

\section{CONCLUSION}

The impacts of the depressed state of the red king crab stocks reach beyond the fishery to affect other economically valuable fisheries. Ideally, "management strategies should be matched with stock and speciesspecific biological characteristics such as growth, terminal molt phenomena, mortality, size of maturity, and recruitment dynamics" (Kruse 1994). But, as discussed in the previous chapters, understanding the biological processes and the effects of human actions (fishing and management measures) on the population is extremely difficult, if not impossible for the foreseeable future. This problem becomes acute when the population in question is unable to support a once-thriving fishery. Fluctuations and changes in the environment and in other species need to be incorporated into management decisions. It is true that we only manage people, but ecosystem considerations that affect natural recruitment and mortality must be worked into management plans so that we will know how best to manage people. Decisions need to be made without complete information and using solutions not specifically designed for the problem. How do we move from this present situation to more ideal management, where the problems, their solutions, and the results of the solutions are known? For this, we need to consider adaptive management: using what we have with the goal of continual modification (Walters 1986, Lee 1993). 


\section{CHAPTER 4. ECOSYSTEM MANAGEMENT AND THE BERING SEA RED KING CRAB FISHERY}

\section{Ecosystem Management Premises Defined}

Ecosystem management has defied any one explicit definition in the last decade, but it continues to be a focus for natural resource managers today. Yet, major legislation that governs interaction with the natural environment has called for ecosystem considerations in their management plans (i.e., the Magnuson Conservation Fisheries Management Act, the Endangered Species Act, and the Marine Mammal Protection Act). The Plan Team for groundfish fisheries of the Bering Sea, Aleutian Islands, and Gulf of Alaska has considered the role of the ecosystem in their management plans submitted to the NPFMC since 1993. Their paper "Ecosystem Considerations-1995" is a significant step towards the goal of ecosystem management (Ackley et al. 1994). By adopting a similar approach, we attempt to apply current concepts of ecosystem management to resolve some of the major issues in the Bering Sea red king crab fishery.

The idea that we might be able to manage any aspect of the natural environment in a large marine ecosystem seems, at best, farfetched. The complexity and variability within the natural environment seem to preclude any attempt at these efforts. We can, however, attempt to manage our own interaction with the ecosystem, and try to understand the processes that are at work there. Grumbine (1994) states, "Ecosystem management integrates scientific knowledge of ecological relationships within a complex sociopolitical and values framework toward the general goal of protecting native ecosystem integrity over the long term." We would clarify this definition by stating that the protection offered by management policies toward ecosystem integrity should also address anthropogenic changes within the structure of the environment. Warren Wooster states that ecosystem management is "management of those human activities that affect an ecosystem, with a view to achieving specific ecosystem characteristics" (W. Wooster, Univ. Washington School of Marine Affairs, Seattle, pers. comm.). We feel it is also important to include an effort to understand the processes in an ecosystem that may affect human activities. The Critical Intersections Approach demonstrates these expanded definitions of ecosystem management applied to the management issues surrounding the red king crab fishery.

The ability to adapt is integral to any management structure that attempts to manage human activities and monitor the processes of an environment the size and complexity of the Bering Sea. Current management of red king crab under the NPFMC and the ADFG can best be described as reactive. However, the long time frame from a proposed management change to its implementation (if, in fact, it is ever implemented) limits the capability to react to changes in scientific knowledge of a fishery, or to changes resulting from previous management decisions. When new control measures have been put in place for red king crab, the political and structural complexities of management (i.e., the time to implement change, the ability to react to new science or evidence), as well as the open access nature of the fishery, may limit the success of these management efforts. Thus, the concept of adaptive management, defined by Lee (1993) as "an approach to natural resource policy that embodies a simple imperative: policies are experiments; learn from them," seems outside the boundaries of the current management structure. Crab management today is, at most, passively adaptive (D. Huppert, Univ. Washington School of Marine Affairs, Seattle, pers. comm.) 
by making adjustments in annual quota and applying gear and season limits based on underlying conditions (e.g., stock abundance). Acquisition of new understanding and knowledge is not a primary goal of passive adaptive management. The Critical Intersections Approach we use in our attempt at ecosystem management is actively adaptive, incorporating monitoring and learning into management decisions. Thus, while seemingly outside the boundaries of the current management structure, the concept of active adaptive management is essential when evaluating the effectiveness of the ecosystem-based program we are proposing.

The political structure of the industry, scientific community, and policy makers must provide a framework in which to acquire new understanding and be able to modify the management plan when new information is developed or discovered. Furthermore, when changes are made it will be necessary to wait for results, which may not be seen for decades. Uncertainty in the natural environment may make it impossible to determine whether, in fact, management efforts will affect any changes in the environment and the population of the species being managed, or changes within the ecosystem itself will cause the results. Hulpert (1993) describes how error must become an acceptable part of an evolving management scheme and how the goals of a plan must be compatible with "natural processes, existing technology, and social norms." Evolving knowledge of crab life history, and results of previous management efforts may provide information that could lead to an adjustment in the management program. Errors in management decisions may be made, yet learning from these mistakes and adjusting the plan accordingly will ultimately strengthen the program.

R.C. Francis (Univ. Washington School of Fisheries, Seattle, pers. comm.) warned us not to seek a silver bullet for the multiplicity of ecological and environmental problems within an ecosystem. The very structure and complexity of ecosystems may prevent a single solution to management issues. R.C. Francis went on to define ecosystem management (single or multiple-species) as an "activity in which two cultures-one composed of scientists, and the other composed of managers-seek to cooperate." It is within this interaction of science and management that the goals, conflicts, and values of society mix and from which a plan to manage an ecosystem will emerge. Here is where the issue of king crab bycatch, multispecies fisheries, and the concept of ecosystem management have been born. Today, the perception of bycatch and discard is defined differently among the different stakeholders: the public may see waste, the fishers may see lost opportunity or increased costs, the scientists may see excessive pressure on a natural system, and the fishery managers may see complex resource allocation issues in the face of dwindling stocks. The values placed on these issues by society often reflect competing objectives. Ecosystem management can offer, at best, a multifaceted management plan that attempts to address all of the issues.

Today, we are charged to manage fisheries with ecosystems in mind. Defining our management goals can be difficult. Apollonio (1994) purports that "current management practice appears to promise a sustained yield for all species, independent of their biological peculiarities." R.C. Francis (Univ. Washington School of Fisheries, Seattle, pers. comm.) pointed out that "in essence the [NPFMC] Council is asked to balance the economic need for extraction with the need to maintain ecosystem 'health' - the necessity of maintaining sufficient ecosystem complexity and flexibility to protect its self-organizing qualities." We also see the goal of ecosystem management as giving managers and policymakers an understanding of the larger ecosystem, incorporating single-species management within this context. This would allow them to think about the system at large and how environment and fishing may affect populations. Apollonio (1994) describes the three ecosystem properties first presented by Dickie (1973). The following property is the essence of an ecosystem: 
A system [ecosystem] is not a machine because quite large perturbations of a part will be compensated for in other parts, thereby preserving the functioning of the whole. The overall function depends on the interrelations among parts but is more or less independent of the nature of the individual parts. (Apollonio 1994).

It is likely that overall productivity and species diversity will remain the same in the Bering Sea even when faced with anthropogenic and natural disturbances (Ackley et al. 1994). However, we suggest that the relative abundance of certain species in the Bering Sea ecosystem may be restructured owing to natural or anthropogenic perturbations. Our ecosystem management plan focuses on those critical stages of the red king crab life history, which can be affected by management actions. We also seek to change the regulations governing the fishery itself in such a manner to promote a stable crab stock and a stable fishery.

\section{The Role of Ecological KNowledge In Ecosystem Management}

An understanding of the relationship among anthropogenic alterations to the ecosystem, the ecology of the ecosystem, the life-history strategies of component species, and how they intersect and overlap is the cornerstone to our management approach. We do not support unlimited spending for scientific research but we do promote a strong, dynamic research program, with an active long-term monitoring component. In Chapter 1, we discussed the life-history phases of red king crab. In this section, we further elaborate on how some ecological considerations may drive important aspects of an ecosystem management plan.

In recent times, our ability to remove and disturb large populations and areas of habitat in the Bering Sea has been dramatic. Historically, we removed large populations of marine mammals, with an unknown effect(s) on ecosystem structure. Major fishing efforts by both foreign and domestic fleets have removed large biomasses of fish since the 1960s. The Committee on the Applications of Ecological Theory to Environmental Problems (CATE, The Committee) has stated, "When a species is removed from an ecological community, its roles are sometimes taken up entirely or in part by other species. The likely effects of species losses on community dynamics depend on the details of current interactions, so an important part of project planning is a survey of competitive, predator-prey, and mutualistic interactions of an obligate and specialized nature" (CATE 1986, emphasis added).

The growth of flatfish communities and salmon populations in conjunction with a severe decline in crab stocks could be considered a restructuring. Environmental perturbations and strong fishing pressures may have been important factors in reducing the abundance of some species in the Bering Sea, and may have contributed to this potential restructuring.

The Committee goes on to say that if communities are repeatedly disturbed for an extended period of time, the effects are more serious than if there was just one disturbance event (CATE 1986). We believe this may be the situation with the habitat and particular species in the Bering Sea red king crab grounds. Habitat is a critical element in several stages of the life history of the crab. Constant pressure on this habitat (by trawling, past and present) may deter or impede the recovery of the red king crab stocks by favoring other species such as flatfish, starfish, and skates. It is also possible that these other species have been affected by alterations to the benthic habitat, but the nature of such impacts remains unknown. However, the multitude of habitat types required by red king crab probably increases their sensitivity to disturbance. The Committee states, "Not only must individuals find all the necessary habitat types at the correct time, but populations are affected by the fluctuations in the availability of habitats for each stage; these fluctuations can be independent of each other" (CATE 1986). The Committee has also indicated that though 
"productivity often increases as a result of perturbation, [it] decreases as [the] perturbations become(s) more severe" (CATE 1986).

In addition to habitat problems, we hypothesize that red king crab may have a patchy distribution that could leave them vulnerable to perturbations of the ecosystem. Fishing pressure may reduce the number of patches and increase the distance between patches, potentially destabilizing the population and increasing its vulnerability. The increase in distance between patches may increase the difficulty of male aggregations attempting to find pre-molt female aggregations on the spawning grounds. Increased inter-patch distance may decrease (or delay) the likelihood of finding mates and decrease overall fecundity in a nonlinear, density-dependent fashion. While current data do not suggest this type of relationship (R. Otto, NMFS, Kodiak, Alaska, pers. comm.), we suggest that this is an area requiring further research before it is discounted as a mechanism influencing the decline of red king crab abundance.

\section{One Possible Ecosystem Management Tool: The Concept OF R- AND K-SPECIES}

To successfully manage a fishery like that for Bering Sea red king crab, we must have tools that allow us to identify changes within the population and measure changes within the ecosystem and related species that intersect with the target population. Ideally, these tools would encompass many life-history strategies that not only indicate population health and growth but are indicative of changes within the environment, either anthropogenic or natural. The concept of $\mathrm{r}$ - and $\mathrm{K}$ selectivity may be one such tool. We acknowledge that the jury is still out on this specific concept but purport that its base assumptions are the building blocks of what an ecosystem management tool may look like. Other tools that may serve a manager in addressing changes in a population structure may be suggested by critics of $r$ and $\mathrm{K}$. We encourage further debate so that the best tools are deployed by the stewards of this system.

When trying to understand relationships and processes in order to establish a general classification of ecosystem structure, the paradigm of $\mathrm{r}$-selected and $\mathrm{K}$-selected species provides "the kind of qualitative ecosystem generalization that has potential value to managers" (Apollonio 1994). This concept integrates a species' "relationship among habitat, ecological strategies, and population parameters. ..." (Adams 1980). Simply, r-species have maximized their reproductive potential and K-species have evolved towards the most efficient use of their environment and exhibit populations that are "close to the carrying capacity of their habitat" (Apollonio 1994). Table 4.1 describes the correlates for $r$ - and K-selection. The life-history strategies are intertwined with the environment of the ecosystem and the perturbations of the system, either anthropogenic or natural. K-species and $r$-species are not separate groups of species, only having the characteristics of one strategy. Either species fall along a continuum which moves from r-selectivity to Kselectivity (Fig. 4.1). Species closer to the ordinate are considered r-selected and species located on the line in a more northeast direction are more $\mathrm{K}$-selected. Where a species falls on this continuum shows how responsive it might be to perturbations within the ecosystem. Species that are r-selected are better able to handle changes within the ecosystem, whereas K-species are less able to adjust. Apollonio (1994) states that ' $\mathrm{K}$-species, because of their biologic attributes, have a role 'structuring' or 'shaping' their systems . . that is, their presence induces predictability into the system, whereas, by inference, their reduction or removal reduces internal control mechanisms and increases variability and unpredictability." 
Table 4.1. Correlates of r- and K-selection. Source: Apollonio (1994, p. 593), Pianka (1970).

\begin{tabular}{|c|c|c|}
\hline Correlates & r-selection & K-selection \\
\hline Climate & Variable and/or unpredictable, uncertain & $\begin{array}{l}\text { Fairly constant and/or predictable, more } \\
\text { certain }\end{array}$ \\
\hline Mortality & $\begin{array}{l}\text { Often catastrophic, non-directed, density- } \\
\text { independent }\end{array}$ & More directed, density dependent \\
\hline Survivorship & Often type III & Usually type I and II \\
\hline Population size & $\begin{array}{l}\text { Variable in time, non-equilibrium usually well } \\
\text { below carrying capacity of environment; } \\
\text { unsaturated communities or portions thereof; } \\
\text { ecological vacuums; recolonization each year }\end{array}$ & $\begin{array}{l}\text { Fairly constant in time, equilibrium; at or } \\
\text { near carrying capacity of the environment; } \\
\text { saturated communities; no recolonization } \\
\text { necessary }\end{array}$ \\
\hline $\begin{array}{l}\text { Intra- and inter-specific } \\
\text { competition }\end{array}$ & Variable, often lax & Usually keen \\
\hline Relative abundance & $\begin{array}{l}\text { Often does not fit MacArthur's broken stick } \\
\text { model }\end{array}$ & Frequently fits the MacArthur model \\
\hline Selection factors & $\begin{array}{l}\text { Rapid development; high rmax; early } \\
\text { reproduction; small body size; semelparity: } \\
\text { single reproduction }\end{array}$ & $\begin{array}{l}\text { Slower development, greater competitive } \\
\text { ability; lower resource threshold; delayed } \\
\text { reproduction; larger body size; iteroparity: } \\
\text { repeated productions }\end{array}$ \\
\hline Length of life & short, usually less than 1 yearr & Longer, usually more than 1 year \\
\hline Leads to & Productivity & Efficiency \\
\hline
\end{tabular}

Apollonio (1994) developed a generalized response to a single perturbation for an $\mathrm{r}$ - and a K-species (Fig. 4.2). The model predicts the variability of fluctuations that are introduced into the population by this event and how the populations respond differently. We suggest that, given the biology of the red king crab described in Chapter 1, they may have reproductive attributes of a more K-selected species relative to many other benthic invertebrates and fishes. Namely, delayed onset of maturity, a single yearly spawning cycle, and prolonged egg incubation and larval development. If one examines Figures 4.2 and 2.2 (which describe the decline of red king crab), we see what looks like a K-selected species responding to disturbances within its ecosystem. However, red king crab have not returned to their former level as Figure 4.2 suggests a K-species would. This might very well be due to the continued presence of increased mortality (predation by crab predators, directed fishery, and bycatch) and previous or continued habitat destruction (either natural or anthropogenic or both), or perhaps because the carrying capacity of the environment for this species has changed.

We could use $\mathrm{r}$ and $\mathrm{K}$ in our approach to the red king crab fishery management in the following way. We suggest that the $\mathrm{r}$ - and K-continuum described previously (Fig. 4.1) be constructed for the Bering Sea ecosystem. Species that have been found to intersect with the crab life-history strategy should be included on this continuum. Especially important are species that have a large economic or existence value for man. Once this continuum framework is established, a fisheries manager will have a clear, simple view of the larger system. Management actions may be observed and/or predicted by the reactions of the measured species to these actions.

Previously, we suggested that red king crab may have patchy distribution. R-selected species are able to survive in a patchy distribution system in the face of disturbances better than $\mathrm{K}$-selected species because 


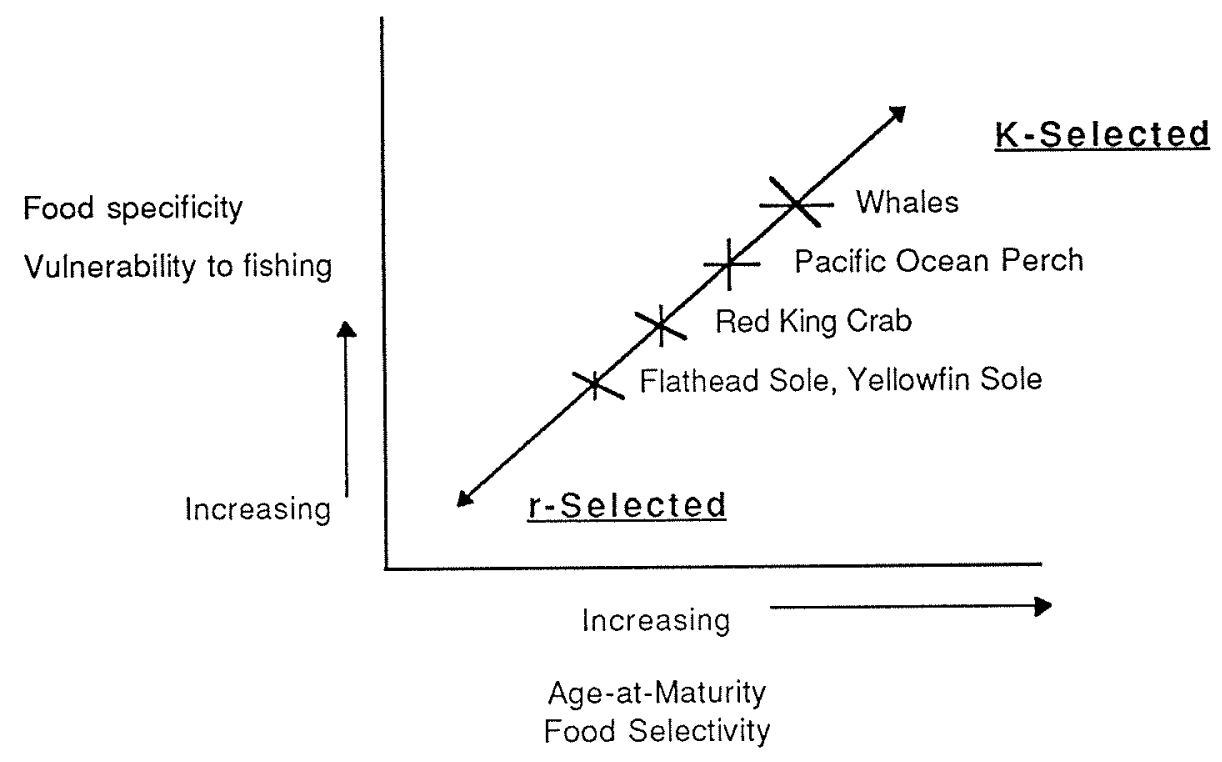

Figure 4.1. $\mathrm{r}$ - and K-selectivity continuum.

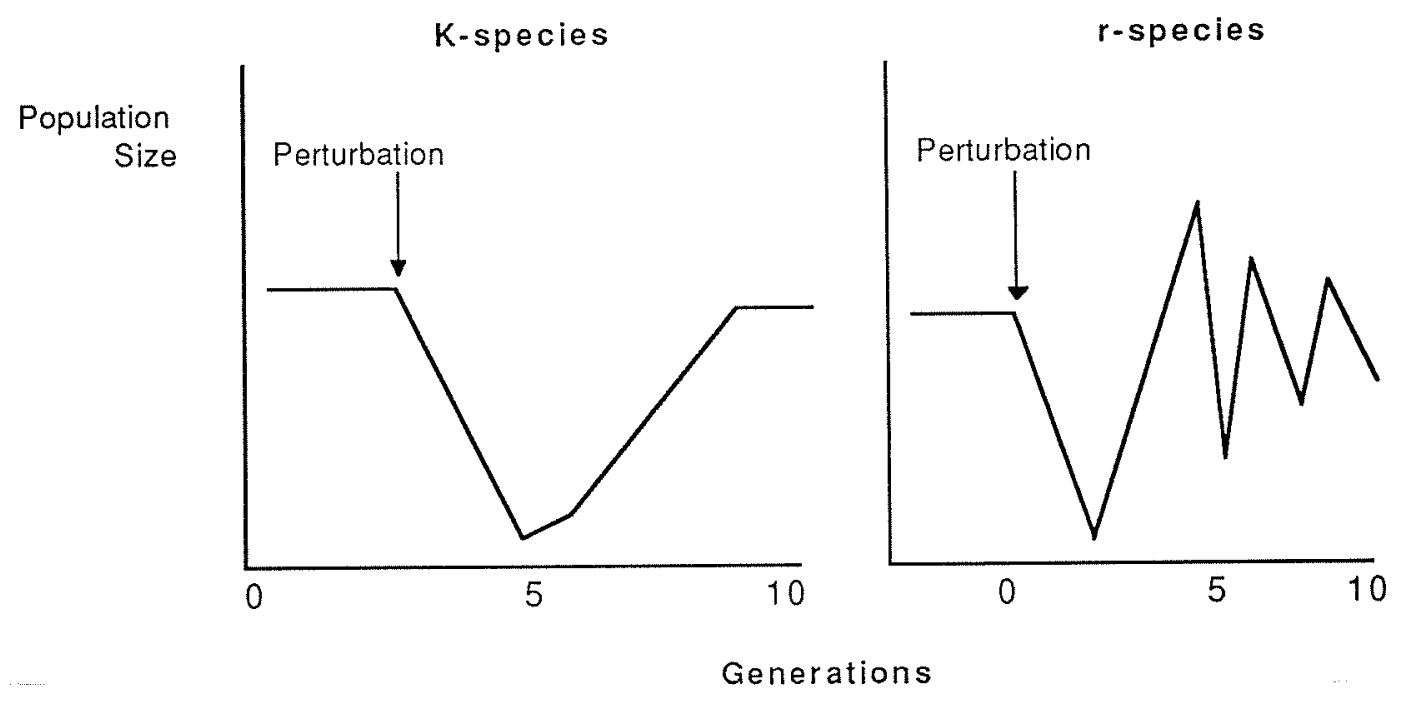

Figure 4.2. Generalized responses of K-selected and r-selected species to a single perturbation. Source: Apollonio (1994). 
of their life-history strategies: "The properties that enable populations to maintain themselves in patchy environments include high dispersal rates, tendencies to cross unsuitable habitats, high growth rates, early reproduction, and high reproductive rates [essentially r-selected species]" (CATE 1986). We infer that because red king crab may show more attributes of a K-selected species they may be more vulnerable to destabilization.

Perturbations in the environment can cause a species to shift position relative to its current location on the $\mathrm{r}$ - and K continuum. Apollonio (1994) goes on to describe the "restructuring [of] the unexploited [segment of the] population (usually through a reduction of average age) to a point where the optimum yield can be obtained by taking advantage of the more rapid growth capabilities of younger fish." He feels this would then shift a population more towards r-selectivity, increasing the uncertainty and variability of fluctuations in population size. This strategy must inevitably affect other life-history parameters of a species, such as age-at-maturity, fecundity, etc. In this shift toward r-selectivity, Apollonio (1994) describes an effect on recruitment of the species into a fishery:

\begin{abstract}
The recruitment problem is that the qualitative and quantitative natures of forces controlling each year class strengths are changing in a manner predictable from the initial character of a species or communities and also from the magnitude of fishing effort; that as long as fishing mortality [we would include excessive predation, habitat loss here] continues at an excessive level, the forces affecting recruitment make the stocks progressively less amenable to conventional management and progressively more vulnerable to the uncontrollable and largely unpredictable physical forces of the environment.
\end{abstract}

Historical and current management practices in the Bering Sea have been designed to target the older year classes of male red king crab. Mean size of crab did decrease during the early years of this fishery, though the tendency is for mean size to remain stable for long periods (B. Otto, NMFS, Kodiak, Alaska, pers. comm.). Anecdotally, some crabbers who fished during the 1970 s noted the lack of larger, older crab as the fishery progressed (B. Lamoreux, commercial fisher, Dutch Harbor, Alaska, pers. comm.). We suggest that this decline of red king crab size may be indicative of its K-selectivity and its response to fishing pressure. Current fishing practices in the Bering Sea could be preventing the crab from returning to a higher level of abundance.

Apollonio (1994), along with Adams (1980), states that "other species [K-selected species] are manageable by traditional methods and more importantly, are particularly vulnerable to fishing effort without management restraint." Apollonio (1994) goes on to say that "species may be destabilized in the sense of increasing their relative r-selectivity by the reduction of the numbers of year classes in the population." Red king crab may be described as having some attributes of a K-selected species in Table 4.1. Yellowfin sole, flathead sole, and arrowtooth flounder can be described as closer to r-selected along this continuum. During the late 1970s and early 1980s, several perturbations (El Niño, climate regime shift, and sustained massive fishing effort) apparently were pressuring the Bering Sea ecosystem. We suspect that these pressures (natural and anthropogenic) on red king crab may have driven them towards increased fluctuations of abundance. These events may have favored $\mathbf{r}$-selective flatfish communities, resulting in dramatic increases in population size. Of important note is the huge fishing effort for flatfish before the late 70s by foreign flagged vessels, whose effect on the environment can only be speculated.

Apollonio purports that knowledge of a species' overall life history will help determine the possible effects from natural environmental fluctuations and anthropogenic disturbances (fishing, habitat destruction, etc.). Establishing the continuum in the Bering Sea using the parameters of $\mathrm{r}$ - and K-selectivity, a species' 
relative position on this continuum for a species could "predict the relative response of the species within the hierarchy of the ecosystem, and thus, the extent to which it is a constraining or regulating force within the system, as a means of modulating fluctuations in the abundance of other species in the system" (Apollonio 1994).

In general, fishing strategy is designed to maximize production of individual species promoting a fishery that maximizes yield-per-recruit. This is contrary to natural evolution, which moves towards efficiency of resource use and a high ratio of biomass to production (Apollonio 1994). A high ratio of production to biomass is a component feature of $\mathrm{r}$-selected species. Thus, current fishing strategy may promote r-selectivity and be contrary to the natural selection processes of K-selected stocks.

The suggestions we offer for the decline of the red king crab described in earlier chapters will not be new to fishery managers working on the problem. In light of the complexity of the mechanisms behind the red king crab decline, we suggest that the $\mathrm{r}$ - and K-selectivity concept may provide management a critical tool. The $\mathrm{r}$ - and K-concept considers intersections of all components of the life history of red king crab. By controlling as many anthropogenic effects that intersect their life history as possible, we are performing a form of "ecosystem management." The paradigm of $\mathbf{r}$ - and K-species intersects all components of the life history of red king crab, their environment, and ultimately their ecosystem. An understanding of the $\mathrm{r}$ - and $\mathrm{K}$-species continuum in the Bering Sea may be a key component in attempting to understand, react to, and predict changes to a single species such as red king crab. By constructing the r- and K-continuum for the Bering Sea, a fishery manager may be able to predict a species' trends of abundance in the face of change and whether it is amenable to traditional management tools (Apollonio 1994).

Additional indices of the health of an ecosystem, like $\mathrm{r}$ - and $\mathrm{K}-$, may be developed for fisheries managers, allowing them to make decisions for a particular species. The Aleutian Low Pressure Index (W. Wooster, Univ. Washington School of Marine Affairs, Seattle, pers. comm.) and Length-of-Day index (D. Beamish, Pacific Biological Station, Nanaimo, British Columbia, pers. comm.) show promise as potential tools to describe recruitment success and species abundance, which could be useful for fisheries managers. These indices could be applied to ecosystems, allowing fisheries management to "(1) absorb specific scientific advice, (2) anticipate probable resource responses to fishing perturbations, (3) anticipate species interactions, and (4) anticipate the effects of management measures" (Apollonio 1994).

\section{The ECONOMICS of ByCATCH IN THE Red King CRAB FiSHERY}

In evaluating and structuring any ecosystem management plan, we feel it is necessary to examine the economic forces governing the actions of individuals involved, either directly or indirectly, in fisheries and other human activities affecting the ecosystem. In the case of the red king crab, management decisions in the form of open-access, derby-style, single-sex, and size-limited fishery may be responsible in part for preventing the crab populations from increasing in size. We focus our discussion and solution to low red king crab abundance on the bycatch of red king crab among both the target red king crab fishery and other fisheries, and other bottlenecks to crab life-history strategies that are directly related to human activity. We suggest that bycatch alone is a major source of continued pressure on these depleted stocks. Because there is opportunity for management control over some of the mechanisms promoting bycatch, there is the potential to rebuild the stocks. The economic concepts discussed in this section are meant to initiate a dialogue, not provide a detailed economic model of this problem nor the proposed solution. 
The economic and political realities of the fishing industry can limit the effectiveness of management plans, and ultimately the success of sustaining and restoring harvestable populations of red king crab. Our management plan considers economic incentives to prevent bycatch and to provide a safer and more efficient crab fishery. Through our ecosystem management approach, we hope to provide benefits for the fishing industry, management, and the natural environment. We define bycatch as incidental catch (retained catch of non-target species) and discarded catch (that portion of the catch returned to the sea as a result of economic, legal, or personal motivation) (Alverson et al. 1994). The current status of the stock of the red king crab has caused management to prohibit any directed fishing. Interactions of other fisheries (trawl fisheries, Tanner crab fishery) with the depressed red king crab stock have forced severe management restrictions in these fisheries as well.

A review by J. Terry (NMFS Alaska Fisheries Science Center, Seattle, unpubl. data) provides insight into the economics of bycatch and the forces at work. He states:

Experience and economic theory demonstrate that, in an open access fishery, each fisherman and processor has incentives to make decisions that are wrong from the perspective of the fleet and society as a whole...Knowing that the current management regime provides incentives to fisherman and processors that typically result in bycatch rates that are too high and utilization rates that are too low, ensures that there is potential for increasing net benefits to the Nation by decreasing bycatch and increasing the utilization of catch and bycatch. The challenge in taking advantage of that potential is to change the fishery management regime in a way that tends to assure that, for a Nation as whole, the benefits of decreasing bycatch and increasing utilization will exceed the costs.

Both increased input costs and decreased product value (benefits) support the bycatch rate in the current management plan (Table 4.2). These added costs and reduced benefits provide the reasons for including market forces into our management plan. We feel that market-oriented measures will provide the right incentives to reduce bycatch levels, which will ultimately benefit the fisher and the stock. S. Bibb and J. Terry (NMFS Alaska Fisheries Science Center, Seattle, unpubl. data) state:

It makes sense to reduce bycatch to its marginal cost point; i.e., when the cost of reducing bycatch even more is higher than the benefit received. This is the market equilibrium approach.

Table 4.2. Increased costs and decreased product value produced by the open-access crab fishery. Adapted from J. Terry (NMFS, unpubl, data).

\begin{tabular}{ll}
\hline Reasons for increased costs & Reasons for decreased product value (benefits) \\
\hline $\begin{array}{l}\text { Increased operating and capital costs for fishers and } \\
\text { processors }\end{array}$ & Decreased catch quotas \\
$\begin{array}{l}\text { Increased fishing mortality not associated with actual } \\
\text { landings (i.e., bycatch, high grading, and ghost fishing) } \\
\text { and the costs of ecosystem effects }\end{array}$ & Decreased utilization of catch \\
$\begin{array}{l}\text { Decreased safety } \\
\begin{array}{l}\text { Decreased stability for the industry and dependent } \\
\text { communities }\end{array}\end{array}$ & $\begin{array}{l}\text { Decreased product quality due to handling } \\
\text { random changes in consumption patterns and prices }\end{array}$ \\
$\begin{array}{l}\text { Increased costs to develop and implement management } \\
\text { actions to address allocation conflicts }\end{array}$ & $\begin{array}{l}\text { Decreased ability to take advantage of seasonal } \\
\text { differences in product quality }\end{array}$ \\
\hline
\end{tabular}


We suggest that the use individual transferable quotas and increased utilization of the captured crab will provide an economic incentive to reduce bycatch as well as sustain a healthier stock for a particular level of harvest.

\section{INDIVIDUAL TRANSFERABLE QUOTAS AND INCREASED UTILIZATION OF RED KING CRAB}

Marasco and Terry (1982) have suggested that the groundfish fishery's incidental catch of prohibited species (including crab) "tends to reduce the harvests of the domestic halibut, salmon and crab fisheries." We speculate that bycatch in the crab fishery itself reduces the potential harvest levels for red king crab and reduces potential economic and biological gains for the fleet and the stocks. Individual transferable quotas (ITQs) and increased utilization (IU) could benefit the stock of red crab and the fishery itself. The basic presumptions of an ITQ system is the ability to set a quota at a level that coincides with sustainable harvest of a stock and at a level on its growth function curve representing rapid growth in its population.

ITQs also promote increased economic yield for a fishery by eliminating marginal producers and reducing overall production cost at the same level of harvest. ITQs (Table 4.3) possess a number of advantages and disadvantages. IU of red king crab (outlined in Table 4.4) may reduce bycatch levels within the crab fishery, ultimately reducing costs to the fishers.

Open access and the current management system for red king crab has created a derby-style fishery and an overcapitalized fleet. These two factors promote very high bycatch levels in the directed fishery. The

Table 4.3. Advantages and disadvantages of individual transferable quotas to reduce bycatch. Adapted from S. Bibb and J. Terry (NPFMC, unpubl. data).

\begin{tabular}{|c|c|}
\hline Appeal of market-oriented measures & Disadvantages to market-oriented measures \\
\hline $\begin{array}{l}\text { It has the potential for eliminating the source of the problem } \\
\text { (the externalities). }\end{array}$ & $\begin{array}{l}\text { The individual accountability of a market solution exists only } \\
\text { if there is adequate monitoring and adequate monitoring may } \\
\text { require a substantial increase in enforcement costs. }\end{array}$ \\
\hline $\begin{array}{l}\text { If catch, including bycatch, is monitored adequately, the } \\
\text { loopholes that exist with many regulatory measures are } \\
\text { eliminated. }\end{array}$ & $\begin{array}{l}\text { The allocation issues associated with the development of } \\
\text { market-oriented measures can be difficult to overcome. }\end{array}$ \\
\hline $\begin{array}{l}\text { It provides flexible incentives that tend to reflect } \\
\text { automatically changes in market conditions. }\end{array}$ & $\begin{array}{l}\text { The use of the market mechanism does not ensure an efficient } \\
\text { allocation of resources, particularly if sources of market } \\
\text { failure are not corrected for. }\end{array}$ \\
\hline \multicolumn{2}{|l|}{$\begin{array}{l}\text { It provides fishers and processors with the greatest range of } \\
\text { options for meeting the desired objective and, as such, it } \\
\text { allows the objective to be met at the lowest cost. }\end{array}$} \\
\hline \multicolumn{2}{|l|}{$\begin{array}{l}\text { It requires less information on the part of fishery management } \\
\text { decision makers and takes advantage of the knowledge of } \\
\text { fishers and processors concerning ways to decrease bycatch, } \\
\text { discards, and utilization. }\end{array}$} \\
\hline $\begin{array}{l}\text { Individual fishers and processors are held accountable for } \\
\text { their actions in that they pay for the fishery resources they } \\
\text { use. Therefore, for example, fishers with low bycatch rates } \\
\text { would not be subject to a fishery closure due to high bycatch } \\
\text { rates by other fishers. }\end{array}$ & \\
\hline
\end{tabular}


Table 4.4. Increased utilization of red king crab stocks under the critical intersections approach to this fishery.

\begin{tabular}{ll}
\hline $\begin{array}{l}\text { Utilization under current fisheries management } \\
\text { plan }\end{array}$ & $\begin{array}{l}\text { Increased utilization under proposed Critical } \\
\text { Intersections Approach }\end{array}$ \\
\hline All male fishery & Male and female fishery \\
Discard females and sub-legal males & Discard all sub-legal \\
Size limits & Size limits \\
male $\geq 6.5$-in carapace width (135 mm carapace length) & male $\geq 6.0$-in carapace width (120 mm carapace length) \\
female-all discarded & female $\geq 6.0$-in carapace width (120 mm carapace length) \\
\hline
\end{tabular}

rate of bycatch in the fishery may be detrimental to both the stock and the profit margin of the fleet. As reported by S. Hughes (United Catcher Boats, Seattle) in a letter to the NPFMC, it is estimated that 7.5 million crab were captured in 1993, including legal males, sub-legal males and females. Of this total, an estimated 5.5 million were sub-legal male and female crab and were discarded-nearly $75 \%$ of the total harvest. Because of the high rate of bycatch, even low levels of mortality associated with discarded crab could substantially affect the recovery of the crab population. Currently, there is no estimate of discard mortality used in measuring incidental take. An estimate of $20 \%$ mortality would have resulted in 1.1 million crab removed from the standing stock. Given the estimated crab population in 1993 of 47.5 million, this mortality rate would have represented $2.3 \%$ of the entire population.

The logic of instilling ITQs and promoting a rebuilding of the stock is to increase catch-per-unit-effort (CPUE). Higher levels of CPUE should allow the same level of harvest at a lower level of effort and lead to less bycatch. ITQs would also work to eliminate derby-style fishing, allowing the crab fleet to harvest the stock in the most efficient manner. ITQs would promote longer soak time, allowing crab pots to "sort" for larger crab, hence reducing discard of small and female crab, and reducing sorting time and costs on the catcher vessel. Both open access (derby-style) fishing and pot limits on crab boats encourage fishing vessel operations to use very short soak times (fishers are simply responding rationally to limited opportunities offered by current management plans). The fishing season length is predictable and longer with ITQs; therefore, individual skippers will be able to slow down operations, promoting longer soak times and higher search efforts for target crab. Longer soak times will reduce the on-deck sorting effort and hence reduce the average cost-per-pound crab. Furthermore, ITQs provide an incentive to design different pots that will allow non-target crab to escape and encourage fishers to move to different grounds when the catch of non-target crab is high.

IU in the red king crab fishery will, we feel, strengthen the potential benefits of ITQs. IU refers to lowering the legal size limit and allowing female crab to be retained. Increasing the utilization of crab likely will decrease the proportion of crab discarded, and thus the incidental mortality, while at the same time utilizing some of the harvest that would otherwise have been discarded and died. We propose retention of all crab with a carapace width of $\geq 6.0$ in (which equates to 122 -mm carapace length; see Table 4.4). P. Hill (Univ. Washington School of Marine Affairs, Seattle, unpubl. data) reports that if this IU plan had been in effect during the 1993 season, there could have been a $30 \%$ reduction of effort with the same level of revenue generated. This reduction of effort would have also equated to $>2.0$ million less crab affected by crab fishing gear. Furthermore, this will utilize a larger size range of male crab and bring females into the fishery. A survey of crab industry representatives revealed mixed opinions regarding the acceptability of IU (P. Hill, Univ. Washington School of Marine Affairs, Seattle, unpubl. data). However, it seems the 
small reduction in legal size should not depress the price for currently legal sizes. As meat quality is not affected by size or sex of the crab, the smaller crab should easily be incorporated into the market. We suggest that this IU program is an economically viable alternative for the fishers in the red king crab fishery. Coupled with ITQs, this IU program would also promote longer soak times and allow the gear to operate as it was designed-to reduce bycatch of non-target crab.

Our review of the life history of the red king crab, the current derby-style management of the fishery, and the natural perturbations of the environment have led us to the conclusion that a management plan for the red king crab should include the application of ITQs and IU. We specifically describe this plan in Chapter 5. The economic benefits of these plans are based on market mechanisms that have been described in detail (J. Terry and S. Bibb, NMFS Alaska Fisheries Science Center, Seattle, unpubl. data). Though these market mechanisms may not ensure an efficient or equitable allocation of the resource among all user groups, we feel these mechanisms are better than the current structure, which does not adequately use market forces (J. Terry, NMFS Alaska Fisheries Science Center, Seattle, unpubl. data).

\section{CONCLUSION}

The situation in the Bering Sea red king crab fishery encompasses both environmental and anthropogenic effects (fishing, habitat destruction, disturbance of natural balance). Can we use an ecosystem management model to improve our ability to monitor the stocks and increase the recruitment for the fisheries without further negatively affecting the stock? Can we, in fact, mitigate the negative anthropogenic externalities and provide a more suitable environment, increasing stock size? In this paper, we have presented evidence suggesting (1) anthropogenic forces intersecting the biology of the red king crab may be detrimentally affecting the recruitment to the fishery, (2) the inherent variability of the environment, (3) changes in the abundance of species in the recent history of the Bering Sea that may be considered a restructuring, and (4) the inadequacy of the current management scheme for red king crab. Our ecosystem management plan includes (1) managing anthropogenic activities within the ecosystem of the Bering Sea intersection points in red king crab life history, (2) attempting to deal with the increased presence of red king crab predators, and (3) conducting extensive scientific research into environmental forcing functions and crab life history.

The economics of fishing activities and the uncertainty in the natural environment must be the foundation of a management structure that regulates this fishery. There must be a paradigmatic shift in the current management structure in order to adopt the ecosystem approach we propose. This new management plan must be actively adaptive if an error is detected, and the political will must be present to wait for results that may not be seen for decades. Our resolution in Chapter 5 details an experimental design where critical anthropogenic intersections in red king crab life history are controlled. Once a management plan is designed that encompasses this concept, long-term monitoring of the effects must begin. Mistakes will be made, but the ability to adjust the plan and learn from these mistakes will be essential to the success of the program. 


\section{CHAPTER 5. THE RESOLUTION}

Discovering the reason behind the collapse of the red king crab is beyond the purview of this paper. There were likely a number of causes and we have touched on a number of viable possibilities. By looking at the present state of the entire system (the crab stock, habitat, current management of the crab, other fisheries, other species, and environment), we can then propose management of certain aspects in order to sustain a red king crab fishery. We suggest that intersections in critical aspects of red king crab life history, by a variety of natural and anthropogenic forces, have negatively affected the stock in the Bering Sea. Data that quantify historical habitat characteristics and the effects of human activity upon them are clearly inadequate. However, in light of the current scientific uncertainties, our resolution attempts to offer guidance towards systems learning and provides for incorporating the critical intersections approach into management.

When the king crab fishery was in its heyday and huge numbers of crab were being caught, subtle environmental changes appear to have been occurring. In addition, it appears that environmental changes along with years of intensive trawling may have combined to change the eastern Bering Sea ecosystem into a less spatially complex habitat (from the perspective of the individual crab) where species such as flatfish and starfish thrive. The currently high abundance of these species, along with sockeye salmon, $\mathrm{Pa}$ cific cod, skates, sculpin, and pollock (just to name a few), presents a formidable barrier to the crab during various stages of its life history.

Taking the whole life history of the crab into account, we have discovered numerous poorly understood intersections with other species (with highly differentiated commercial values) and potentially vital habitat areas in need of either preservation or rebuilding. We feel that protecting settlement and juvenile habitat may be a key to rebuilding the stock. In addition, the current management regime appears to inflict negative impacts on the crab, while creating an inefficient fishery for the fishers. Experimental design is an integral part of the critical intersections approach. In order for management to adapt to successes or failures in a scheme, they must be able to discern which mechanisms have worked and which have failed. In designing our resolution, we have incorporated different strategies in adjacent areas in order to facilitate active adaptive management. Our resolution is a sixfold approach that attempts to address all the major problems we have presented.

1. Establish nearshore trawl management zones that encompass the prime settlement and juvenile crab habitat. Given sufficient time, lower human impact (trawl restrictions) should allow any prefishing biogenic structure in these nursery areas to return, providing young crab a source of food and protection from predators. Additionally, flatfish and predatory fish abundance may be expected to change in the presence or absence of fishing pressure.

We have designated three nearshore zones containing what appears to be the most suitable juvenile habitat (Fig. 5.1). Included in the designated zones are migration corridors that lead from the nursery areas to the deeper adult no-trawl preserve. Restricted trawling within the corridors will afford sub-adult crab a means to migrate to the adult preserve without being susceptible to trawl gear. We propose that trawling be completely closed in Zone A, restricted in Zone B (restrictions could include gear restrictions, time/area closures, etc.) and allowed in Zone C. This will establish 


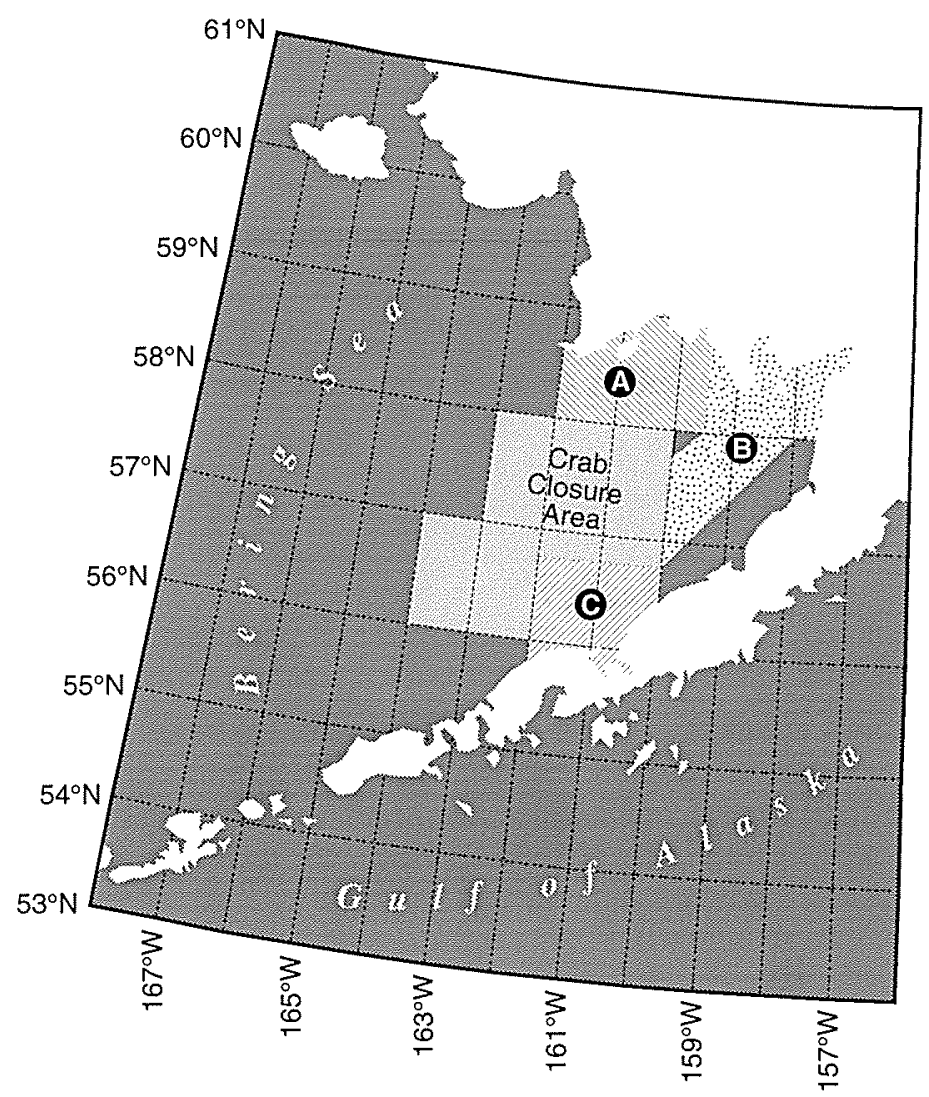

Figure 5.1. Proposed no-trawl zones. The "adult refuge" roughly corresponds to the previous no-trawl area to protect breeding adults. The three "zones" provide refuge for settlement areas and for juveniles migrating from these sites to adult habitat. Zone A: area between $162^{\circ}-159^{\circ} 30^{\circ} \mathrm{W}$ and north of $58^{\circ} \mathrm{N}$. Zone B: area east of $159^{\circ} 30^{\prime} \mathrm{W}$ and north of $58^{\circ} \mathrm{N}$ and the area between the following points, connected by straight lines: $\left(58^{\circ} \mathrm{N} 159^{\circ} 30^{\prime} \mathrm{W}\right.$ and $\left.57^{\circ} 45^{\prime} \mathrm{N} 160^{\circ} 00^{\prime} \mathrm{W}\right)\left(58^{\circ} \mathrm{N} 158^{\circ} 00^{\prime} \mathrm{W}\right.$ and $56^{\circ} 45^{\prime} \mathrm{N}$ $\left.160^{\circ} 00^{\prime} \mathrm{W}\right)$. Zone $C$ : an area from land between $160^{\circ}-162^{\circ} \mathrm{W}$ and north to $56^{\circ} 45^{\prime} \mathrm{N}$. Crab closure area: between $164^{\circ}-162^{\circ} \mathrm{W}$ and $57^{\circ}-56^{\circ} 45^{\prime} \mathrm{N}$, and between $163^{\circ}-160^{\circ} \mathrm{W}$ and $56^{\circ} 45^{\prime}-58^{\circ} \mathrm{N}$.

different trawl effort levels in each zone. These can then be compared with indices of predator and juvenile abundance, as well as epifaunal community recovery, in order to quantify whether or not the restrictive measures are actually enhancing juvenile survivorship and delivery to later year-classes. It is pertinent to note that our proposed closures may be no more restrictive than other current plans. The North Pacific Fishery Management Council's proposed "North Bristol Bay" closure area roughly corresponds to our Zone A, and overlaps Zone B. Furthermore, we would allow trawling on the southern shelf of their "Crab Protection Zone 1" in order to combine management with a potential for better scientific understanding and accountability.

2. Establish an adult no-trawl preserve to protect the majority of the population from trawl gear. The preserve will encompass the crab's center of abundance along with the breeding and molting areas. This adult preserve would encompass the NPFMC Crab Protection Zone 1 and the Red King Crab Savings Area. All forms of bottom trawling would be excluded from this area.

3. Certain fishing operations should be allowed to occur, and in fact would be encouraged, in the resolution areas. Our intent is to allow operations that will reduce crab predator numbers while having as little direct impact as possible on crab stocks and the substrate. Research and develop- 
ment of new gear for capturing flatfish while safeguarding juvenile crab stocks and their habitat should be a priority.

In the adult preserve, longlining and pot fishing should be allowed, except during crab molting and breeding, in order to minimize potential impacts on the crab stock. Midwater trawling should be restricted during the crab fishing season to minimize gear conflicts, though it could occur during molting and breeding seasons. We acknowledge that new restrictions on bottomfishing could result in an initial increase in the abundance of potentially predatory fishes. However, we believe that the impacts of this initial increase will be offset by increased refuge habitat for juvenile crab, ultimately resulting in lower predation rates and increased crab recruitment.

In the juvenile preserve zones, we propose allowing the same operations. However, as we consider these areas the most important for young crab, extreme care must be taken to avoid impacting the bottom community in any way. Our goal is to allow regeneration of the biogenic structure as best as possible. Trawling in the zones adjacent to the corridors is highly encouraged in order to regulate the predator populations. However, vessels operating in these adjacent waters must have $100 \%$ observer coverage to assure no bottom trawling is conducted in regulated critical habitat areas.

4. Establish ITQs for the crab fishery. This market-based incentive program is proposed as a way of eliminating the current derby-style fishery, typical in an open access system, while reducing the level of bycatch. In theory, establishing property rights through ITQs will remove marginal producers and encourage the fisher to operate in the most economical fashion. The elimination of this derby-style of fishery is, by far, the single biggest improvement for both the fishery and the stock under ITQs. ITQs will allow fishers to pick when, within the established season, to fish. This should lead to safer working conditions for the crabbers since they can choose to stop fishing and seek shelter when weather conditions deteriorate. We have lost too many lives in this fishery over its history and hope that the ITQ program will increase the overall safety.

The elimination of the derby-style fishery also promotes longer soak times, which will allow a majority of the smallest crab to escape. New pot designs that encourage escapement of non-target (pre-reproductive) crab, combined with longer soak times, should prove beneficial. The fishers will spend less time sorting crab since the catches will contain a lower proportion of non-target crab. Thus, overall fishing costs may decrease with less bycatch. Again, ITQs require $100 \%$ observer coverage to be effective. Furthermore, it is beyond the purview of this paper to decide the manner in which the ITQ permits would initially be allocated. However, the perceived equity of the initial allocation will determine the political acceptability and, thus, the overall success of the program.

5. Establish mandatory increased utilization (IU) of crab caught in the fishery to reduce bycatch. We advocate an IU strategy that encompasses harvesting a wider size range of crab as well as a dualsex fishery. Earlier, we discussed our concerns about harvesting only larger males, including reduced average fecundity of remaining males and genetic effects of moving the breeding population towards a smaller overall size. Further, it appears that fishing only males may create inappropriate sex ratios, the various ramifications of which were also discussed earlier. Evidence suggests that maintaining size and sex ratios closer to the natural condition could increase the overall fecundity and genetic fitness of the stock, as well as increase fishery yields by opening to exploitation a portion of the population that may not serve any function in increasing stock biomass. 
The mechanisms for achieving this goal are as follows: (1) reduce the size limit, (2) allow retention of female crab, and (3) modify the gear. Reducing the minimum size will allow a broader size range of mature males to be retained and will bring a portion of the mature female population into the fishery. We suggest decreasing the minimum legal size to a 6-in carapace width $(\sim 122$ $\mathrm{mm}$ in length). In an analysis of the 1993 fishery (P. Hill, Univ. Washington School of Marine Affairs, Seattle, unpubl. data), and assuming a constant ex-vessel price per pound, this .5-in reduction in legal size and retention of females could lead to a $30 \%$ reduction in effort, while achieving the same amount of total revenue generated by the fishery. Assuming a constant CPUE, a $30 \%$ reduction in effort would equate to nearly 2.25 million crab not being directly affected by the crab fishery. A small relative decrease in legal size (such as the .5 in we suggest) may minimally depress the price for currently legal sizes by adding smaller crab to the market. In addition, the processing industry should not oppose the lower legal size owing to their fear of increased processing costs or difficulties in processing smaller crab. Gear modification, in conjunction with an ITQ program, will promote longer soak times and lead to a substantial decrease in bycatch of sub-legal crab. Overall, the program should allow fishers access to crab for the duration of the season and greater availability of fresh crab to consumers.

Increasing the utilization will lead to a greater availability fishable stock. We do not propose increasing the level of the quota (guideline harvest level, GHL). The harvest strategy of setting the GHL to $20 \%$ of the mature male stock will still hold, though under our proposal it will be easier to ascertain the actual exploitation levels on mature males since the vast majority will be retained. This will greatly reduce the unknown proportion of the mature male stock (those smaller mature males) that are discarded each year and die owing to handling mortality. In addition, maintaining a threshold level for females to open the fishery will still be in effect to ensure adequate levels of protection to the female spawning stock.

For IU to be more effective at reducing bycatch and increasing the long-term productivity of the fishery, it must be implemented with an ITQ program to eliminate the derby-style fishery. Retention of all crab above the minimum legal size must be mandatory, as without mandatory retention smaller size classes of crab will likely be discarded. This will require 100\% observer coverage so that high-grading and quota busting do not occur.

6. Integrate a research program into the management scheme. When creating a management plan, all the essential data are rarely available, yet there is the need to take action. During this process, learning occurs where our understanding is lacking, providing the impetus for new research. Thus, management planning must be integrated with research. In our proposal, we advocate a research program to address five major areas of concern: (1) the importance of crab larval supply on fishery recruitment, (2) the impact of benthic predator communities on crab survival, (3) the effectiveness of no-trawl zones in aiding habitat recovery, (4) the importance of bycatch as a source of crab mortality, and (5) the effect of behavior and genetics on overall fecundity. At this point, we feel it would be beyond the scope of our report to outline specific research plans and protocols.

In general, we consider it important to track cohorts through time in order to determine where potential bottlenecks to recruitment may occur. With such monitoring, it may be determined which actions can be taken to ameliorate such impacts. The concept of "time" is an important one in this context. The appropriate time scale for management actions will depend upon the system being managed. In this case, we must afford time for the benthic communities to rebuild or we will never know the effectiveness of our measures. It will be desirable to track the survival of a 
number of cohorts at least to sexual maturity, if not into the fishery. In this case, perhaps a decade of consistent management and monitoring would be required to gain any understanding of what has been done. It is important to realize that an initial lack of effect does not necessarily mean a failure of the measures, nor is an immediate change necessarily the result of the measures imposed. Only through consistent monitoring can we accurately assess the effectiveness of the designed management program. Given the existing uncertainties, monitoring and feedback of our resolution is crucial and will ensure the long-term viability of our plan.

A common argument against comprehensive study is that cost will be prohibitive. In this case, we disagree. Most of the study that would be required is either already a priority or is fairly unsophisticated. Clearly, bycatch mortality is already receiving attention. Likewise, NMFS routinely conducts trawl surveys in this region. Some new protocols (such as smaller net designs and plankton tows) may be required to obtain the desired data, but certainly not sweeping changes. Other work, such as diet studies on non-target species and analyses of epibenthic species coverage, is simple enough to conduct such that highly paid specialists and expensive facilities are not required. At the risk of being blunt, much of this could be effectively done by graduate students, who are relatively inexpensive. It seems plausible that given some incentive and modest support, researchers, ecologists, and graduate students already working in the region would be willing to examine some of these problems. We simply need to refocus existing effort on some of these specific problems. 


\section{BIBLIOGRAPHY}

Ackley, D., C. Blackburn, K. Brix, D. Clausen, J. DiCosimo, R. Ferrero, L. Fritz, A. Grossman, J. Heifetz, P. Livingston, L.-L. Low, R. Merrick, E. Varosi, and D. Witherell. 1994. Ecosystem considerations-1995. Compiled by the plan teams for the groundfish fisheries of the Bering Sea, Aleutian Islands, and Gulf of Alaska. North Pacific Fisheries Management Council, Anchorage, Alaska.

Adams, P.B. 1980. Life history patterns in marine fishes and their consequences for fisheries management. Fish Bull. U.S. $78(1): 1-12$

Alaska Department of Fish and Game. 1994. Annual management report for the shellfish fisheries of westward region, 1993. Regional Inf. Rep. No. 4K94-29.

Alverson, D.L., M.L. Freeburg, S.A. Murawski, and J.H. Pope. 1994. A global assessment of fisheries bycatch and discards. FAO Fisheries Technical Paper 339. Food and Agriculture Organization of the United Nations, Rome.

Apollonio, S. 1994. The use of ecosystem characteristics in fisheries management. Rev. Fish. Sci. 2:157-180.

Armstrong, D.A., L.S. Incze, D.L. Wencker, and J.J. Armstrong. 1981. Distribution and abundance of decapod crustacean larvae in the southeastern Bering Sea with emphasis on commercial species. US Dep. Commerce, NOAA, OCSEAP Final Rep. 53(1986):481-878. Anchorage, Alaska.

Armstrong, D.A., T.C. Wainright, G.C. Jensen, P.A. Dinnel, and H.B. Anderson. 1993. Taking refuge from bycatch issues: red king crab (Paralithodes camtschaticus) and trawl fisheries in the eastern Bering Sea. Can. J. Fish. Aquat. Sci. 50:19932000 .

Bailey, R. 1982. Relationship between catches of snow crab, C. opilio (O. fabricus), and abundance of cod (Gadus morhua L.) in the southwestern Gulf of St. Lawrence. Pages 485-520 in B.R. Melteff (coordinator), Proceedings of the International Symposium on the Genus Chioneocetes, Fairbanks, Alaska, May 3-6, 1982. Univ. Alaska Sea Grant Program, Rep. 82-10.

Bakkala, R.G. 1993. Structure and historical changes in the groundfish complex of the eastern Bering Sea. US Dep. Commerce, NOAA Tech. Rep. NMFS 114. Springfield, Virginia.

Barshaw D.E. and K.L. Lavalli. 1988. Predation upon postlarval lobsters Homarus americanus by cunners Tautogolabrus adspersus and mud crabs Neopanope sayi on three different substrates: eelgrass, mud and rocks. Mar. Ecol. Prog. Ser. 48:119-123.

Baumgartner, T.R., A. Soutar, and V. Ferriera-Bartrina. 1992. Reconstructions of the history of Pacific sardine and northern anchovy populations over the past two millennia from sediments of the Santa Barbara Basin, California. CalCOFI Rep. $33: 24-40$.

Beers, D. 1991. A summary of data contained in the mandatory crab observer database. Alaska Dep. Fish and Game. Reg. Info. Rep. 4K91-14. Kodiak, Alaska.

Berrill, M. and R. Stewart. 1973. Tunnel digging in mud by newly settled American lobster, Homarus americanus. J. Fish. Res. Board Can. 30:285-287.

Botero, L. and J. Atema. 1982. Behavior and substrate selection during larval settling in the lobster Homarus americanus. J. Crust. Biol. 2:59-69.

Brodeur, R.D. and D.M. Ware. 1992. Long-term variability in zooplankton biomass in the subarctic Pacific Ocean. Fish. Oceanogr. 1:32-38.

Brodeur, R.D. and P.A. Livingston. 1988. Food habits and diet overlap of various eastern Bering Sea fishes. US Dep. Commerce, NOAA Tech. Memo. NMFS-F/NWC-127. Seattle, Washington.

Caddy, J.F. 1973. Underwater observations on tracks of dredges and trawIs and some effects of dredging on a scallop ground. J. Fish. Res. Board Can. 12:139-156.

Choat, J.H. 1982. Fish feeding and the structure of benthic communities in temperate waters. Ann. Rev. Ecol. Syst. 13:423-449.

Coachman, L.K. 1986. Circulation, water masses, and fluxes on the southeastern Bering Sea shelf. Pages 23-108 in D.W. Hood (ed.), Processes and Resources of the eastern Bering Sea shelf. Continental Shelf Research, Vol 5. Pergamon Press, Oxford.

Cobb, J.S., T. Gulbanson, B.F. Phillips, D. Wang, and M. Syslo. 1983. Behavior and distribution of larval and early juvenile Homarus americanus. Can. J. Fish. Aquat. Sci. 40:2184-2188. 
Committee on the Applications of Ecological Theory to Environmental Problems. 1986. Ecological knowledge and environmental problem-solving: Concepts and case studies. National Academy Press, Washington, D.C.

Dawson, E.W. and J.C. Yaldwyn. 1985. King crabs of the world or the world of king crabs: an overview of identity and distribution-with illustrated diagnostic keys to the genera of the Lithodidae and to the species of Lithodes. Pages 167-185 in B.R. Melteff (coordinator), Proceedings of the International King Crab Symposium, Anchorage, Alaska, January 22-24, 1985. Univ. Alaska, Anchorage.

Dayton, P.K. and R.R. Hessler. 1972. Role of biological disturbance in maintaining diversity in the deep sea. Deep Sea Res. 19:199-208.

deGroot, S.J. 1984. The impact of bottom trawling on benthic fauna of the North Sea. Ocean Mgmt. 9:177-190.

Dew, C.B. 1990. Behavioral ecology of podding red king crab, Paralithodes camtschatica. Can. J. Fish. Aquat. Sci. 47:19441958.

Dickie, L.M. 1973. Management of fisheries: ecological subsystems. Trans. Am. Fish. Soc. 102(2):470-480.

Donaldson, W.E., S. Beyersdorfer, D. Pengilly, and F. Blau. 1992. Growth of red king crab, Paralithodes camtschaticus (Tilesius, 1815), in artificial habitat collectors at Kodiak, Alaska. J. Shellfish Res. 11:85-89.

Dudnik, Y.I. and E.A. Usol'tsev. 1968. The herrings of the eastern part of the Bering Sea. Pages 236-240 in Soviet Fisheries Investigations in the Northeast Pacific, part 2. (Translated from Russian by the Israel Program for Scientific Translations.) US Dep. Commerce, Springfield, VA, 1968.

Feder, H.M. and S.C. Jewett. 1978. A survey of the epifaunal invertebrates of the southeastern Bering Sea with notes on the feeding biology of selected species. IMS Rep. R78-5, Inst. Marine Science, Univ. Alaska, Fairbanks.

Francis, R.C. and S.R. Hare. 1994. Decadal-scale regime shifts in the large marine ecosystems of the Northeast Pacific: a case for historical science. Fish. Oceanogr. 3-4:279-291.

Gilinsky, E. 1984. The role of fish predation and spatial heterogeneity in determining benthic community structure. Ecology 65:445-468.

Goddard, P. and M. Zimmerman. 1993. Distribution, abundance, and biological characteristics of groundfish in the eastern Bering Sea based on results of the U.S. bottom trawl survey during June-September 1991. US Dep. Commerce, NOAA, NMFS, AFSC Processed Rep. 93-15. Seattle, Washington.

Graham, M. 1955. Effect of trawling on the animals of the sea bed. Pages 1-6 in Papers in Marine Biology and Oceanography. Deep-Sea Res. (Suppl.) 3:1-6.

Grumbine, R.E. 1994. What is ecosystem management? Cons. Biol. 8:27-38

Hayes, M.L. 1983. Variation in the abundance of crab and shrimp with some hypothesis on its relationship to environmental causes. Pages 86-101 in W.S. Wooster (ed.), From Year to Year. Washington Sea Grant Program, Seattle.

Hollowed, A.B. and W.S. Wooster. 1992. Variability of winter ocean conditions and strong year classes of Northeast Pacific groundfish. ICES Mar. Sci. Symp. 195:433-444.

Hood, D.W. and J.A. Calder (eds.). 1981. The Eastern Bering Sea shelf: Oceanography and Resources. Volume 1. US Dep. Commerce, NOAA. Univ. Washington Press, Seattle.

Hood, D.W. 1983. The Bering Sea. Pages 337-373 in B.H. Ketchum (ed.), Estuaries and Enclosed Seas. Elsevier, Amsterdam.

Hsu, C.C. 1987. Spatial and temporal distribution patterns of female red king crabs in the southeastern Bering Sea. Ph.D. dissertation. Univ. Washington School of Fisheries, Seattle.

Hulpert, C.L. 1993. How adaptive is adaptive management? Implementing adaptive management Washington State and British Columbia. Rev. Fish. Sci. 1(3):261-283

Jensen, G.C. and D.A. Armstrong. 1989. Biennial reproductive cycle of blue king crab, Paralithodes platypus, at the Pribilof Islands, Alaska and comparison to a congener, Paralithodes camtschatica. Can. J. Fish. Aquat. Sci. 46:932-940.

Jewett, S.C. 1982. Predation on crabs of the genus Chioneocetes: a literature review. Pages 521-538 in B.R. Melteff (coordinator), Proceedings of the International Symposium on the Genus Chioneocetes, Fairbanks, Alaska, May 3-6, 1982. Univ. Alaska Sea Grant Program, Rep. 82-10.

Jones, R. and J.R.G. Hislop. 1978. Changes in North Sea haddock and whiting. Rapp. Proc. Verg. Res. Cons. Perm. Int. Expl. Mer. 172:58-71

Kaiser, M.J. and B.E. Spencer. 1993. Opportunistic predation on benthos around trawl tracks by gurnards and lesser spotted dogfish. J. Fish. Biol. 43(Suppl. A):327-328. 
Kamba, M. 1977. Feeding habits and vertical distribution of walleye pollock, Theragra chalcogramma (PALLAS), in early life stage in Uchiura Bay, Hokkaido. Pages 175-197 in Fisheries Biological Production in the Subarctic Pacific Region. Research Institute of North Pacific Fisheries, Hokkaido University, Hakodate, Japan.

Karinen, J.F. 1985. Occurrence of juvenile king crab, Paralithodes camtschatica (Tilesius), in Auke Bay, Alaska, on sediments with relatively high concentrations of aromatic hydrocarbons. Pages 377-388 in B.R. Melteff (coordinator), Proceedings of the International King Crab Symposium, Anchorage, Alaska, January 1985. Univ. Alaska.

Kinder, T.H. and J.D. Schumacher. 1981. Circulation over the continental shelf of the southeastern Bering Sea. In Hood, D.W. and J.A. Calder (eds.), The Eastern Bering Sea shelf: Oceanography and Resources, Vol. 1. US Dep. Commerce, NOAA. Univ. Washington Press, Seattle.

Kruse, G.H. 1993. Biological perspectives on crab management in Alaska. Pages 355-383 in Management of Exploited Fish. Alaska Sea Grant Program.

Kruse, G.H. 1994. King and Tanner crab research in Alaska: Annual Report for July 1, 1993 through June 30, 1994. Alaska Dep. Fish and Game, Juneau.

Lavalli, K.L. and D.E. Barshaw. 1986. Burrows protect postlarval lobsters Homarus americanus from predation by the nonburrowing cunner Tautogolabrus adspersus, but not from the burrowing mud crab Neopanope texani. Mar. Ecol. Progr. Ser. 32:13-16.

Lee, K.N. 1993. Compass and Gyroscope: Integrating Science and Politics for the Environment. Island Press, Washington, DC.

Livingston, P.A. 1993. Importance of predation by groundfish, marine mammals and birds on walleye pollock Theragra chalcogramma and Pacific herring Clupea pallasi in the eastern Bering Sea. Mar. Ecol. Progr. Ser. 102:205-215.

Livingston, P.A., A. Ward, G.M. Lang, and M-S. Yang. 1993. Groundfish food habits and predation on commercially important prey species in the eastern Bering Sea from 1987 to 1989. NOAA Tech. Memo. NMFS-AFSC-11. Seattle, Washington.

Loher, T. 1992. Cunner predation in the shallow rocky subtidal: effects on juvenile barnacles and mussels. MS thesis, Northeastern University Dep. Zoology. Boston, Massachussetts.

Main, J. and G.I. Sangster. 1979. A study of bottom trawling gear on both sand and hard ground. Scottish Fisheries Research Rep. No.14.

Main, J. and G.I. Sangster. 1981. A study of the sand clouds produced by trawl boards and their possible effect on fish capture. Scottish Fisheries Research Rep. No. 20.

Mann, K.H. 1988. Towards predictive models for coastal ecosystems. Chapter 15 in L.R. Pomeroy, and J.J. Alberts (eds.), Concepts of Ecosystem Ecology. Springer-Verlag, New York.

Marasco, R.J. and J.M. Terry. 1982. Controlling incidental catch: an economic analysis of six management options. Marine Policy, April, 131-139.

Matulich, S.C. 1989. Importance of bioeconomic analysis in managing the king industry. In Proceedings of the International Symposium on King and Tanner Crabs. Alaska Sea Grant College Program Rep. No. 90-04. Anchorage, Alaska, Nov. 28-30, 1989.

Matulich, S.C., J.E. Hanson, and R.C. Mittelhammer. 1988. A biological simulation of the Alaska king crab industry. US Dep. Commerce, NOAA Tech. Memo., NMFS-F/NWC-157 and 158.

McConnaughey, R.A. and D.A. Armstrong. 1991. Dungeness crab, Cancer magister, recruitment variability and Ekman transport during the pelagic larval phase. J. Shellfish Res. 10:239.

McGurk, M., D. Warburton, J.E. Edinger, and E.M. Buchak. 1991. Fisheries oceanography of the southeast Bering Sea: relationships of growth, dispersion and mortality of herring larvae to environmental conditions in the Port Moller estuary. Dep. Interior, Minerals Mgmt. Serv., Ocean Coastal Survey Rep. MMS 92/0018.

McMurray, G., A.H. Vogel, P.A. Fishman, D.A. Armstrong, and S.C. Jewett. 1984. Distribution of larval and juvenile red king crab (Paralithodes camtschatica) in Bristol Bay. US Dep. Commerce, NOAA, OCSEAP Final Rep. 53(1986):267-477. Anchorage, Alaska.

Miller, A.J., D.R. Cayan, T.P. Barnett, N.E. Graham, and J.M. Oberhuber. 1994. The 1976-77 climate shift of the Pacific Ocean. Oceanography $7(1): 21-26$.

Miller, B.S. 1970. Food of the flathead sole (Hippoglossoides elassodon) in East Sound, Orcas Island, Washington. J. Fish. Res. Board Can. 27:1661-1665.

National Marine Fisheries Service Crab Plan Team. 1994. 1994 annual area management report for the Bering Sea and Aleutian Island area king and Tanner crab fisheries. September 6, 1994. 
Nakanishi, T. 1985. The effect of the environment on the survival rate, growth and respiration of eggs, larvae and post-larvae of king crab (Paralithodes camtschatica). Pages 167-186 in B.R. Melteff (coordinator), Proceedings of the International King Crab Symposium, Anchorage, Alaska, January 22-24, 1985. Univ. Alaska.

Niebauer, H.J. 1983. Multiyear sea ice variability in the eastern Bering Sea: an update. J. Geograph. Res. 88:2733-2742.

Novikov, N.P. 1968. Basic elements of the biology of the Pacific halibut (Hippoglossus hippoglossus olepis schmidt) in the Bering Sea. Pages 102-108 in Soviet Fisheries Investigations in the Northeast Pacific, part 2. (Translated from Russian by the Israel Program for Scientific Translations). US Dep. Commerce, Springfield, VA, 1968.

Ojeda, F.P. 1987. Rocky subtidal community structure in the Gulf of Maine: the role of mobile predators. PhD dissertation, Univ. Maine, Orono.

Otto, R.S. 1981. Eastern Sea Crab Fisheries. Pages 1037-1068 in D.W. Hood and J.A. Calder (eds.), The eastern Bering Sea Shelf: Oceanography and Resources. Vol. 2. Office of Marine Pollution Assessment, Juneau, Alaska.

Otto, R.S. 1986. Management and assessment of eastern Bering Sea king crab stocks. Pages 83-106 in G.S. Jamieson and N. Bourne (eds.), North Pacific Workshop on Stock Assessment and Management of Invertebrates. Can. Spec. Pub. Fish. Aquat. Sci. 92.

Otto, R.S. 1993. Recent changes in the species composition of Bering Sea fishery resources. An oral presentation to the Polar Research Board, National Research Council.

Overland, J.E. and C.H. Pease. 1982. Cyclone climatology of the Bering Sea and its relation to sea ice extent. Monthly Weather Review 110:5-13.

Paul, J.M. and A.J. Paul. 1990. Breeding success of sublegal size male red king crab Paralithodes camtschaticus (Tilesius, 1815) (Decapoda, Lithodidae). J. Shellfish Res. 9:29-32.

Pautzke, C.G. 1995. Memorandum to NPFMC on crab bycatch issues. North Pacific Fishery Management Council internal document. Anchorage, Alaska.

Pianka, E.R. 1970. On r- and K-selection. Am. Nat. 104:592-597.

Powell, G.C. and R.B. Nickerson. 1965. Aggregations among juvenile king crabs Paralithodes camtschatica (Tilesius), Kodiak, Alaska. Anim. Behav. 13:374-380.

Quin, J.P. and J. Janssen. 1989. Crayfish competition in southwestern Lake Michigan: a predator mediated bottleneck. J. Freshwat. Ecol. 5:75-85.

Reeves, J.E. 1993a. Use of lower minimum size limits to reduce discards in the Bristol Bay red king crab (Paralithodes camtschaticus) fishery. US Dep. Commerce, NOAA Tech. Memo. NMFS-AFSC-20. Seattle, Washington.

Reeves, J.E. 1993b. Shellfish Resources. Pages 65-75 in Status of Living Marine Resources Off Alaska. NOAA Tech. Memo. NMFS-AFSC-27. Seattle, Washington.

Reise, K. 1982. Long-term changes in the macrobenthic invertebrate fauna of the Wadden Sea: are polychaetes about to take over? Netherlands Journal of Sea Research 16:29-63.

Richards, W. 1995. Shell Game: Crabs Come and Go, Leaving the Fishermen of Bering Sea at a Loss. The Wall Street Journal, June 26, 1995, front page.

Rothschild, B.J. 1986. Dynamics of Marine Fish Populations. Harvard University Press.

Russ, G.R. 1980. Effect of predation by fishes, competition, and structural complexity of the substratum on the establishment of a marine epifaunal community. J. Exp. Biol. Ecol. 42:55-69.

Schumacher, J.D. and R.K. Reed. 1983. Interannual variability in the abiotic environment of the Bering Sea and Gulf of Alaska. Pages 111-133 in W.S. Wooster (ed.), From Year to Year. Washington Sea Grant Program, Seattle.

Sebens, K.P. 1991. Habitat structure and community dynamics in marine benthic systems. Pages 211-234 in S.S. Bell, E.D. McCoy and H.R. Mushinsky (eds.), Habitat Structure-The Physical Arrangement of Objects in Space, Chapman and Hall, New York.

Serobaba, I.I. 1974. Spawning ecology of the walleye pollock (Theragra chalcogramma) in the Bering Sea. J. Ichthyol. 14:544552.

Shirley, S.M. and T.C. Shirley. 1989. Interannual variability in density, timing and survival of Alaskan red king crab Paralithodes camtschaticus larvae. Mar. Ecol. Progr. Ser. 54:51-59.

Soutar, A. and J.D. Issacs. 1974. Abundance of pelagic fish during the 19 th and 20 th centuries as recorded in anaerobic sediments off the Californias. Fish. Bull. U.S. 72:257-273. 
Steger, R. 1987. Effects of refuges and recruitment on gonadactylid stomatopods, a guild of mobile prey. Ecology 68:1520-1533.

Stevens, B.G., J.H. Bowerman, R.A. MacIntosh, and J.A. Haaga. 1992. Report to industry on the 1992 eastern Bering Sea crab survey. NOAA, NMFS, AFSC Processed Rep. 92-12.

Stevens, B.G., J.A. Hagen, and R.A. MacIntosh. 1994. Report to Industry on the 1994 Eastern Bering Sea Crab Survey. NOAA, NMFS, AFSC Processed Rep. 94-07. November 1994.

Stone, R.P., C.E. O'Clair, and T.C. Shirley. 1993. Aggregating behavior of ovigerous female red king crab (Paralithodes camtschaticus), in Auke Bay, Alaska. Can. J. Fish. Aquat. Sci. 50:750-758.

Sundberg, K.A. and D. Clausen. 1977. Post-larval king crab (Paralithodes camtschaticus) distribution and abundance in Kachemak Bay Lower Cook Inlet, Alaska, 1976. In L.L. Trasky, L.B. Flagg and D.C. Burbank (eds.), Environmental Studies of Kachemak Bay and Lower Cook Inlet, Vol. 5. Alaska Dep. Fish and Game, Anchorage.

Thompson, A. 1989. An industry perspective on problems facing the rebuilding of king and Tanner (bairdi) crab stocks of the eastern bering sea. In Proceedings of the International Symposium on King and Tanner Crabs, Anchorage, Alaska, Nov. 2830, 1989. Alaska Sea Grant College Program Rep. No. 90-04,

Thompson, A. 1995. Letter to the Editor, Seattle Times. Jan. 25, 1995. Alaska Crab Coalition.

Thompson, G. 1993. Impacts of trawling on the seabed and benthic community. BSAI Amendment 24, Appendix F. NMFS, Kodiak, Alaska.

Thompson, G. and R. Methot. 1993. Pacific cod. In Stock Assessment and Fishery Evaluation Report for the Groundfish Resources of the Bering Sea/Aleutian Islands Regions as Projected for 1994. North Pacific Fishery Management Council, Anchorage, Alaska.

Tokranov, A.M. 1990. Feeding of the yellowfin sole, Limanda aspera, in the southwestern part of the Bering Sea. J. Ichthyol. 30:59-67.

VanBlaricom, G. 1982. Experimental analyses of structural regulation in a marine sand community exposed to oceanic swell. Ecol. Monogr. 52:283-305.

VanDolah, R.F., P.H. Wendt, and N. Nicholson. 1987. Effects of a research trawl on a hard-bottom assemblage of sponge and coral. Fish. Res. 5:39-54.

VanDolah, R.F., P.H. Wendt, and N. Nicholson. 1991. A study of the effects of shrimp trawling on benthic communities in two South Carolina sounds. Fish. Res. 12:139-156.

Wahle, R.A. 1991. Implications for lobster fishery enhancement from natural benthic recruitment, hatchery-reared 'blues', and experimental cobbles. J. Shellfish Res. 10:287.

Wahle, R.A. and R.S. Steneck. 1991. Recruitment habitats and nursery grounds of the American lobster Homarus americanus: a demographic bottleneck? Mar. Ecol. Progr. Ser. 69:231-243.

Walters, C. 1986. Adaptive Management of Renewable Resources. MacMillan Publishing Company, New York.

Wespestad, V.G., P.A. Livingston, and J.E. Reeves. 1994. Juvenile sockeye salmon (Oncorhynchus nerka) predation on Bering Sea red king crab (Paralithodes camtschaticus) larvae as a cause of recruitment variation. ICES C.M. R:10.

Witherell, D. 1995. Crab Rebuilding Committee report. North Pacific Fishery Management Council, Anchorage, Alaska.

Witman, J.D. 1985. Refuges, biological disturbance, and rocky subtidal community structure in New England. Ecol. Monogr. $55: 421-445$.

Zhang, C.I. 1988. Food habits and ecological interactions of Alaska plaice, Pleuronectes quadrituberculatus, with other flatfish species in the eastern Bering Sea. Bulletin of the Korean Fisheries Society 21:150-166.

Zhou, S. and T.C. Shirley. 1994. Effects of handling, feeding, and survival of red king crabs. In King and Tanner crab research in Alaska: annual report for July 1, 1993 through June 30, 1994. Alaska Dep. Fish and Game, Regional Information Report 5J94-18. Commercial Fisheries Management and Development Division, Juneau, Alaska. 